\title{
एबत
}

Instituto de Pesquisas Energéticas e Nucleares

Autarquia Associada à Universidade de São Paulo

\section{ESTUDOS DAS PROPRIEDADES ÓPTICAS DOS COMPLEXOS EURÓPIO TETRACICLINAS E SUAS APLICAÇÕES NA DETECÇÃO DE LIPOPROTEÍNAS}

\author{
Luciane dos Santos Teixeira
}

Dissertação apresentada como parte dos requisitos para a obtenção do Grau de Mestre em Ciências na área de Tecnologia Nuclear - Materiais.

Orientadora: Dra. Lilia Coronato Courrol 
Dedico este trabalho primeiramente a Deus que fortalece a minha fé $e$ esperança a cada dia e aos meus pais Maria Ap. dos Santos Teixeira e Ivanildo Ap. Peluco Teixeira pelo apoio e carinho oferecido em todo momento de minha vida. 


\section{AGRADECIMENTOS}

Primeiramente gostaria de agradecer a Deus que tornou possível a realização de mais um grande sonho.

Gostaria de agradecer também a Professora Lilia Coronato Courrol pelo carinho, atenção e orientação durante a realização deste trabalho.

Aos meus pais Maria Ap. dos Santos Teixeira e Ivanildo Ap. Peluco Teixeira e ao meu irmão Carlos Eduardo dos Santos Teixeira pelo apoio e carinho oferecidos em todo momento de minha vida e principalmente neste.

Ao meu namorado e eterno companheiro André, por todo apoio e incentivo.

Ao CNPq pela bolsa concedida.

A Flávia Rodrigues pela ajuda prestada no inicio deste trabalho.

A Andrea Nastri Grasso pela importante ajuda durante a realização deste trabalho e principalmente pela grande amizade.

Ao Dr. Antônio Martins Figueiredo Neto por conceder as amostras de frações colesterol e ao Dr. Magnus A. Gidlund e sua aluna Andréa M. Monteiro do Instituto de Ciências Biomédicas da Universidade de São Paulo pela preparação destas amostras.

Ao Dr. Laércio Gomes, pelas preciosas discussões a respeito do tema.

Aos Drs. Nilson, Luiz e Laércio pela utilização da infraestrutura dos laboratórios. 
Bom mesmo é ir a luta com determinação, abraçar a vida com paixão, perder com classe e vencer com ousadia, pois o triunfo pertence a quem se atreve... A vida é muita para ser insignificante.

(Charles Chaplin) 


\title{
ESTUDOS DAS PROPRIEDADES ÓPTICAS DOS COMPLEXOS EURÓPIO TETRACICLINAS E SUA APLICAÇÕES NA DETECÇÃO DE LIPOPROTEÍNAS
}

\author{
Luciane dos Santos Teixeira
}

\begin{abstract}
RESUMO
Este trabalho apresenta as propriedades ópticas dos complexos Európio Tetraciclinas (EuTcs) na presença de LDL e de LDL oxidada com potenciais aplicações em análises clínicas. Foram escolhidos quatro elementos da família das Tetraciclinas: Tetraciclina (Tc), Clorotetraciclina (CTc), Metatetraciclina (MTc) e Oxitetraciclina (OTc) para fazerem parte dos complexos com o íon európio. As melhores condições para se formar os complexos eficientemente foram determinadas, através das medidas dos parâmetros ópticos como: absorção, emissão e de tempo de vida. As melhores concentrações de európio nos complexos EuTcs e possíveis influências de íons inorgânicos normalmente presentes no plasma sanguíneo também foram analisadas. As amostras foram preparadas em $\mathrm{pH}$ neutro e a luminescência visível do lantanídeo foi detectada após tempo de repouso das amostras de 15 minutos. Os resultados deste trabalho mostraram que as moléculas de LDL e de LDL oxidada apresentaram um importante papel no aumento da intensidade de emissão dos complexos das Tcs. As medidas realizadas com os complexos EuTcs não apresentaram deslocamentos nos comprimentos de onda dos espectros de absorção e de emissão na presença de LDL, o que demonstra a ausência de interação direta entre as moléculas de Tcs e as moléculas de LDL e LDL oxidada. No entanto, o íon európio pode interagir em diferentes sítios das moléculas de tetraciclinas o que diferenciou a intensidade de emissão de cada complexo. Comparando os resultados obtidos entre os complexos de EuTcs, o complexo EuTc foi o que apresentou perspectivas promissoras na quantificação de LDL e LDL oxidada.
\end{abstract}

Palavras-chave: Európio, Tetraciclinas, LDL e LDL oxidada. 


\title{
STUDIES OF OPTICAL PROPERTIES OF COMPLEXES EUROPIUM TETRACYCLINE AND ITS APPLICATIONS IN DETECTION OF LIPOPROTEINS
}

\author{
Luciane dos Santos Teixeira
}

\begin{abstract}
This work presents the optical properties of europium complexes - Tetracyclines (EuTcs) in the presence of LDL and oxidized LDL with potential applications in clinical analysis. Four elements were chosen from the Tetracyclines family: Tetracycline (Tc), Chlortetracycline (CTc), Metatetraciclina (MTc) and Oxytetracycline (OTc) to be part of complexes with europium ion. The best conditions to form the complex efficiently were determined through measurements of optical parameters such as absorption, emission and lifetime. The best concentrations of europium complexes in EuTcs and possible influences of inorganic ions normally present in blood plasma were also analyzed. The samples were prepared at neutral $\mathrm{pH}$ and the visible luminescence of lanthanide was detected after resting time of the samples of 15 minutes. These results showed that the molecules of LDL and oxidized LDL have an important role in increase of the emission intensity for Tcs complexes. The measurements performed with the complex EuTcs showed no shifts in the wavelengths of the absorption and emission spectra in the presence of LDL, which demonstrates the absence of direct interaction between the molecules of Tcs and the molecules of LDL and oxidized LDL. However, the europium ion can interact at different sites of the tetracyclines molecules which differed the emission intensity of each complex. Comparing the results obtained between the complexes EuTcs, the complex EuTc is the one that presented the promising prospects in the quantification of LDL and oxidized LDL.
\end{abstract}

Keywords: Europium, Tetracyclines, LDL and oxidized LDL. 


\section{LISTA DE FIGURAS}

Figura 1: Estrutura básica das tetraciclinas 19

Figura 2: Mecanismo de emissão de fluorescência de complexos de $\mathrm{Eu}^{3+} \ldots \ldots \ldots . .24$

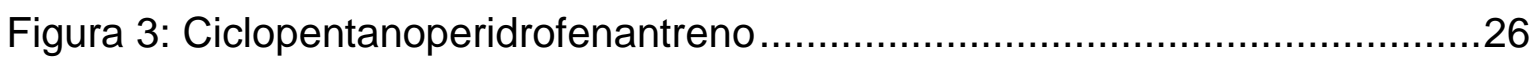

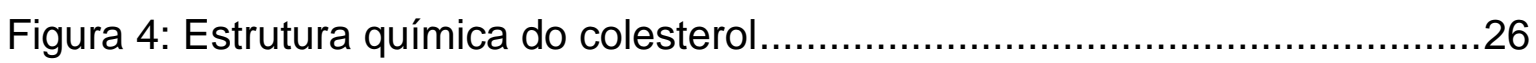

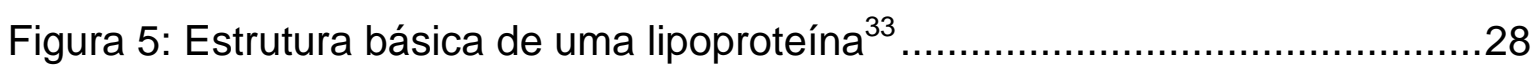

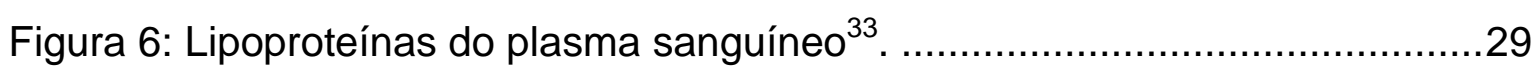

Figura 7: Processo de formação da placa de ateroma........................................32

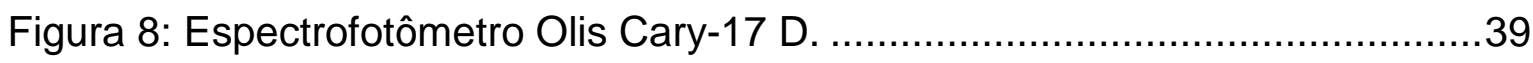

Figura 9: Espectrofotômetro Fluorolog 3................................................. 40

Figura 10: a) Espectro de absorção óptica das amostras de európio, tampão, MOPS e tetraciclinas; b) Espectro de absorção óptica das tetraciclinas na presença do európio. .43

Figura 11: a) espectros de emissão das tetraciclinas Tc, OTc, MTc e CTc.

Espectro das tetraciclinas Tc, OTc, MTc, CTc complexadas com o íon európio...45

Figura 12: Espectro de absorção do complexo EuOTc em diferentes razões

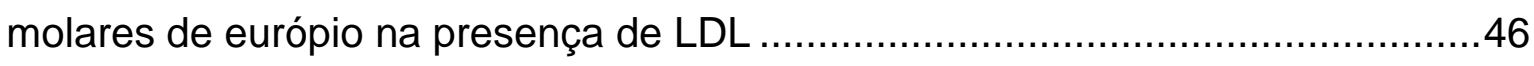

Figura 13: Espectro de emissão dos complexos de EuOTc................................47

Figura 14: Espectro de absorção óptica do complexo EuCTc em diferentes razões molares de európio na presença de LDL. ......................................................47

Figura 15: Espectro de emissão dos complexos de EuCTc................................48

Figura 16: Espectro de absorção óptica do complexo EuMTc em diferentes razões

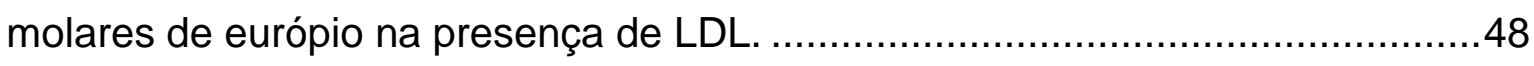

Figura 17: Espectro de emissão dos complexos de MTc...................................49

Figura 18: Espectro de emissão de EuOTc com LDL.......................................16

Figura 19: Espectro de emissão de EuMTc com LDL.......................................16

Figura 20: Espectro de emissão de EuCTc com LDL.......................................16

Figura 21: Espectro de emissão de EuTc com LDL......................................16

Figura 22: Possíveis sítios em comum de ligações do íon európio com as Tcs ..52

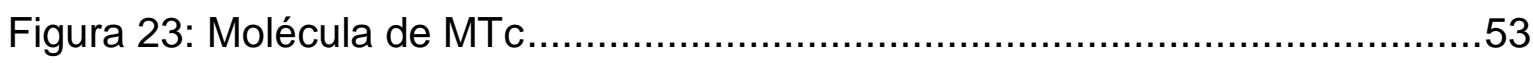

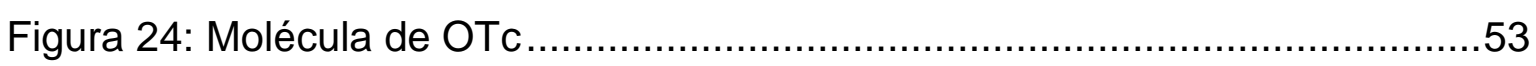


Figura 25: Monocamada da molécula de LDL ilustrando as regiões hidrofílica (região externa) e hidrofóbica (região interna) da molécula.

Figura 26: Curva de calibração do complexo EuOTc na presença de diferentes concentrações de LDL

Figura 27: Curva de calibração do complexo EuMTc na presença de diferentes concentrações de LDL

Figura 28: Curva de calibração do complexo EuTc na presença de diferentes concentrações de LDL

Figura 29: Curva de calibração do complexo EuCTc na presença de diferentes concentrações de LDL .58

Figura 30: Tempo de vida do complexo EuTc com LDL .................................16

Figura 31: Tempo de vida do complexo EuCTc com LDL ..................................16

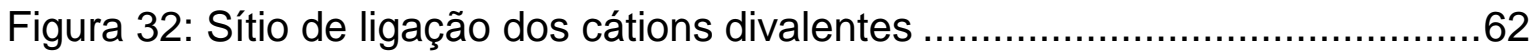

Figura 33: Curva de calibração do complexo EuOTc na presença de LDL oxidada 65

Figura 34: Curva de calibração do complexo EuCTc na presença de LDL oxidada .65

Figura 35: Curva de calibração do complexo EuTc na presença de LDL oxidada 66 


\section{LISTA DE TABELAS}

Tabela 1: Elementos da Família das Tetraciclinas............................................19

Tabela 2: Elementos lantanídeos e sua respectiva configuração eletrônica..........21

Tabela 3: Relação entre o tamanho e a proporção de lipídeos nas lipoproteínas

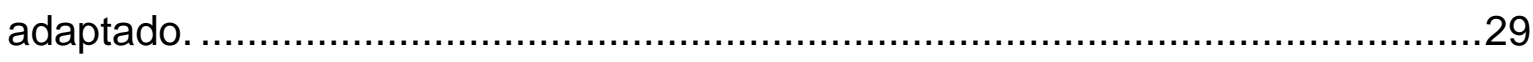

Tabela 4: Níveis de colesterol pela Sociedade Brasileira de Cardiologia. ….........30

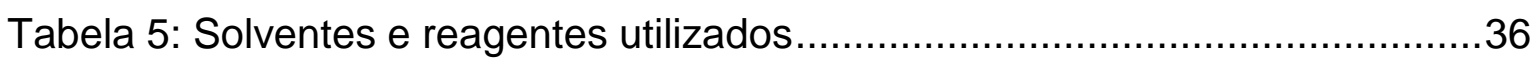

Tabela 6: Valor de referência dos interferentes encontrados no plasma sanguíneo 38

Tabela 7: Preparo dos complexos de EuTcs em diferentes razões molares de $\mathrm{Eu}^{3+}$

Tabela 8: Valores das posições dos máximos dos compostos TC, OTC, CTc e MTc.

Tabela 9: Bandas de absorção dos compostos EuTC, EuOTC, EuCTc e EuMTc.

Tabela 10: Parâmetro do ajuste das equações 1 e 2, para os dados experimentais da Figura 30.

Tabela 12: Parâmetro do ajuste das equações 1 e 2, para os dados experimentais da Figura 31.

Tabela 13: Parâmetro do ajuste das equações 1 e 2, para os dados experimentais da Figura 35.

Tabela 14: Parâmetro do ajuste das equações 1 e 2, para os dados experimentais da Figura 36. 



\section{LISTA DE ABREVIATURAS E SÍMBOLOS}

EuTc: Európio-Tetraciclina

EuCTc: Európio-Clorotetraciclina

EuMTc: Európio-Metaciclina

EUOTc: Európio-Oxitetraciclina

LDL: Low Density Lipoproteins

HDL: High Density Lipoproteins

TC: tetraciclina

Mg: Magnésio

$\mathrm{Mn}$ : Manganês

Fe: Ferro

Ag: Prata

Al: Alumínio

Co: Cobalto

$\mathrm{Ni}$ : Níquel

Cu: Cobre

Ca: Cálcio

Zn: Zinco

Xe: Xenônio

Sc: Escândio

Y: Ítrio

Sc: Escândio

La: Lantânio

Yb: Iterbio

Lu: Lutécio

Ce: Cério

Pr: Praseodímio

Nd: Neodímio

Pm: Promécio

Sm: Samário

Eu: Európio

Gd: Gadolínio 
Tb: Térbio

Dy: Disprosio

Ho: Holmio

Er: Érbio

Tm: Túlio

$\mathrm{OH}$ : Hidroxila

$\mathrm{S}_{0}$ : Estado singleto fundamental

$\mathrm{S}_{1}$ : Estado singleto excitado

T: Estado tripleto

$\mathrm{C}_{22} \mathrm{H}_{45} \mathrm{OH}$ : Colesterol

LPL: Lipoproteina Lipase

VLDL: Very Low Density Lipoproteins

IDL: lipoproteína de densidade intermediária

$\lambda$ : Comprimento de onda

CLA: Centro de Lasers e Aplicações

IPEN: Instituto de Pesquisas Energéticas e Nucleares

MOPS: Ácido propanesulfônico 3 (N-Morpholino)

ICB-USP: Instituto de Ciências Biomédicas da Universidade de São Paulo

CTc: Clorotetraciclina

OTc: Oxitetraciclina

MTc: Metatetraciclina

AgNO4: Nitrato de prata

$\mathrm{Al}_{2}(\mathrm{SO} 4)_{3}$ : Sulfato de alumínio

$\mathrm{CoSO}_{4} .7 \mathrm{H}_{2} \mathrm{O}$ : Sulfato de cobalto heptahidratado

$\mathrm{CaCl}_{2} \cdot 2 \mathrm{H}_{2} \mathrm{O}$ : Cloreto de cálcio dihidratado

$\mathrm{Cu}\left(\mathrm{NO}_{3}\right)_{2} \cdot 3 \mathrm{H}_{2} \mathrm{O}$ : Nitrato de cobre trihidratado

$\mathrm{FeCl}_{3} \cdot 6 \mathrm{H}_{2} \mathrm{O}$ : Cloreto de ferro hexahidratado

$\mathrm{MgSO}_{4} .7 \mathrm{H}_{2} \mathrm{O}$ : Sulfato de magnésio heptahidratado

$\mathrm{MnSO}_{4} \cdot \mathrm{H}_{2} \mathrm{O}$ : Sultato de manganês monohidratado

$\mathrm{NiSO}_{4} \cdot 6 \mathrm{H}_{2} \mathrm{O}$ : Sulfato de níquel hexahidratado

$\mathrm{ZnSO} 4.7 \mathrm{H}_{2} \mathrm{O}$ : Sulfato de zinco heptahidratado

$\mathrm{EuCl}_{3} .6 \mathrm{H}_{2} \mathrm{O}$ : Cloreto de Európio Hexahidratado

$\mathrm{H}_{2} \mathrm{O}$ : Água bideionizada 
$\mathrm{NaOH}$ : Hidróxido de sódio

LDL oxidada: Lipoproteína de baixa densidade oxidada

PMSF (fenil-metil-sulfonil-fluoreto)

PBS: Tampão fosfato salino

EDTA: Ácido etilenodiaminotetracético

$\mathrm{CuSO}_{4}$ : Sulfato de cobre

$\mathrm{CH}_{3}$ : Alcanos

$\mathrm{CH}_{2}$ : Alcenos

a: Ruído de fundo

b: Coeficiente angular

$\mathrm{x}$ : Concentrações desconhecida de LDL

$\sigma:$ Incerteza da medida

$y$ : Intensidade do sinal

$\tau_{1}$ : Tempos de decaimento

$A_{1}$ : Amplitudes do sinal

$\tau_{\mathrm{av}}:$ Média do tempo de vida 


\section{SUMÁRIO}

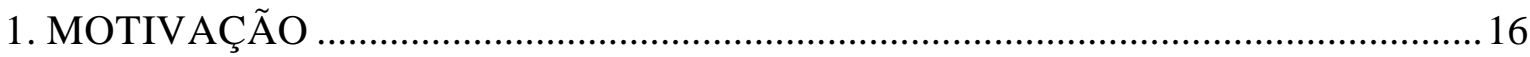

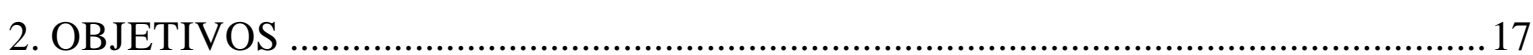

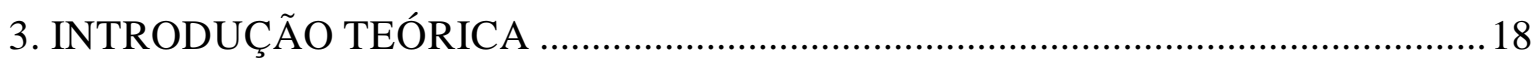

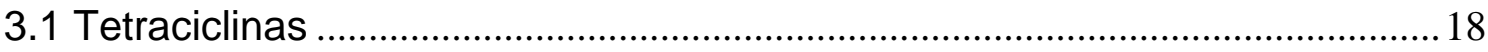

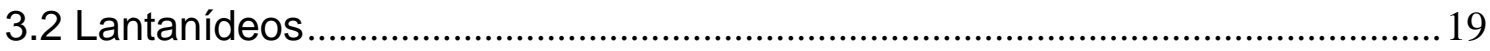

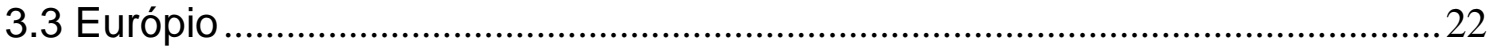

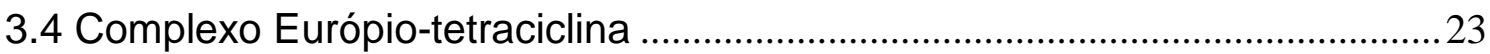

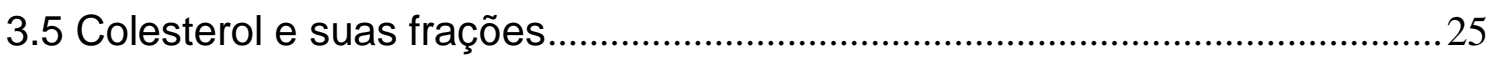

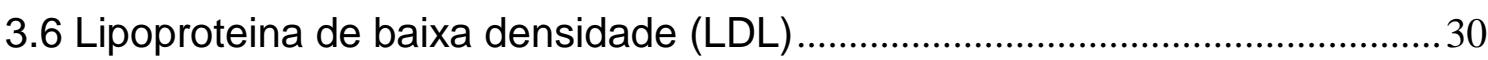

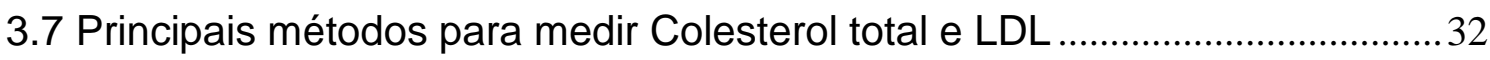

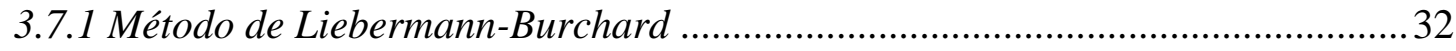

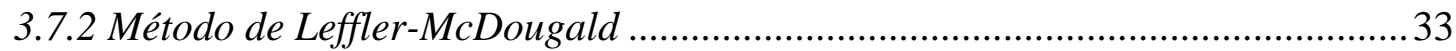

3.7.3 Método que utilizam processo enzimático- colorimétrico ...................................33

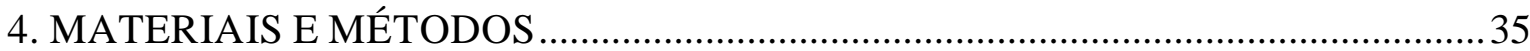

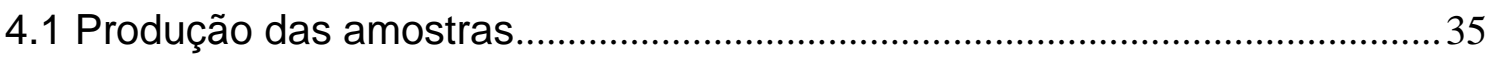

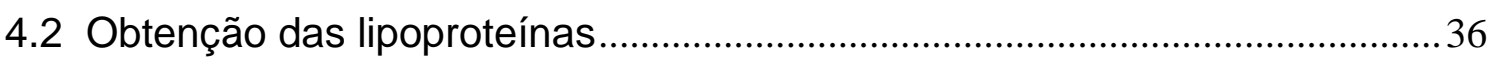

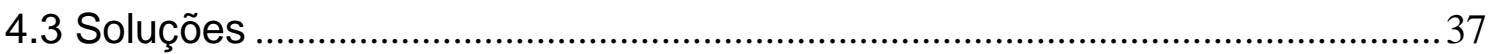

4.4 - Técnicas usadas para caracterização das amostras ....................................39

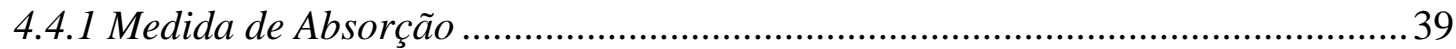

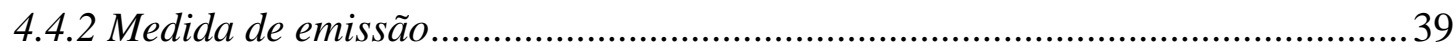

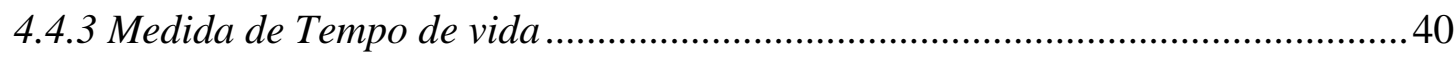

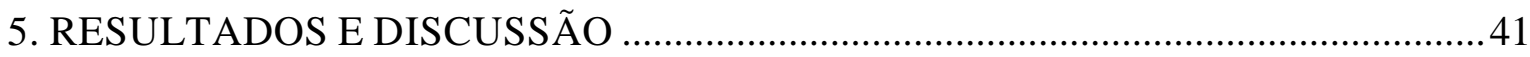

5.1 Caracterização dos complexos Európio-Tetraciclinas (EuTcs) ......................41

5.2 Estudo dos complexos EuTcs na presença de LDL ......................................45

5.2.1 Melhores razões molares dos complexos EuTcs na presença de LDL ...............45

5.2.2 Comparação dos complexos EuTcs na presença de diferentes concentrações de

$L D L$

5.2.3 Curva de calibração dos complexos na presença de LDL ................................55

5.2.4 Tempo de vida dos complexos EuTc e EuCTc na presença de LDL....................58

5.2.5 Complexos EuTc+LDL e EuCTc+LDL na presença de possíveis interferentes inorgânicos

5.3 Medidas dos complexos EuTcs na presença de LDL oxidada 
5.3.1 Comparação das curvas de calibração dos complexos EuTcs na presença de diferentes concentrações de LDL oxidada.

5.3.2 Tempo de vida dos complexos EuTc e EuCTc na presença de LDL oxidada.....66 5.3.3 Complexos EuCTc $+L D L$ oxidada e EuTc $+L D L$ oxidada na presença de

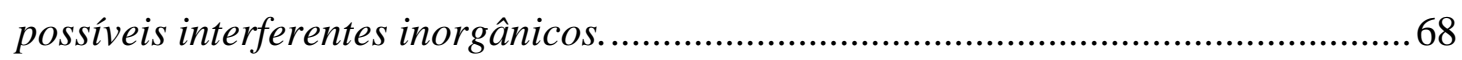

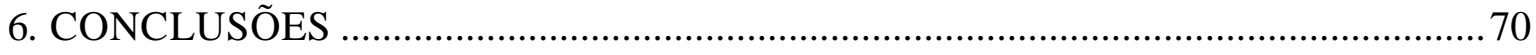

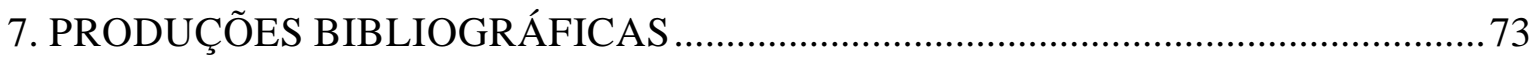




\section{MOTIVAÇÃO}

O transporte do colesterol no corpo humano é feito principalmente pelas lipoproteínas LDL (lipoproteína de baixa densidade) e HDL (lipoproteína de alta densidade). O excesso de colesterol associado à lipoproteína LDL no sangue é um dos principais fatores de risco para o desenvolvimento de doenças arteriais coronarianas (principalmente o infarto do miocárdio), além de doenças cérebrovasculares ${ }^{1}$.

Para a determinação do colesterol alguns métodos enzimáticos são empregados, utilizando, por exemplo, a enzima colesterol oxidase. Porém esses métodos exigem muitas vezes uma grande quantidade de reagentes e reações, fato esse que o torna um tanto indireto e caro, além de não ser em tempo real ${ }^{2}$.

É conhecido da literatura que o complexo Európio-Tetraciclina (EuTc) apresenta propriedades ópticas interessantes. Possui absorção em torno de 400 $\mathrm{nm}$ e emissão em torno de $615 \mathrm{~nm}$ e, portanto grande deslocamento Stokes. A emissão do európio proveniente de um efeito antena é fortemente dependente das características da solução, tais como $\mathrm{pH}^{3}$.

Estudos realizados recente indicaram um aumento da banda de emissão do európio, no complexo EuTc na presença de colesterol e LDL. Neste caso nenhum outro tipo de reagente precisou ser incorporado à solução, possibilitando a quantificação de $\mathrm{LDL}^{4}$.

Portanto, esse trabalho nos motivou a estudar as propriedades ópticas de outras tetraciclinas tais como: oxitetraciclina, clorotetraciclina e metatetraciclina, complexadas com o íon európio e dessa forma analisar a possibilidade de quantificação de LDL e LDL oxidada.

Esta observação abre o leque para uma ampla área de pesquisa que vai desde a obtenção de curvas de calibração de LDL e LDL oxidada até potencial obtenção de um sensor baseado na presença de EuTcs e utilizados como marcadores fluorescentes para a arterosclerose. 


\section{OBJETIVOS}

O objetivo deste trabalho é a caracterização espectroscópica de complexos de Európio-Tetraciclinas (EuTcs) na presença de LDL e LDL oxidada em soluções aquosas, através da determinação de parâmetros ópticos tais como absorção óptica, emissão e tempo de vida. Além de outras medidas, como a influência de íons inorgânicos presentes no plasma sanguíneo.

Através da análise destes dados, pretende-se identificar, dentre os complexos de Tcs, aquele que apresenta melhor desempenho na quantificação de LDL e LDL oxidada. 


\section{INTRODUÇÃO TEÓRICA}

\subsection{Tetraciclinas}

Em meados de 1948 surge uma importante família de antibióticos denominada tetraciclinas. Os primeiros membros foram isolados e purificados de produtos naturais de fermentação de microorganismos (Streptomyces aureofancins e S. rimosus) dando origem respectivamente à clorotetraciclina e oxitetraciclina ${ }^{5,6}$. Mais tarde, outros membros foram sintetizados como é caso da tetraciclina sintetizada a partir da clorotetraciclina, metaciclina, doxiciclina entre outras ${ }^{7}$.

As tetraciclinas (Tc) são antibióticos de amplo espectro de ação contra microorganismos como bactérias gram positivas, gram negativas, Chlamydias, Mycoplasmas e Rickettsia ${ }^{6}$.

As principais indicações clínicas das tetraciclinas são para as infecções causadas por microorganismo acima citados como, por exemplo, infecções respiratórias mistas, além de serem utilizadas na medicina veterinária, nutrição animal e aditivos alimentares destinado a uso pecuário ${ }^{8,9}$.

Quanto a sua estrutura química (Figura 1 e Tabela 1) as Tcs apresentam em comum um sistema de quatro anéis ( $A, B, C$ e $D)$ unidos linearmente com seis carbonos em cada anel, além de possuírem importantes sítios de ligações: sistema $\beta$ - dicetona (posição 11 e 12), enol (posição 1 e 3) e carboxamida (posição 2) anel $A^{3}$.

As Tcs apresentam diferentes sítios de ligações dependendo do $\mathrm{pH}$ em que as mesmas se encontram, de acordo com alguns estudos as tetraciclinas apresentam em geral 3 constantes de acidez (pKa) que variam em torno dos seguintes valores: $\mathrm{pKa}_{1}=3,30, \mathrm{pKa}_{2}=7,29$ e $\mathrm{pKa}_{3}=9,88^{3}$.

Em estudos recentes foi observado que em $\mathrm{pH} 7$ as tetraciclinas apresentaram ionização das hidroxilas presentes nos anéis BCD e com grande potencial de formar complexos estáveis com cátions multivalentes incluindo a formação de complexos com íons de lantanídeos trivalentes ${ }^{6,3,10}$.

O estudo de Palm e colaboradores ${ }^{11}$ demonstrou que as tetraciclinas formam complexos de coordenação estáveis com íons metálicos da primeira série 
de transição, entre eles: $\mathrm{Mg}^{2+}, \mathrm{Mn}^{2+}, \mathrm{Fe}^{2+}, \mathrm{Co}^{2+}, \mathrm{Ni}^{2+}, \mathrm{Cu}^{2+}, \mathrm{Ca}^{2+}$ e $\mathrm{Zn}^{2+}$ e que os mesmos ligam-se em sítios semelhante ao do íon európio.

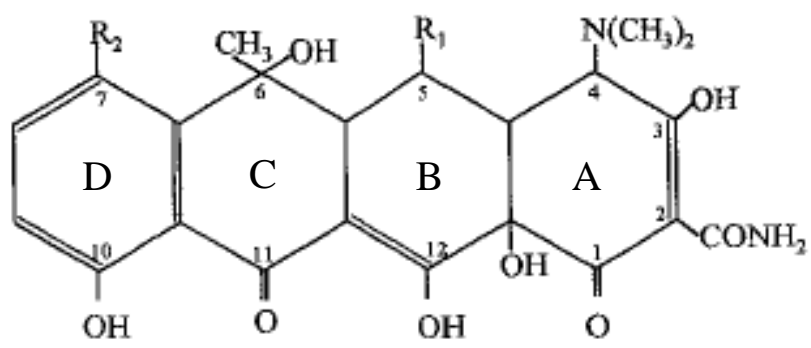

Figura 1: Estrutura básica das tetraciclinas

Tabela 1: Elementos da Família das Tetraciclinas.

\begin{tabular}{lcccc}
\hline Elementos da Família das Tetraciclinas & $\boldsymbol{R}_{\boldsymbol{1}}$ & $\boldsymbol{R}_{\mathbf{2}}$ & $\boldsymbol{R}_{\mathbf{3}}$ & $\boldsymbol{R}_{\mathbf{4}}$ \\
\hline Tetraciclina & $\mathrm{H}$ & $\mathrm{CH}_{3}$ & $\mathrm{OH}$ & $\mathrm{H}$ \\
Clorotetraciclina & $\mathrm{Cl}$ & $\mathrm{CH}_{3}$ & $\mathrm{OH}$ & $\mathrm{H}$ \\
Oxitetraciclina & $\mathrm{H}$ & $\mathrm{CH}_{3}$ & $\mathrm{OH}$ & $\mathrm{OH}$ \\
Metatetraciclina & $\mathrm{H}$ & $\mathrm{CH}_{2}$ & - & $\mathrm{OH}$ \\
\hline
\end{tabular}

\subsection{Lantanídeos}

Os elementos lantanídeos compreendem os dois membros do grupo IIIB (Escândio e Ítrio) e quinze membros da série Lantanídica (do Lantânio $Z=57$ ao Lutécio $Z=71)^{1}$.São conhecidos também como terras-raras quando os elementos químicos Escândio $Z=21$ e o Ítrio $Z=39$ são incluídos ${ }^{2,12}$.

A expressão "terras" deve-se ao fato de tais elementos serem isolados na forma de seus óxidos e "raras" pelas dificuldades iniciais na separação de um mineral novo e incomum descoberto no final do século 18. Foi somente no inicio do século $X X$ que se obtiveram técnicas capazes de separar esses elementos tornando-os suficientemente puros para o estudo de suas propriedades magnéticas, químicas entre outras ${ }^{13}$.

Os lantanídeos apresentam configuração eletrônica que derivam do gás nobre Xenônio (Xe). Somente os elementos Escândio ( $\mathrm{Sc}$ ) e Ítrio (Y) não derivam dessa configuração ${ }^{14}$. Dentre outras propriedades, destacam-se que todos eles, com exceção do Escândio (Sc), Ítrio (Y), Lantânio (La), Itérbio (Yb) e Lutécio (Lu) 
possuem a camada $4 \mathrm{f}$ incompleta o que lhes confere uma configuração eletrônica [Xe] $4 f^{n} 5 d^{1} 6 s^{2}(0<n<14)$, Tabela $2^{15}$.

A camada $4 f$ é a camada mais interna e acima dela estão a $6 s$ e $5 d$ e mesmo as camadas $5 p$ e 5 s são mais externas que a camada 4f, por terem uma extensão radial maior. As camadas pertencentes aos íons lantanídeos que participam das ligações químicas com outros elementos são as camadas $6 s$ e $5 d$, dessa forma, a camada $4 \mathrm{f}$, ainda que incompleta, fica blindada pelas mais externas.

As propriedades químicas dos lantanídeos são muito semelhantes entre si, porém pequenas diferenças podem ser observadas como conseqüência da diminuição progressiva dos raios iônicos com o aumento do número atômico, fato esse denominado contração lantanídica. A contração lantanídica deriva-se da blindagem imperfeita que um elétron $4 \mathrm{f}$ exerce sobre outro elétron $4 \mathrm{f}$, resultando em um aumento da carga nuclear efetiva ao longo da série lantanídica ${ }^{16}$.

Os lantanídeos quando estão na forma de íons apresentam-se em sua grande maioria no estado trivalente de oxidação $(+3)$, por ser o estado mais comum e ainda o mais estável termodinamicamente. Este estado de oxidação (+3) não depende apenas da configuração eletrônica, mas também de um balanço entre as energias de ionização, de ligação e de solvatação para o caso de soluções ${ }^{17}$.

Considerando que a energia para remover um quarto elétron da subcamada $4 \mathrm{f}$ é muito alta, os íons terras raras apresentam-se quase que exclusivamente no estado de oxidação $+3^{16}$.

Porém menos comum, alguns íons lantanídeos podem ser encontrados em outros estados de oxidação como é o caso do térbio, praseodímio e neodímio que podem apresentar estado de oxidação tetravalente $(+4)$ mas são todos instáveis em solução, podendo ser obtidos somente como sólidos, na forma de fluoretos, ou de óxidos, e o európio que pode apresentar o estado de oxidação divalente (+2) mas em solução e em complexos, esse estado de oxidação é mais difícil de ser encontrado devido à fácil oxidação para o estado de oxidação (+3) ${ }^{13,16}$. 
Tabela 2: Elementos lantanídeos e sua respectiva configuração eletrônica

\begin{tabular}{|c|c|}
\hline ELEMENTO & CONFIGURAÇÃO \\
\hline $\mathrm{Sc}(21)$ & {$[\mathrm{Ar}] 3 \mathrm{~d}^{1} 4 \mathrm{~s}^{2}$} \\
\hline$Y(39)$ & {$[\mathrm{Kr}] 4 d^{15} s^{2}$} \\
\hline La (57) & {$[\mathrm{Xe}] 5 d^{16} s^{2}$} \\
\hline $\mathrm{Ce}(58)$ & {$[\mathrm{Xe}] 4 \mathrm{f}^{15} \mathrm{~d}^{16} \mathrm{~s}^{2}$} \\
\hline $\operatorname{Pr}(59)$ & {$[X e] 4 f^{36} s^{2}$} \\
\hline $\mathrm{Nd}(60)$ & {$[\mathrm{Xe}] 4 \mathrm{f}^{46} \mathrm{~s}^{2}$} \\
\hline $\operatorname{Pm}(61)$ & {$[X e] 4 f^{56} s^{2}$} \\
\hline $\mathrm{Sm}(62)$ & {$[\mathrm{Xe}] 4 \mathrm{f}^{66} \mathrm{~s}^{2}$} \\
\hline Eu (63) & {$[\mathrm{Xe}] 4 \mathrm{f}^{76} \mathrm{~s}^{2}$} \\
\hline Gd (64) & {$[\mathrm{Xe}] 4 \mathrm{f}^{75} \mathrm{~d}^{16} \mathrm{~s}^{2}$} \\
\hline $\mathrm{Tb}(65)$ & {$[\mathrm{Xe}] 4 \mathrm{f}^{96} \mathrm{~s}^{2}$} \\
\hline Dy (66) & {$[\mathrm{Xe}] 4 \mathrm{f}^{106} \mathrm{~s}^{2}$} \\
\hline Ho (67) & {$[\mathrm{Xe}] 4 f^{116} s^{2}$} \\
\hline $\operatorname{Er}(68)$ & {$[\mathrm{Xe}] 4 \mathrm{f}^{126} \mathrm{~s}^{2}$} \\
\hline $\operatorname{Tm}(69)$ & {$[\mathrm{Xe}] 4 \mathrm{f}^{136} \mathrm{~s}^{2}$} \\
\hline Yb (70) & {$[\mathrm{Xe}] 4 \mathrm{f}^{14} 6 \mathrm{~s}^{2}$} \\
\hline Lu (71) & {$[\mathrm{Xe}] 4 \mathrm{f} 1^{45} \mathrm{~d}^{16} \mathrm{~s}^{2}$} \\
\hline
\end{tabular}

Nos compostos que apresentam os íons lantanídeos no estado de oxidação $(+3)$, a camada $4 \mathrm{f}$ localiza-se na parte mais interna do átomo sendo totalmente protegida pelos orbitais $5 s$ e $5 p$, ocorrendo somente um pequeno envolvimento com os orbitais dos ligantes devido a isso os lantanídeos podem formar complexos iônicos ${ }^{17}$.

Os íons lantanídeos, por apresentarem grandes números de níveis de energia, proporcionam emissões desde o infravermelho até o ultravioleta, porém muitas emissões ocorrem na região do visível ${ }^{15}$.

De uma maneira geral as transições eletrônicas do estado $4 \mathrm{f}$ podem ser explicadas de uma maneira geral pela teoria de Judd- Ofelt que considera as transições dos lantanídeos oriundas de uma mistura dos estados $4 f$ e $5 d^{14}$. 
As propriedades espectroscópicas podem ser melhor entendidas observando a absorção e as emissões ópticas desses elementos.

Os íons lantanídeos absorvem a radiação em bandas estreitas e bem definidas oriundas das transições $f-f$. As transições $f-f$ isoladas são proibidas pela regra de seleção para o espectro atômico, de acordo com essa regra somente transições que são acompanhadas da troca de paridade são permitidas como é o caso das transições $f-d$. As transições f-f só são permitidas quando a simetria do íon é removida devido ao campo cristalino que não apresente simetria de inversão ${ }^{14}$.

A excitação direta do íon de lantanídeo não é favorável devido a rápida relaxação térmica da energia de excitação quando se utilizam íons lantanídeos para sistemas luminescentes ${ }^{18}$. Essa relaxação não radiativa pode ocorrer pela interação dos níveis eletrônicos do íon lantanídeo com os modos vibracionais ressonantes do solvente. Quando o solvente contém grupos $\mathrm{OH}$ na coordenação do íon lantanídeo, ocorre eficiente relaxação não radiativa devido ao acoplamento ressonante dos estados vibracionais dos osciladores $\mathrm{OH}^{9}$.

A blindagem dos elétrons do orbital $4 \mathrm{f}$ mostra que o espectro de absorção dos íons lantanídeos é fracamente perturbado depois de ligado com um ligante orgânico ${ }^{15}$.

Já a eficiência do processo de emissão de radiação depende da diferença energética entre o estado excitado e fundamental, da energia vibracional do oscilador e da vizinhança ao redor do íon lantanídeo ${ }^{15}$.

Neste trabalho utilizou-se o lantanídeo európio para formar complexos estáveis com o ligante orgânico representado pelas tetraciclinas.

\subsection{Európio}

O elemento Európio (Eu) com número atômico 63 foi descoberto por Paul Émile Lecoq de Boisbaudran em 1980 quando obteve um concentrado de samário e gadolínio e observou que as linhas espectrais não pertenciam a nenhum dos dois elementos. Porém a descoberta é geralmente creditada ao químico francês Eugène-Antole Demarçay em 1986, quando suspeitou que as amostras do elemento samário haviam sido contaminada por um elemento desconhecido. 
Eugène isolou esse elemento em 1901 e nomeou esse elemento como európio, em homenagem ao continente europeu ${ }^{15}$.

As propriedades ópticas do ín Európio são amplamente estudadas e empregadas como, por exemplo, em luminóforos para iluminação, agente de contraste para ressonância magnética nuclear de imagem, sondas marcadoras de biomoléculas, marcadores de proteínas e aminoácidos, entre outras aplicações ${ }^{16}$.

O íon Európio apresenta alta luminescência na região do vermelho e a partir de seus espectros de emissão podem-se obter informações sobre o processo de transferência de energia ${ }^{16}$.

O espectro de emissão do íon Európio deriva das bandas oriundas das transições intraconfiguracionais ${ }^{5} \mathrm{D}_{0} \rightarrow{ }^{7} \mathrm{~F}_{\mathrm{j}}$ (onde $\mathrm{J}=0,1,2,3,4,5$ e 6), sendo que as transições ${ }^{5} \mathrm{D}_{0} \rightarrow{ }^{7} \mathrm{~F}_{5}$ e ${ }^{5} \mathrm{D}_{0} \rightarrow{ }^{7} \mathrm{~F}_{6}$ apresentam intensidade muito baixa e dificilmente podem ser notadas nos espectros de compostos de coordenação ${ }^{16}$.

As bandas e emissão do íon Európio são de fácil interpretação na região do visível devido à estrutura dos níveis de energia, o que possibilita a sua utilização como sonda espectroscópica, e dessa forma possibilitando que sejam obtidas informações de sistemas bioinorgânicos ${ }^{16}$.

\subsection{Complexo Európio-tetraciclina}

É conhecido da literatura que a emissão do íon európio é extensivamente utilizada como sonda para análise de sistemas biológicos como, por exemplo, estrutura de enzimas, proteínas, funções celulares, entre outras ${ }^{19}$.

No entanto a luminescência destes íons em solução aquosa é fraca, isso porque os modos de vibração das moléculas de água favorecem a perda de energia por processos não luminescentes. Com a formação de complexos utilizando ligantes orgânicos, se completam as oito coordenações para impedir a coordenação da água com o íon lantanídeo ${ }^{20}$.

A formação do complexo európio-tetraciclina foi relatada pela primeira vez por Hirschy et $\mathrm{al}^{10}$, que descreveu a transferência da energia intramolecular da tetraciclina para o íon európio. A partir daí houveram várias aplicações deste complexo desde a detecção de teores de algumas tetracíclicas, até detecção de peróxido de hidrogênio, glicose, heparina, peróxido de uréia, etc ${ }^{21,22,23,24 .}$ 
A tetraciclina quando complexada com o íon Európio (III) forma um complexo altamente estável e com forte luminescência, o mecanismo de transferência de energia e de emissão será apresentado a seguir e ilustrado na Figura 2 (diagrama de Jablonski) ${ }^{25}$.

Primeiramente o complexo Eu-Tc é excitado por uma radiação externa, e a parte orgânica do complexo (TC) absorve a energia excitando os elétrons do estado singleto fundamental $\left(S_{0}\right)$ para o estado singleto excitado $\left(S_{1}\right)$. Porém do estado $\left(S_{1}\right)$ pode ocorrer uma decaimento não radiativo (processo de conversão interna) para o mais baixo nível vibracional $S_{1}$, no qual a emissão da fluorescência se origina. Outra possibilidade é o decaimento não radiativo para o estado fundamental $\left(\mathrm{S}_{0}\right)^{20}$.

A partir do mais baixo nível vibracional (S1), ocorre à conversão para o primeiro estado tripleto $\left(T_{1}\right)$, processo conhecido como cruzamento intersistema. Do estado tripleto $\left(T_{1}\right)$ há transferência de energia do ligante para nível mais alto do íon európio $\left({ }^{5} \mathrm{D}_{1}\right)$ cujo nível de energia excitado é mais baixo que o nível $\left(\mathrm{T}_{1}\right)^{20}$.

O estado excitado do európio é depopulado, ocorrendo desta forma um decaimento radiativo para o estado fundamental resultando na emissão do európio através das transições ${ }^{5} D_{0} \rightarrow{ }^{7} F_{J}(J=0,1,2,3,4)$ e ${ }^{5} D_{1} \rightarrow{ }^{7} F_{J}(J=1,2,3$, $5,6)$, porém a transição mais provável é a ${ }^{5} D_{0} \rightarrow{ }^{7} F_{2}$ aproximadamente em $612 \mathrm{~nm}^{20}$.

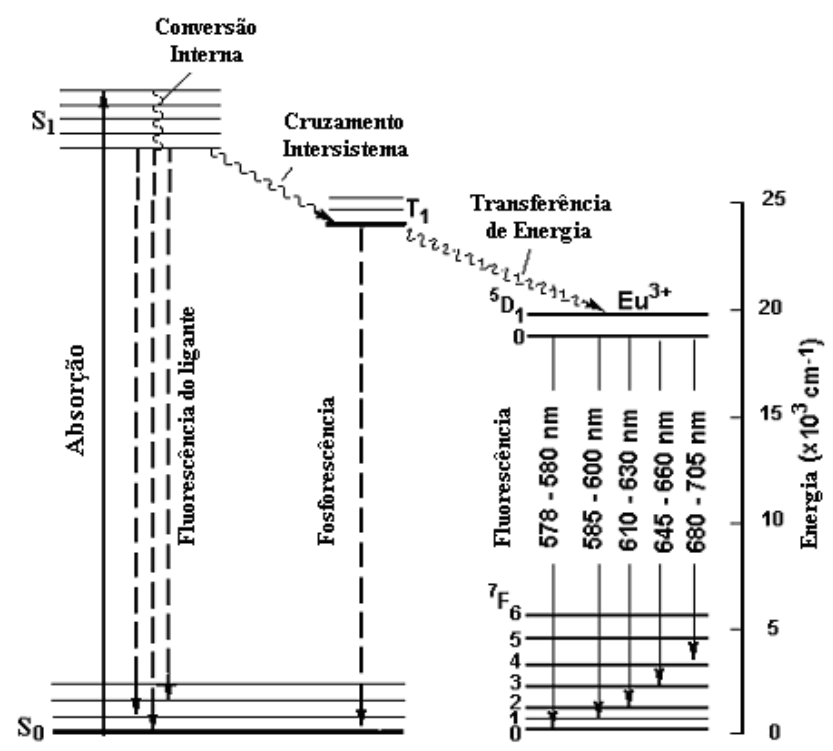

Figura 2: Mecanismo de emissão de fluorescência de complexos de $\mathrm{Eu}^{3+}$ 
Desta forma o complexo EuTc apresenta importantes características: como o aumento da intensidade de emissão do Európio no sistema complexado que é cerca de dez vezes maior que no caso do európio livre, grande deslocamento "Stokes" (absorção 395 nm e emissão 615 nm, 220nm) e longo tempo de vida de emissão ( 20 $\mu \mathrm{s})$. Devido a blindagem realizada pelos elétrons $4 \mathrm{f}$ das subcamadas $5 s^{2}$ e $5 p^{6}$ as bandas de emissão do íon európio são extremamente finas e bem definidas na região do visível ${ }^{10,20,26}$.

Estudos realizados recentemente indicaram um aumento da banda de emissão do európio, no complexo EuTc na presença de colesterol e também de LDL. Nestes casos nenhum outro tipo de reagente foi incorporado às soluções 27,28 .

O complexo EuTc na presença de colesterol e de LDL apresentou aumento em sua intensidade de emissão em torno de $618 \mathrm{~nm}$. Notou-se que com o aumento do aumento da concentração de colesterol também ocorria o aumento progressivo na intensidade de emissão do complexo EuTc, desta forma foi possível determinar a curva de calibração do complexo EuTc-colesterol e também o tempo de vida, que foi na ordem de $80 \mu$ s $^{27,28}$. Semelhante ao colesterol, o complexo EuTc apresentou aumento em sua intensidade de emissão com o aumento da concentração de LDL. A curva de calibração também foi determinada e o tempo de vida do complexo EuTc na presença de LDL foi da ordem de $89 \mu \mathrm{s}^{27,28}$.

Desta forma a determinação do colesterol, seja total ou fracionado pode ser simplesmente medido pela adição das frações de colesterol à solução de EuTc.

\subsection{Colesterol e suas frações}

$\mathrm{O}$ colesterol é um esteróide de fórmula molecular $\mathrm{C}_{22} \mathrm{H}_{45} \mathrm{OH}$, seu nome origina-se do grego chole- (bile) e stereos (sólido), e o sufixo químico -ol para um álcool $^{29}$.

Nos seres humanos o colesterol apresenta importantes funções como, por exemplo, reagente necessário para a biossíntese de vários hormônios, vitamina $D$ e de ácidos biliares, presença em quase todos os tecidos corporais e na maioria das células com exceção das hemácias ${ }^{29},{ }^{30}$. 
Em sua estrutura química 0 colesterol deriva do ciclopentanoperidrofenantreno um composto que apresenta quatro anéis nãoplanares fusionados ${ }^{31}$ (Figura 3).

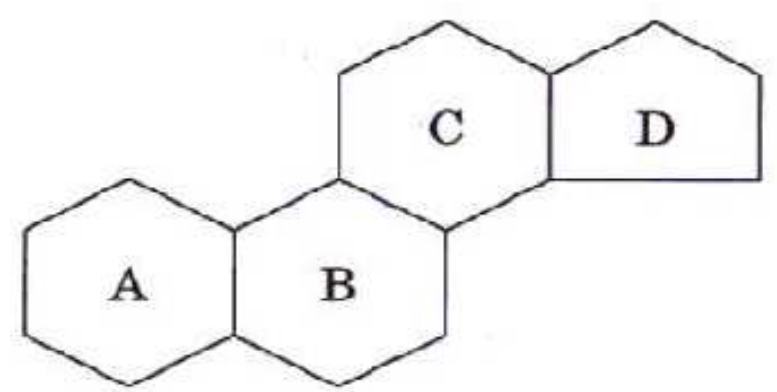

Figura 3: Ciclopentanoperidrofenantreno

O colesterol apresenta uma grande cadeia de hidrocarboneto e apenas um grupamento hidroxila $(\mathrm{OH})$ na posição do carbono 3, o que the confere uma baixa característica anfipática ${ }^{31}$ (Figura 4).

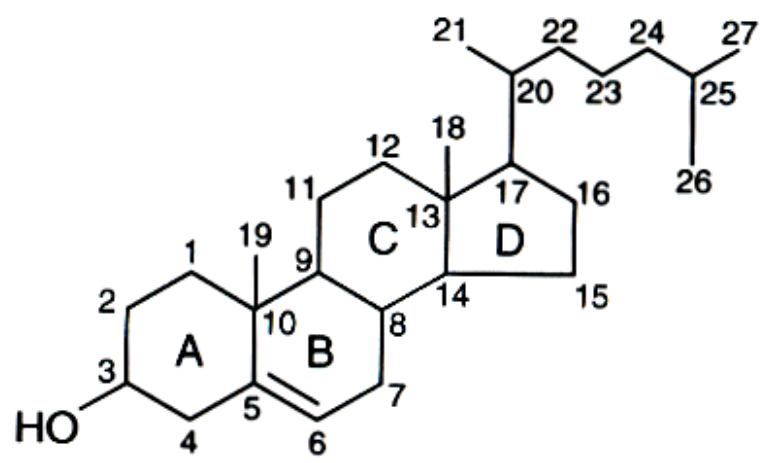

Figura 4: Estrutura química do colesterol

O colesterol pode ser obtido por meio de síntese celular (colesterol endógeno -70\%) e da dieta (colesterol exógeno- 30\%). O colesterol endógeno é produzido em sua grande maioria pelo fígado, por um sistema compensatório, isto é, quanto maior for a ingestão de colesterol vindo dos alimentos, menor é a quantidade sintetizada pelo fígado ${ }^{29}$.

Por apresentar característica hidrofóbica o colesterol é transportado no sangue por lipoproteínas ${ }^{29}$. 
As lipoproteínas são sintetizadas pelos enterócitos e pelos hepatócitos e são constituídas por triacilgliceróis, éster de colesterol, fosfolipídeos e apoproteínas (proteínas) que podem interagir com receptores de membrana celular. Os fosfolipídeos, colesterol livre e proteínas formam uma capa hidrofílica que reveste o centro hidrofóbico constituído de triglicerídeos e ésteres de colesterol $^{1,32}$. As lipoproteinas são partículas menores que as hemácias.

As lipoproteínas são classificadas de acordo com a natureza e pela densidade dos lipídeos e proteínas. Dentre estas classes, destacam-se: Quilomicrons, VLDL, LDL e HDL ${ }^{29}$.

Quilomicrons: São sintetizados pelas células intestinais e caracterizam por serem ricos em triglicerídeos e pelo transporte de colesterol da dieta ${ }^{29}$. O próprio intestino sintetisa suas principais Lipoproteinas. Uma delas, exclusiva do Quilomicron é a Apo B-48. O Quilomicron entra na circulação através do sistema linfático intestinal, atingindo a circulação sistêmica via ducto torácico. $\mathrm{Na}$ circulação o Quilomicron distribui os triglicérides aos tecidos muscular e adiposo, através da ação (hidrólise) da lipoproteina lipase (LPL), por ação da apo $\mathrm{C} \|{ }^{33}$.

VLDL (very low density lipoproteins): são sintetizadas no fígado e apresentam principalmente triglicerídeos e as Apos B-100. Quando entram em contato com a enzima lipase lipoprotéica as VLDL podem dar origem as IDL ((intermediate density lipoproteins) sendo que $1 / 3$ das IDL sofrem ação da lípase hepática formando as $\mathrm{LDL}^{29}$.

LDL (low density lipoproteins): São as principais carreadoras de colesterol para os tecidos periféricos (cerca de $70 \%$ de todo o colesterol no sangue), quando no interior das células as LDL se fragmentam liberando o colesterol $^{29}$.

As LDL em excesso são as principais causadoras dos depósitos arterioscleróticos nos vasos sanguíneos podendo dar origem ao infarto agudo do miocardio, angina e acidente vascular cerebral ${ }^{29}$.

HDL (high density lipoproteins): São sintetizadas no intestino e no fígado, apresentam grande importância no transporte de colesterol dos tecidos periféricos para o fígado ${ }^{30}$. 


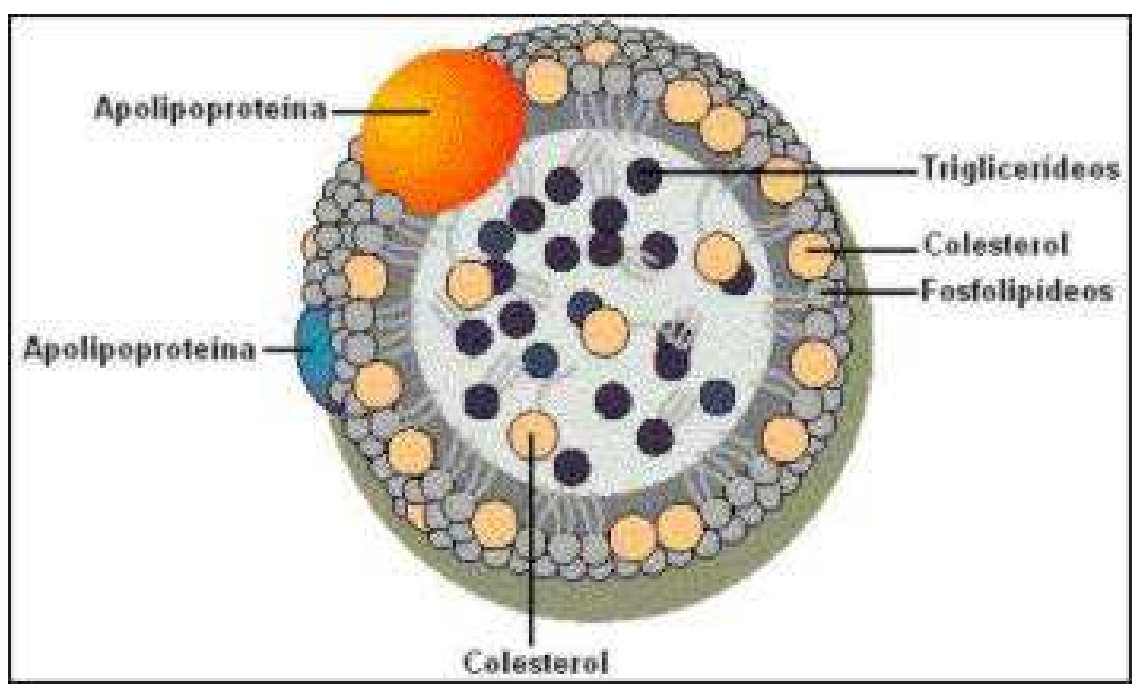

Figura 5: Estrutura básica de uma lipoproteína ${ }^{34}$

Ao passar de partículas de maior tamanho para a de menor tamanho, a densidade protéica do envoltório externo aumenta e o teor de lipídeo presente no núcleo central diminui. A densidade das lipoproteínas são inversamente proporcional à quantidade de lipídeos, ou seja, quanto menor for a lipoproteína maior quantidade de lipídeo ela carrega ${ }^{34}$.

A HDL possui menor tamanho, porém possui metade do seu peso formado por apoproteínas, já a LDL possui cerca de $50 \%$ do seu peso representado por colesterol $^{34}$. 


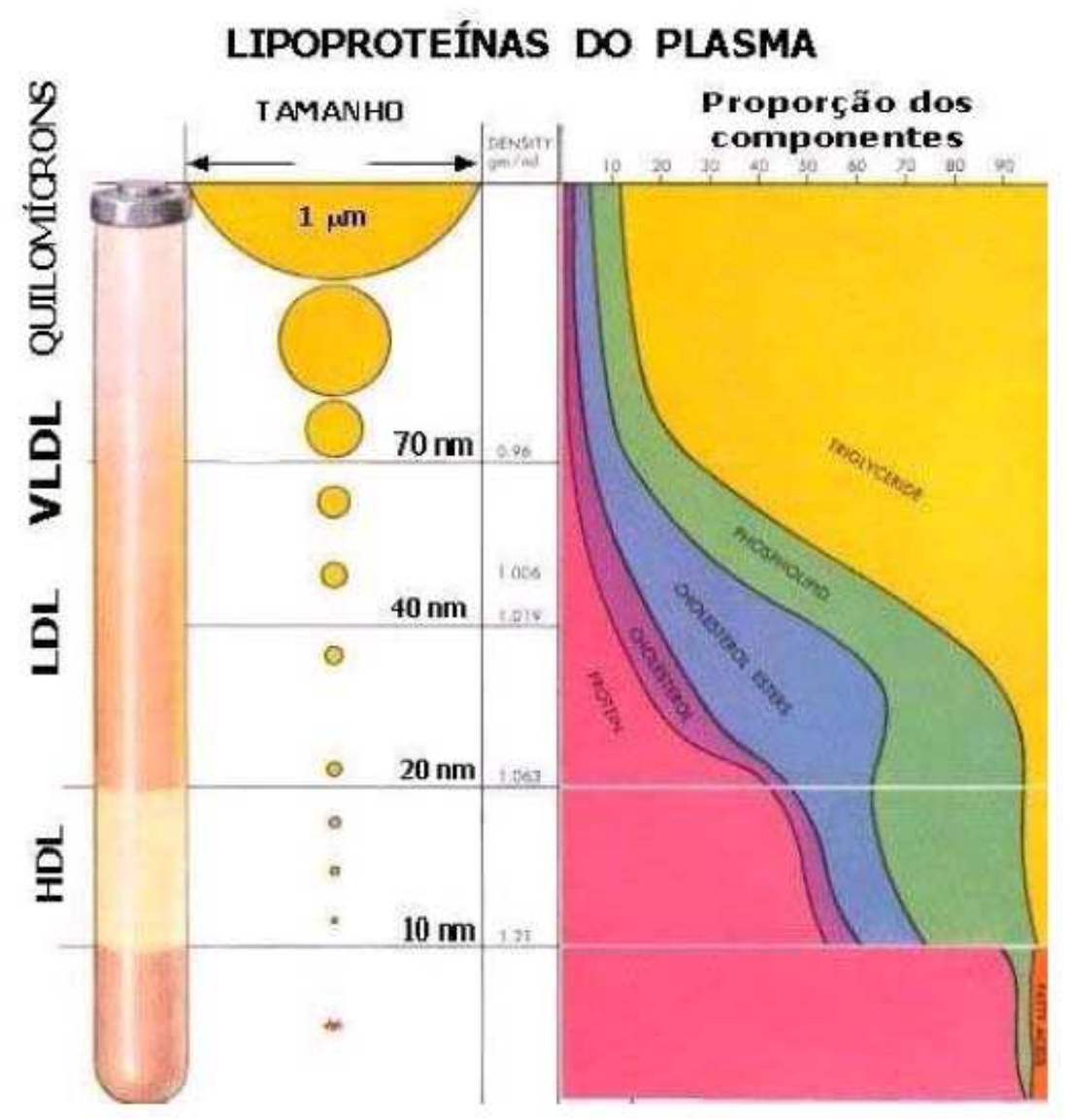

Figura 6: Lipoproteínas do plasma sanguíneo ${ }^{34}$.

Tabela 3: Relação entre o tamanho e a proporção de lipídeos nas lipoproteínas adaptado ${ }^{34}$.

\begin{tabular}{|c|c|c|c|c|c|}
\hline & Quílomícros & VLDL & IDL & LDL & HDL \\
\hline Densidade $\left(\right.$ g.cm $\left.{ }^{-3}\right)$ & $<0,95$ & $<1,006$ & $1,006-1,019$ & $1,019-1,063$ & $1,063-1,210$ \\
\hline Diâmetro (A) & $750-12000$ & $300-800$ & $250-350$ & $180-250$ & $50-120$ \\
\hline$\%$ de proteína & $1,5-2,5$ & $5-10$ & $15-20$ & $20-25$ & $40-55$ \\
\hline$\%$ de fosfolipídeos & $7-9$ & $15-20$ & 22 & $15-20$ & $20-35$ \\
\hline$\%$ de colesterol livre & $1-3$ & $5-10$ & 8 & $7-10$ & $3-4$ \\
\hline$\%$ de triglicérides & $84-89$ & $50-65$ & 22 & $7-10$ & $3-5$ \\
\hline$\%$ de colesterol & $3-5$ & $10-15$ & 30 & $35-40$ & 12 \\
\hline
\end{tabular}

As principais causas de morte da população são principalmente pelo infarto agudo do miocárdio e pelo acidente vascular encefálico. Entre os fatores que predispõem ao aparecimento dessas doenças estão as dislipidemia tanto pelo seu papel na gênese dessas doenças como pela possibilidade de atuação sobre elas.

A dislipidemia que está mais claramente associada com o aumento do risco de desenvolvimento de doenças cardiovasculares é em particular a hipercolesterolemia, particularmente níveis elevados de $\operatorname{LDL}^{35,36}$. 
Segundo a Sociedade Brasileira de Cardiologia os níveis ideais de colesterol são:

Tabela 4: Níveis de colesterol pela Sociedade Brasileira de Cardiologia.

\begin{tabular}{ll}
\hline COLESTEROL & Níveis Desejáveis \\
\hline Total $(\mathrm{mg} / \mathrm{dL})$ & $<200$ \\
LDL $(\mathrm{mg} / \mathrm{dL})$ & $<100$ \\
& Homens $>40$ \\
HDL $(\mathrm{mg} / \mathrm{dL})$ & Mulheres $>50$ \\
\end{tabular}

\subsection{Lipoproteina de baixa densidade (LDL)}

A formação da LDL é resultado da hidrólise da VLDL, catalisada pela lipase lipoprotéica plasmática ou ainda pela lipase hepática, que remove os triglicerídeos desta partícula e como conseqüência forma inicialmente a (lipoproteína de densidade intermediária) IDL e a seguir a $\operatorname{LDL}^{37}$.

A LDL apresenta diâmetro de 180 a $250 \AA$, constituída por uma molécula de apolipoproteína apo B-100, e o núcleo constituído principalmente por colesterol esterificado $^{38}$.

A remoção da LDL da circulação é realizada mais lentamente em comparação com a remoção das outras lipoproteínas. A captação de LDL é essencialmente feita pelos receptores de LDL presente em células que estão em processo ativo de divisão celular e também por tecidos que utilizam colesterol na síntese de hormônio ${ }^{34}$.

Devido ao seu tamanho, a LDL consegue atravessar o endotélio e alcançar as paredes vasculares possuindo grande potencial aterogênico.

Existem grandes evidencias que demonstram que a LDL circulante quando se fixa no endotélio das artérias pode sofrer processo oxidativo produzido por produtos metabólicos, radicais livres e enzimas produzidas por macrófagos, células musculares e endoteliais. Esse processo oxidativo é catalizado pelos metais cobre e ferro ${ }^{38}$. 
Inicialmente, a LDL sofre oxidação sem apresentar modificações da apo B, formando a LDL minimamente oxidada que contribui para o estado inflamatório das paredes vasculares, através da sinalização celular os monócitos são recrutados para local onde se diferenciam em macrófagos e aderem-se nas paredes dos vasos. A LDL fixada nos vasos sanguíneo sofre intensa oxidação por espécies reativas transformando-a em LDL altamente oxidada. Essa fase é marcada pela formação de produtos de decomposição lipídica que reagem com resíduos da apolipoproteina- $\mathrm{B}$, tornando a LDL mais eletronegativa.

Os receptores dos macrófagos passam a reconhecer a LDL oxidada e conseqüentemente passam a captá-la, formando as chamadas células espumosas ${ }^{38}$.

O acúmulo das células espumosas leva a um processo de inflamação e espessamento da parede arterial além da migração de células musculares lisas, proteoglicanos, fibras colágenas e células de tecido conjuntivo denso dando origem a placa de ateroma ${ }^{32}$.

Com a evolução do processo há o acúmulo de cálcio e de células necróticas, o processo pode evoluir para a ruptura e hemorragia da placa. A placa ainda pode se desprender dos vasos sanguíneos ocasionando a deposição de plaquetas, coagulação sanguínea, trombose e oclusão dos vasos sanguíneos ${ }^{32}$. 


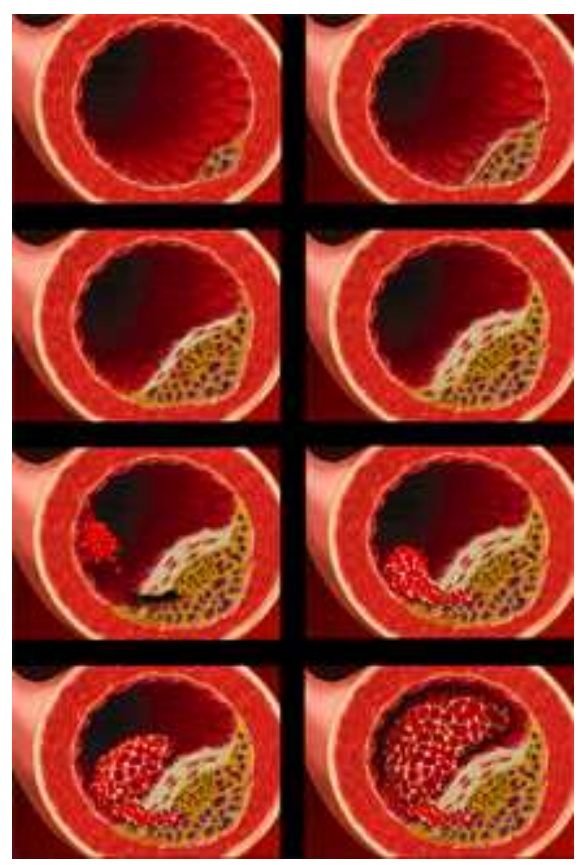

Figura 7: Processo de formação da placa de ateroma

\subsection{Principais métodos para medir Colesterol total e LDL}

Colesterol total e suas frações podem ser determinados por diferentes variedades de métodos laboratoriais, porém, os resultados desses métodos muitas vezes não exibem completa correspondência e são expressos de maneiras diversas. Esta noção é importante para a interpretação dos resultados, isto porque, os valores numéricos fornecidos irão depender do método empregado.

A determinação do colesterol total inclui a medição das formas livres e esterificadas do esteróide, sendo que dois terços do colesterol total encontrado no plasma estão na forma de éster e o restante na forma livre. Portanto o conhecimento químico de diferentes métodos de medição assim como as vantagens e as limitações na escolha do método a ser empregado são de suma importância.

Algumas técnicas a seguir serão citadas:

\subsubsection{Método de Liebermann-Burchard}

O método se baseia na utilização do ácido sulfúrico concentrado adicionado a uma solução de colesterol em anidro acético. A reação se processa 
e ocorre a mudança de coloração que variam do vermelho ao violeta e ao azul esverdeado. A cor esverdeada é devida a formação de um derivado sulfônico de colesterialeno.

O colesterol poderá ser determinado qualitativamente medindo a absorção do complexo reagente-colesterol em torno de 550nm.

\subsubsection{Método de Leffler-McDougald}

No método de Leffler- Mc Dougald utiliza-se o isopropanol para precipitar as proteínas e, ao mesmo tempo, extrair o colesterol. Em uma alíquota do extrato, adiciona-se o reativo férrico-acético que, em meio sulfúrico, forma um composto colorido que é determinado espectrofotometricamente.

\subsubsection{Método que utilizam processo enzimático- colorimétrico}

Esse método é baseado na reação de hidrolise dos ésteres de colesterol realizado pela enzima colesterol esterease formando como produto colesterol livre e ácido graxos. Em seguida utiliza-se a enzima colesterol - oxidase, formando como produto o peróxido de hidrogênio que reage com o fenol e 4aminoantipirina, catalisado pela peroxidase produz um complexo de cor avermelhada. A medida de absorbância $(\lambda=500 \mathrm{~nm})$ é proporcional a concentração de colesterol na amostra.

Os métodos mais usuais para a determinação de LDL na rotina de laboratório são: LDL direto e o LDL indireto.

O método indireto é utilizado amplamente na rotina de laboratório por apresentar vantagens, tais como, baixo custo e a facilidade de utilização. O método se baseia no cálculo de resultados combinados de colesterol total, colesterol HDL e triglicerídeos usando a equação de Friedwald $^{39}$, onde: concentração de triglicerídeos/5 corresponde ao colesterol ligado à VLDL. Esse método requer apenas uma rápida analise dos lipídeos e a rápida precipitação do HDL sem a necessidade da ultracentrifugação.

A fórmula de Friedwald pode ser utilizada apenas no jejum e apresenta varias limitações: não pode ser aplicada em amostras com valores de 
triglicerideos maiores que $400 \mathrm{mg} / \mathrm{dL}$, em amostras com quilomicrons, nem em amostras de pacientes com disbetalipoproteinemia. Alguns autores ainda consideram que a formula não deve ser utilizada para pacientes diabéticos, nefropatas e hepatopatas, mesmo com valores de triglicerídeos inferiores a 400 $\mathrm{mg} / \mathrm{dl}^{39}$.

Já nos métodos diretos, utiliza-se combinações físico- químicas de surfactantes além de complexos polimérico e moléculas ligantes para medir seletivamente o colesterol presente na $\mathrm{LDL}^{39}$.

Entre os métodos diretos está o método de primeira geração que se baseia na precipitação química das partículas de LDL pela utilização de certos reagentes, como heparina, polivinilsulfato, polimeros anfipáticos inespecificos ou sulfato de dextran. O LDL-colesterol precipitado pode ser medido diretamente depois de dissolvido o precipitado.

Já o método de segunda geração, utiliza reagentes contendo anticorpos policlonais para apo A-I e apo $E$ humanos que ligam-se a perolas de latex poliestireno e removem partículas de quilomicrons, HDL-colesterol, VLDLcolesterol e IDL-colesterol, permitindo a determinação direta de LDL-colesterol.

O método de terceira geração utiliza detergentes específicos que permitem atingir especificamente o colesterol presente na LDL e medido enzimaticamente na mesma cubeta ${ }^{39}$.

Comparando os métodos indiretos e diretos, o método direto apresenta a vantagem de não sofrer a ação de outras lipoproteínas, além de conseguir medir LDL mesmo na presença de triglicerídeos acima de $400 \mathrm{mg} / \mathrm{dL}$ e a capacidade de medir a LDL em indivíduos que não estão em jejum ${ }^{39}$.

Porém os métodos diretos apresentam alto custo, são pouco conhecidos e muitas vezes apresentam técnicas demoradas e trabalhosas.

Outras técnicas utilizadas para a determinação de LDL são a ultracentrifulgação e a eletroforese ${ }^{34}$.

A ultracentrifulgação é a técnica mais antiga e comum, o princípio dessa técnica é ajustar apropriadamente a densidade do plasma e dessa forma isolar as classes e as subclasses das lipoproteínas. No entanto essa técnica envolve várias etapas e requer mais de um dia para ser concluída ${ }^{34}$. 
A eletroforese é uma técnica amplamente utilizada para as medidas das subclasses de LDL, utiliza-se gel de agarose submerso em um tampão contido em uma cuba com diferença de potencial, dessa forma as partículas são isoladas pelo seu tamanho e pela carga. As desvantagens dessa técnica é a necessidade de produzir um gel de gradiente uniforme e também por ser uma técnica refinada que poucos laboratórios fazem uso dela ${ }^{34}$.

Este trabalho visa o estudo da interação entre os complexos EuTcs e as lipoproteínas de baixa densidade permitindo a obtenção de curvas de calibração para uma quantificação direta de LDL.

\section{MATERIAIS E MÉTODOS}

\subsection{Produção das amostras}

O preparo e as medidas presentes nesse estudo foram realizadas no Centro de Lasers e Aplicações (CLA) do Instituto de Pesquisas Energéticas e Nucleares (IPEN).

As tetraciclinas utilizadas foram importadas de Sigma Aldrich, tampão MOPS (Carl Roth, Germany), cloreto de európio hexa-hidratado (Molecular Probe), colesterol (kit comercial de dosagem de colesterol $(200 \mathrm{mg} / \mathrm{dL}$ ) por método enzimático da Laborlab) e a LDL gentilmente cedida pela equipe do Dr Magnus A. Gidlund do Instituto de Ciências Biomédicas da Universidade de São Paulo (ICBUSP).

Todos os reagentes foram pesados em uma balança analítica com precisão de $\pm 0,0001 \mathrm{~g}$. Durante 0 procedimento de preparação das amostras tomou-se os devidos cuidados com a limpeza das vidrarias, evitando assim possíveis contaminações das amostras.

A Tabela 5 mostra os solventes e reagentes utilizados e as respectivas nomenclaturas utilizadas para identificar cada um deles. 
Tabela 5: Solventes e reagentes utilizados

\begin{tabular}{cc}
\hline Solventes e reagentes & Nomenclatura \\
\hline Cloreto de Európio Hexahidratado & $\mathrm{EuCl}_{3} \cdot 6 \mathrm{H}_{2} \mathrm{O}$ \\
Tetraciclina & $\mathrm{Tc}$ \\
Clorotetraciclina & $\mathrm{CTc}$ \\
Oxitetraciclina & $\mathrm{OTc}$ \\
Metatetraciclina & $\mathrm{MTc}$ \\
água bideionizada & $\mathrm{H}_{2} 0$ \\
Hidróxido de sódio & $\mathrm{NaOH}$ \\
Ácido propanesulfônico 3 (N-Morpholino) & $\mathrm{MOPS}$ \\
Lipoproteína de baixa densidade & $\mathrm{LDL}$ \\
Lipoproteína de baixa densidade oxidada & $\mathrm{LDL} \mathrm{oxidada}$ \\
Prata & $\mathrm{Ag}$ \\
Alumínio & $\mathrm{Al}$ \\
Cálcio & $\mathrm{Ca}$ \\
Cobalto & $\mathrm{Co}$ \\
Cobre & $\mathrm{Cu}$ \\
Ferro & $\mathrm{Fe}$ \\
Magnésio & $\mathrm{Mg}$ \\
Manganês & $\mathrm{Mn}$ \\
Níquel & $\mathrm{Ni}$ \\
Zinco & $\mathrm{Zn}$ \\
&
\end{tabular}

\subsection{Obtenção das lipoproteínas}

As amostras foram gentilmente fornecidas pelo Dr. Magnus A. Gidlund e o procedimento foi realizado por sua aluna Andréa M. Monteiro do Instituto de Ciências Biomédicas da Universidade de São Paulo (ICB-USP). Coletou-se sangue de doadores voluntários saudáveis normolipidêmicos em jejum (12h). $\mathrm{O}$ plasma foi obtido após centrifugação a $10^{3} \mathrm{~g}$, a $4^{\circ} \mathrm{C}$, por 15 minutos. Depois disso foi adicionado, ao plasma, benzamidine $(2 \mathrm{mM})$, gentamicina $(0.5 \%)$, cloranfenicol (0.25\%), PMSF (fenil-metil-sulfonil-fluoreto) $(0.5 \mathrm{mM})$, e aprotinina $(0.1 \mathrm{unid} / \mathrm{mL})$. As lipoproteínas do plasma foram então isoladas por ultracentrifugação seqüencial. Para isolamento seqüencial a densidade do plasma foi ajustada para VLDL $d<1,006 \mathrm{~g} / \mathrm{mL}$, LDL $d=1.030-1.063 \mathrm{~g} / \mathrm{mL}$ e HDL $\mathrm{d}=1.063-1.21 \mathrm{~g} / \mathrm{mL}$ e então centrifugado a $10^{5} \mathrm{~g}$, à $4^{\circ} \mathrm{C}$, por 20 horas, usando rotor $75 \mathrm{Ti}$ (Beckman Instruments). Imediatamente após a obtenção, as lipoproteínas foram dialisadas 
durante 48 h (PBS-EDTA $0,01 \%)$ e filtradas $(0,22 \mu \mathrm{m}$ de diâmetro, Millipore $\AA$ ). A concentração de proteínas foi quantificada utilizando o kit BCA (PIERCE) de acordo com as instruções do fabricante.

Oxidação das lipoproteínas por íons cobre: As amostras também foram fornecidas pelo Dr. Magnus A. Gidlund e o procedimento foi realizado por sua aluna Andréa M. Monteiro do Instituto de Ciências Biomédicas da Universidade de São Paulo (ICB-USP). Para obtenção de LDL oxidada por íons cobre, a lipoproteína foi dialisada de um dia para o outro em PBS, sem EDTA, seguida de incubação com $\mathrm{CuSO}_{4}, 20 \mathrm{mM} / \mathrm{mg}$ de proteína da $\mathrm{LDL}$, à ${ }^{3 \circ} \mathrm{C}$, de um dia pa ra o outro. Obteve-se uma completa oxidação das lipoproteínas definida por uma fase platô, medida pelo ensaio de TBARS. O processo de oxidação foi finalizado pela adição de $1 \mathrm{mM}$ de EDTA.

\subsection{Soluções}

Foram preparadas as seguintes soluções:

Solução I: Solução tampão de MOPS: 2.09 g de MOPS em $1000 \mathrm{~mL}$ de água destilada (o pH foi ajustado com $\mathrm{NaOH}$ para 6.9).

Solução II: Solução EuTcs: foram preparadas amostras em diferentes concentrações de $\mathrm{EuCl}_{3} .6 \mathrm{H}_{2} \mathrm{O}$ para $21 \mathrm{mmolL}^{-1}$ das Tetraciclinas (Oxitetraciclina, Clorotetraciclina e Metatetraciclina) completando o volume com a solução I para $100 \mathrm{~mL}$ aguardou-se 15 minutos para a completa complexação).

Solução III: EuTcs-LDL: $1 \mathrm{~mL}$ de solução III e 10 $\mu \mathrm{L}$ de LDL (aguardou-se 15 minutos).

Solução IV: EuTcs-LDL oxidada: $1 \mathrm{~mL}$ de solução III e $10 \mu \mathrm{L}$ de $\mathrm{LDL}$ oxidada (aguardou-se 15 minutos). 
Solução V: Interferentes: Para obter as concentrações dos íons inorgânicos normalmente encontrados no plasma sanguineo, utilizou-se os sais abaixo relacionados, diluídos em água bideionizadas:

$$
\begin{aligned}
& \checkmark \mathrm{AgNO}_{4} \\
& \checkmark \mathrm{Al}_{2}\left(\mathrm{SO}_{4}\right)_{3} \\
& \checkmark \mathrm{CoSO}_{4} \cdot 7 \mathrm{H}_{2} \mathrm{O} \\
& \checkmark \mathrm{CaCl}_{2} \cdot 2 \mathrm{H}_{2} \mathrm{O} \\
& \left.\checkmark \mathrm{Cu}^{2} \mathrm{NO}_{3}\right)_{2} \cdot 3 \mathrm{H}_{2} \mathrm{O} \\
& \checkmark \mathrm{FeCl}_{3} \cdot 6 \mathrm{H}_{2} \mathrm{O} \\
& \checkmark \mathrm{MgSO}_{4} \cdot 7 \mathrm{H}_{2} \mathrm{O} \\
& \checkmark \mathrm{MnSO}_{4} \cdot \mathrm{H}_{2} \mathrm{O} \\
& \checkmark \mathrm{NiSO}_{4} \cdot 6 \mathrm{H}_{2} \mathrm{O} \\
& \checkmark \mathrm{ZnSO}_{4} \cdot 7 \mathrm{H} 2 \mathrm{O}
\end{aligned}
$$

A tabela abaixo mostra o valor de referência dos interferentes encontrados no plasma sanguíneo ${ }^{40,41,42,43,44}$ :

Tabela 6: Valor de referência dos interferentes encontrados no plasma sanguíneo

\begin{tabular}{cc}
\hline Interferentes & Valor de referência no sangue \\
\hline $\mathrm{Ag}$ & $0.093 \mu \mathrm{M}$ \\
$\mathrm{Al}$ & $12 \mu \mathrm{M}$ \\
$\mathrm{Ca}$ & $1.12 \mu \mathrm{M}$ \\
$\mathrm{Co}$ & $0.1 \mu \mathrm{M}$ \\
$\mathrm{Cu}$ & $11.02 \mu \mathrm{M}$ \\
$\mathrm{Fe}$ & $10.74 \mu \mathrm{M}$ \\
$\mathrm{Mg}$ & $0.75 \mathrm{mM} \mathrm{a} \mathrm{mM}$ \\
$\mathrm{Mn}$ & $0.2 \mu \mathrm{M}$ \\
$\mathrm{Ni}$ & $0.1 \mu \mathrm{M}$ \\
$\mathrm{Zn}$ & $20 \mu \mathrm{M}$ \\
\hline
\end{tabular}




\section{4 - Técnicas usadas para caracterização das amostras}

Nesta primeira etapa do trabalho utilizamos apenas as técnicas de medida de absorção e emissão. Passaremos a descrevê-las.

\subsubsection{Medida de Absorção}

Os espectros de absorção óptica das amostras foram medidos em temperatura ambiente, com o auxílio de um espectrofotômetro Olis Cary-17 D, da Varian, do Laboratório de Espectroscopia de Absorção Óptica do Centro de Lasers e Aplicações (CLA) do IPEN, empregando-se cubeta de quartzo com caminho óptico de $1 \mathrm{~mm}$. As amostras foram analisadas na região de 200 a 500 $\mathrm{nm}$, com resolução de $1 \mathrm{~nm}$.

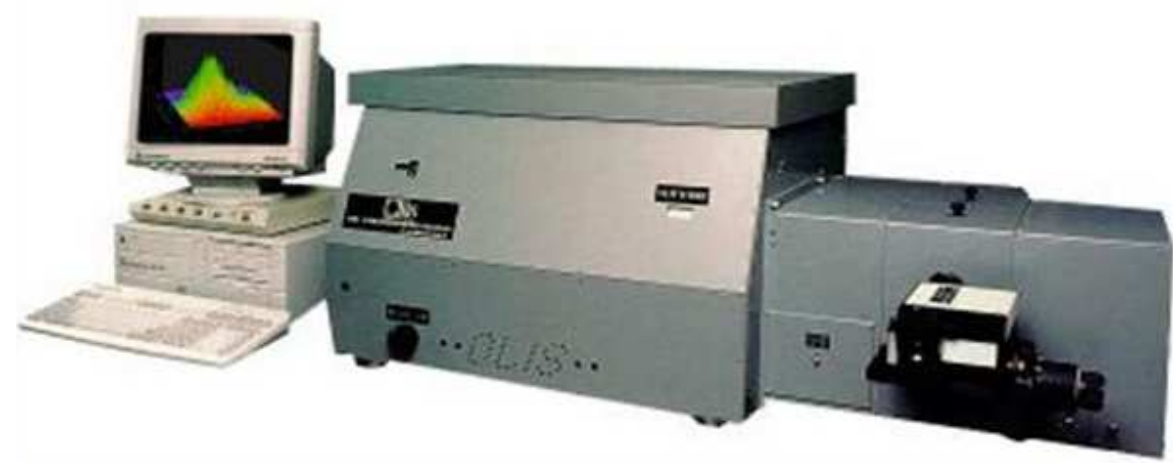

Figura 8: Espectrofotômetro Olis Cary-17 D.

\subsubsection{Medida de emissão}

Para a obtenção dos espectros de emissão foi utilizado o sistema Fluorolog 3 da Jobin Yvon, Figura 9.

As medidas foram realizadas em temperatura ambiente e os espectros de emissão foram obtidos com o auxilio do software FluorEssence. $O$ aparelho permite medidas espectrais e temporais.

Em todas as medidas de emissão as amostras foram colocadas em cubetas com as quatro faces polidas, de $1 \mathrm{~mm}$ de caminho óptico. 


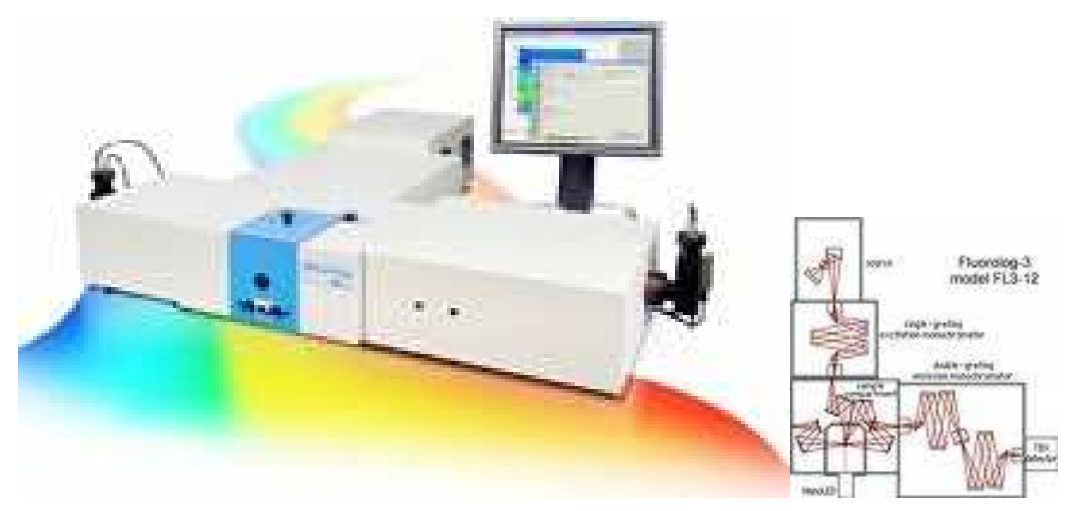

Figura 9: Espectrofotômetro Fluorolog 3.

$>$ Excitação : Lâmpada de Xe 450 Watts

$>$ Acurácia $0.5 \mathrm{~nm}$

$>$ Velocidade $150 \mathrm{~nm} / \mathrm{s}$

$>$ Range $0-1100 \mathrm{~nm}$

$>$ Grades $330 \mathrm{~nm}(200-700 \mathrm{~nm}$ range) e $500 \mathrm{~nm}(300-1000 \mathrm{~nm}$ range);

$>$ Sensibilidade S/N >5000:1 (R928 PMT) em 397 nm, com slits de $5 \mathrm{~nm}$.

\subsubsection{Medida de Tempo de vida}

As medidas de tempo de vida foram obtidas no mesmo espectrofotômetro, Figura 9, utilizando como fonte de excitação uma lâmpada de xenônio pulsada que fornece a capacidade de discriminação em tempo. Devido a duração de cada pulso de ( $3 \mu \mathrm{s}$ ), a interferência da largura do pulso da lâmpada durante a aquisição da curva de decaimento é minimizada. A excitação foi fixada em 400 $\mathrm{nm}$ e a emissão em $615 \mathrm{~nm}$ com 61 flashes em $\mu$ s. 


\section{RESULTADOS E DISCUSSÃO}

A caracterização dos complexos Európio-Tetraciclinas (EuTcs) na presença de LDL e de LDL oxidada foram realizadas através de medidas de absorção óptica, emissão e tempo de vida. Também foram realizadas medidas de emissão dos complexos de EuTcs na presença de alguns íons comuns no plasma sanguíneo, verificando dessa forma se os mesmos interferem na intensidade de emissão dos complexos de EuTcs.

\subsection{Caracterização dos complexos Európio-Tetraciclinas (EuTcs)}

Na primeira etapa do estudo foram preparadas soluções de Tcs (solução III) e solução de európio na concentração molar de $63 \mu \mathrm{M}$. Foram preparadas também as amostras EuTcs (solução IV) na razão molar de (3:1), conforme Tabela 7.

As amostras foram agitadas por cerca de 5 minutos para sua homogeinização e em seguida foram deixadas em repouso por 15 minutos antes de serem medidas.

Estas amostras foram estudadas com 0 objetivo de avaliar 0 comportamento espectroscópico das tetraciclinas quando complexadas com o íon európio.

Tabela 7: Preparo dos complexos de EuTcs em diferentes razões molares de Eu ${ }^{3+}$

\begin{tabular}{ccc}
\hline $\begin{array}{c}\text { Concentração }(\mu \mathrm{M}) \\
\text { de } \\
\text { Európio }\end{array}$ & $\begin{array}{c}\text { Concentração }(\mu \mathrm{M}) \\
\text { de } \\
\text { Tetraciclinas (Tcs) }\end{array}$ & $\begin{array}{c}\text { Melhores razões molares } \\
\text { de Európio e Tcs presente } \\
\text { no complexo }\end{array}$ \\
\hline 21 & 21 & $1: 1$ \\
31,5 & 21 & $1,5: 1$ \\
42 & 21 & $2: 1$ \\
52,5 & 21 & $2,5: 1$ \\
63 & 21 & $3: 1$ \\
73,5 & 21 & $3,5: 1$ \\
84 & 21 & $4: 1$ \\
\hline
\end{tabular}

As medidas de absorção óptica foram realizadas em temperatura ambiente nos comprimentos de onda de $200-500 \mathrm{~nm}$. 
A Figura 10a mostra o espectro de absorção óptica das amostras de Európio com concentração de $63 \mu \mathrm{M}$ diluídas em MOPS, Tampão MOPS e das soluções de tetraciclinas: Metaciclina (MTc), Clorotetraciclina (CTc), Oxitetraciclina (OTc) e Tetraciclina (Tc) com concentrações molares de $21 \mu \mathrm{M}$ diluídas em tampão MOPS.

Observa-se que o Európio em MOPS não apresenta banda de absorção óptica nos comprimentos de onda medidos (200 à 500nm), isso pode ser explicado devido as transições (f-f) do íon Európio que são proibidas, resultando em baixo coeficiente de absorção. Portanto a excitação direta desse íon em solução é desfavorável ${ }^{45}$.

O tampão MOPS também não apresenta absorção óptica na faixa de 200 à $500 \mathrm{~nm}$ demonstrando que o mesmo não interfere nos resultados obtidos nesse estudo.

As soluções de tetraciclinas apresentam bandas de absorção óptica mais intensas em $359 \mathrm{~nm}, 357 \mathrm{~nm}, 370 \mathrm{~nm}$ e $350 \mathrm{~nm}$ respectivamente para a Tc, OTc, CTc e MTc.

A Figura 10b mostra o espectro de absorção óptica das tetraciclinas na presença do európio.

Nota-se, que quando as tetraciclinas estão na presença do íon európio há o deslocamento das bandas de absorção, o que demonstra a sua complexação com o íon európio, Figura 10b.

A MTc foi a que apresentou maior deslocamento da banda de absorção, quando complexada com o íon európio quando a banda de absorção em $350 \mathrm{~nm}$ se desloca para $392 \mathrm{~nm}$. O mesmo ocorre com as outras tetraciclinas estudadas, porém a CTc foi a que apresentou menor deslocamento na banda de absorção quando complexada com o íon európio. 


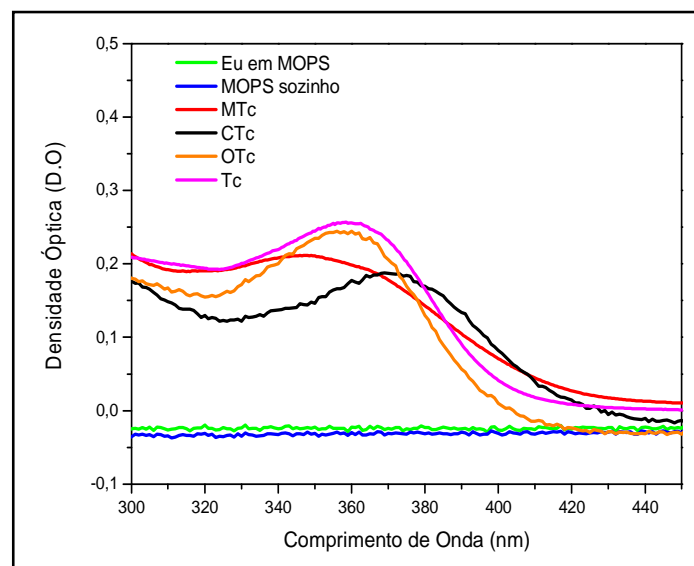

a)

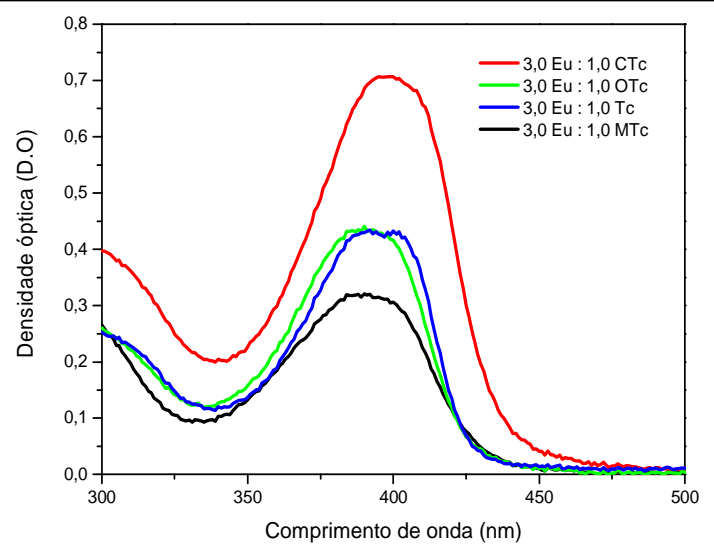

b)

Figura 10: a) Espectro de absorção óptica das amostras de európio, tampão, MOPS e tetraciclinas; b) Espectro de absorção óptica das tetraciclinas na presença do európio.

Tabela 8: Valores das posições de máximo dos compostos TC, OTC, CTc e MTc.

\begin{tabular}{lccc}
\hline \multicolumn{1}{c}{ Compostos } & $\begin{array}{c}\text { Tcs em solução } \\
(\mathrm{nm})\end{array}$ & $\begin{array}{l}\text { EuTcs } \\
(\mathrm{nm})\end{array}$ & $\begin{array}{c}\text { Shift } \\
(\mathrm{nm})\end{array}$ \\
\hline Tetraciclina (Tc) & 359 & 398 & 39 \\
Oxitetraciclina (OTc) & 357 & 391 & 34 \\
Clorotetraciclina (CTc) & 370 & 401 & 31 \\
Metaciclina (MTc) & 350 & 392 & 42 \\
\hline
\end{tabular}

A Figura 11a mostra os espectros de emissão das tetraciclinas com bandas de emissão com máximos em torno de: $540 \mathrm{~nm}, 501 \mathrm{~nm}$, 510nm e $544 \mathrm{~nm}$ respectivamente para Tc, OTc, MTc e CTc. As amostras foram excitadas nos comprimentos de ondas relativos as bandas de absorção característica de cada Tcs, Tabela 8.

Nota-se que as Tcs apresentam em comum largas bandas de emissão, características de compostos orgânicos eletroluminescentes. Quando as Tcs estão complexadas com o íon európio, Figura 11b, as bandas de emissão dos complexos passam a ser extremamente finas e definidas, relativas as transições proibidas (f-f) e oriundas da blindagem realizada pelas subcamadas mais 
externas, $5 s^{2}$ e $5 p^{6}$, o que impede um maior envolvimento dos elétrons $4 f$ do íon európio como o meio externo ${ }^{45}$.

A luminescência dos complexos EuTcs é resultado da energia de excitação transferida do ligante tetraciclinas (Tcs) para o íon $\mathrm{Eu}^{+3}$. O forte pico de emissão $(\sim 616 \mathrm{~nm})$ ocorre das transições ${ }^{5} \mathrm{D}_{0} \rightarrow \mathrm{F}_{2}{ }^{46}$.

O deslocamento das bandas de emissão das Tcs, para comprimentos de onda na região em torno de $615 \mathrm{~nm}$, demonstram a efetiva transferência de energia intramolecular do ligante (Tcs) para o íon Európio o que revela a formação dos complexos de EuTcs. Para a realizações das medidas dos complexos EuTcs as amostras foram excitadas nos comprimentos de ondas relativos às bandas de absorção característica de cada complexo de EuTcs, Tabela 9.

Analisando a Tabela 9 pode-se observar o deslocamento entre a banda de absorção e a banda de emissão dos complexos EuTcs.

Os complexos que apresentaram maior deslocamento "Stokes" foram os complexos EuOTc e EuMTc com deslocamento de 226nm. Já os complexos EuTc e EuCTc apresentaram deslocamento Stokes de $217 \mathrm{~nm}$.

Tabela 9: Bandas de absorção dos compostos EuTC, EuOTC, EuCTc e EuMTc.

\begin{tabular}{lccc}
\multicolumn{1}{c}{$\begin{array}{c}\text { Compostos } \\
\text { EuTcs }\end{array}$} & $\begin{array}{c}\text { Absorção } \\
(\mathrm{nm})\end{array}$ & $\begin{array}{c}\text { Emissão } \\
(\mathrm{nm})\end{array}$ & $\begin{array}{c}\text { Stokes Shift } \\
(\mathrm{nm})\end{array}$ \\
\hline EuTc & 400 & 617 & 217 \\
EuOTc & 390 & 616 & 226 \\
EuCTc & 400 & 617 & 217 \\
EuMTc & 390 & 616 & 226 \\
\hline
\end{tabular}




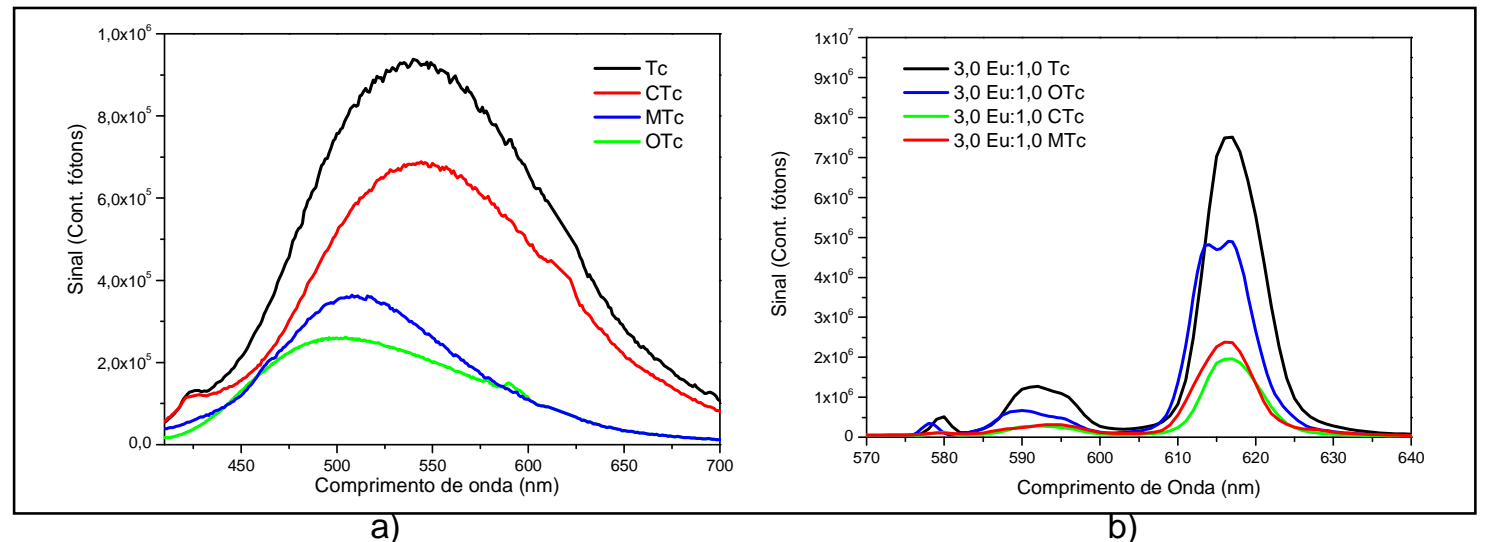

Figura 11: a) espectros de emissão das tetraciclinas Tc, OTc, MTc e CTc. Espectro das tetraciclinas Tc, OTc, MTc, CTc complexadas com o íon európio.

\subsection{Estudo dos complexos EuTcs na presença de LDL}

\subsubsection{Melhores razões molares dos complexos EuTcs na presença de $L D L$}

A escolha das melhores razões molares de európio nos complexos EuTcs na presença de LDL foram realizadas preparando as amostras de acordo com a Tabela 7. Também foi utilizado o volume de $10 \mu \mathrm{L}$ de LDL para $1 \mathrm{~mL}$ dos complexos de EuTcs. Após a adição de LDL nos complexos de EuTcs as amostras foram homogeinizadas por cerca de 5 minutos, em seguida mantidas em repouso por 15 minutos antes de serem estudadas. Vale ressaltar que todas as amostras foram preparadas e medidas em triplicatas.

As medidas de absorção óptica foram realizadas no intervalo $200-500$ nm. Já as medidas de emissão, foram realizadas excitando as amostras nos comprimentos de onda relativo ao pico da banda de absorção óptica dos complexos de EuTcs na presença de LDL.

As medidas foram realizadas com o objetivo de eleger a melhor razão molar de európio nos complexos: EuOTc, EuCTc e EuMTc, para a quantificação de LDL.

Como mencionado no início desse trabalho, o complexo EuTc foi extensivamente estudado por diversos pesquisadores devido às suas propriedades ópticas importantes que o torna mais seletivo e sensível na bioanálise de algumas moléculas. Estudos recentes relataram aumento da intensidade de emissão do complexo EuTc na razão molar (3:1) na presença de 
$\mathrm{LDL}^{47}$. Portanto elegemos essa razão molar para prosseguimos as medidas do complexo EuTc.

A Figura 12 mostra o espectro de absorção óptica do complexo EuOTc em diferentes razões molares de európio na presença de $0,517 \mathrm{mg} / \mathrm{mL}$ de LDL.

As bandas de absorção óptica dos complexos não apresentam deslocamentos apreciáveis, sendo o pico de absorção óptica em torno de $390 \mathrm{~nm}$. Nota-se maior aumento na banda de absorção do complexo nas razões molares $(4: 1)$ e $(3: 1)$ e densidade óptica em torno de $3 \times 10^{-1}$.

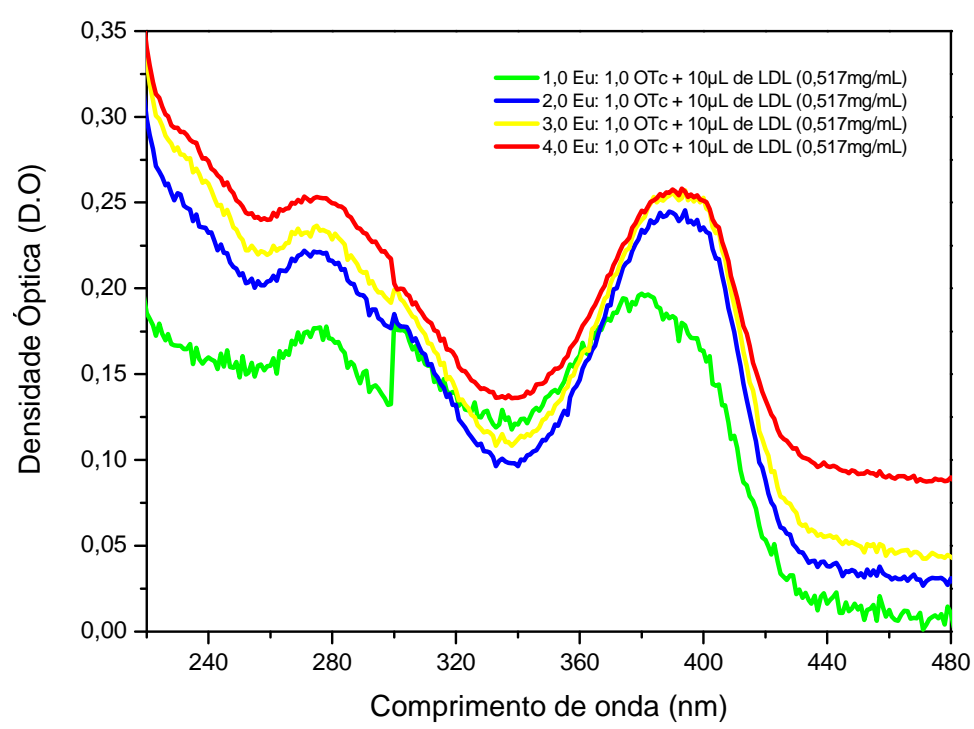

Figura 12: Espectro de absorção do complexo EuOTc em diferentes razões molares de európio na presença de LDL

Posteriormente realizou-se medidas de emissão excitando as amostras dos complexos de EuOTc no comprimento de onda de 390nm, Figura 13.

O complexo EuOTc na presença de LDL $(0,517 \mathrm{mg} / \mathrm{mL})$ apresentou maior intensidade de emissão na razão molar de (1:1), com pico de emissão em torno de $616 \mathrm{~nm}$ e intensidade de emissão em torno de $6 \times 10^{6}$ fótons. 


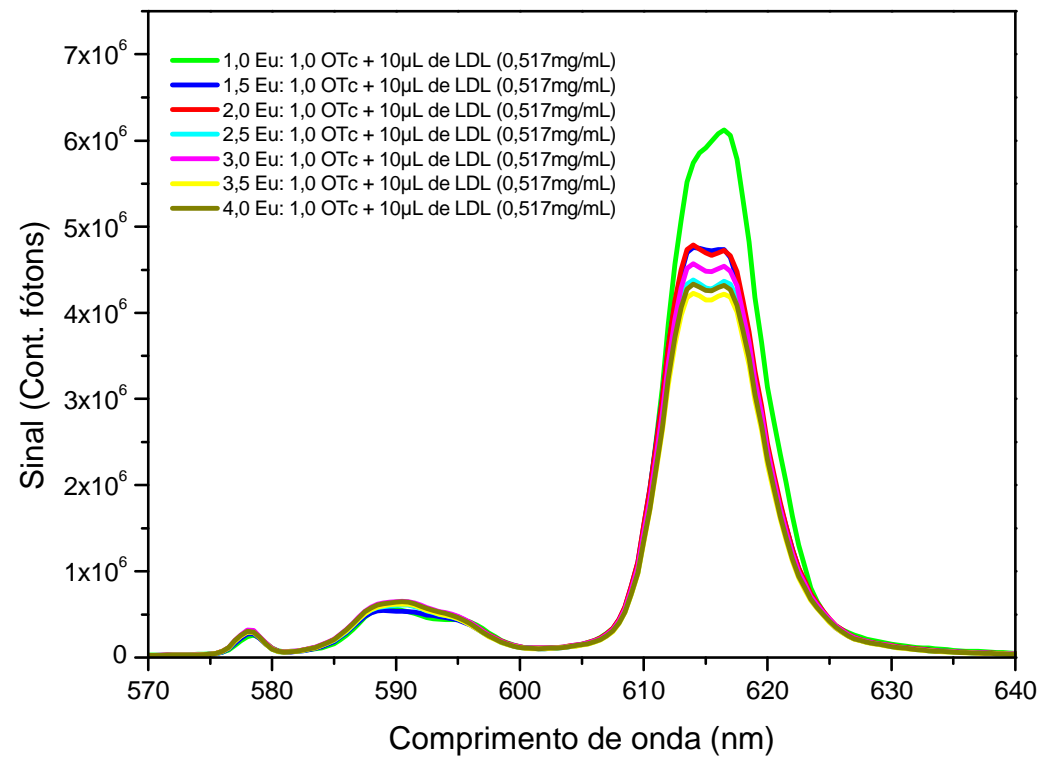

Figura 13: Espectro de emissão dos complexos de EuOTc

A Figura 14, mostra o espectro de absorção óptica do complexo EuCTc em diferentes razões molares de európio na presença de $2,96 \mathrm{mg} / \mathrm{mL}$ de LDL.

As bandas de absorção óptica dos complexos apresentaram pico de absorção óptica em torno de $400 \mathrm{~nm}$. Nota-se maior aumento na banda de absorção do complexo na razão molar de (2:1) e adensidade óptica em torno de $5 \times 10^{-1}$

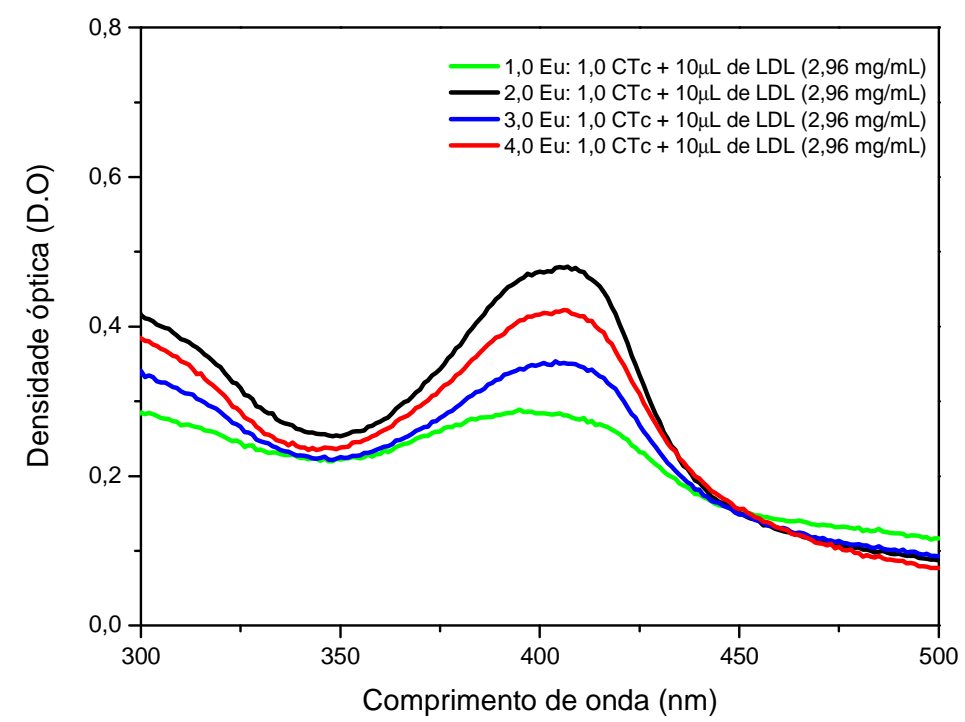

Figura 14: Espectro de absorção óptica do complexo EuCTc em diferentes razões molares de európio na presença de LDL.

Em seguida, foram realizadas as medidas de emissão excitando as amostras em 400nm, Figura 15. 
O complexo EuCTc na presença de LDL $(1,75 \mathrm{mg} / \mathrm{mL})$ apresentou maior intensidade de emissão na razão molar de $(1,5: 1)$ com pico de emissão em torno de $616 \mathrm{~nm}$ e intensidade de emissão em torno de $4,4 \times 10^{6}$ fótons de emissão.

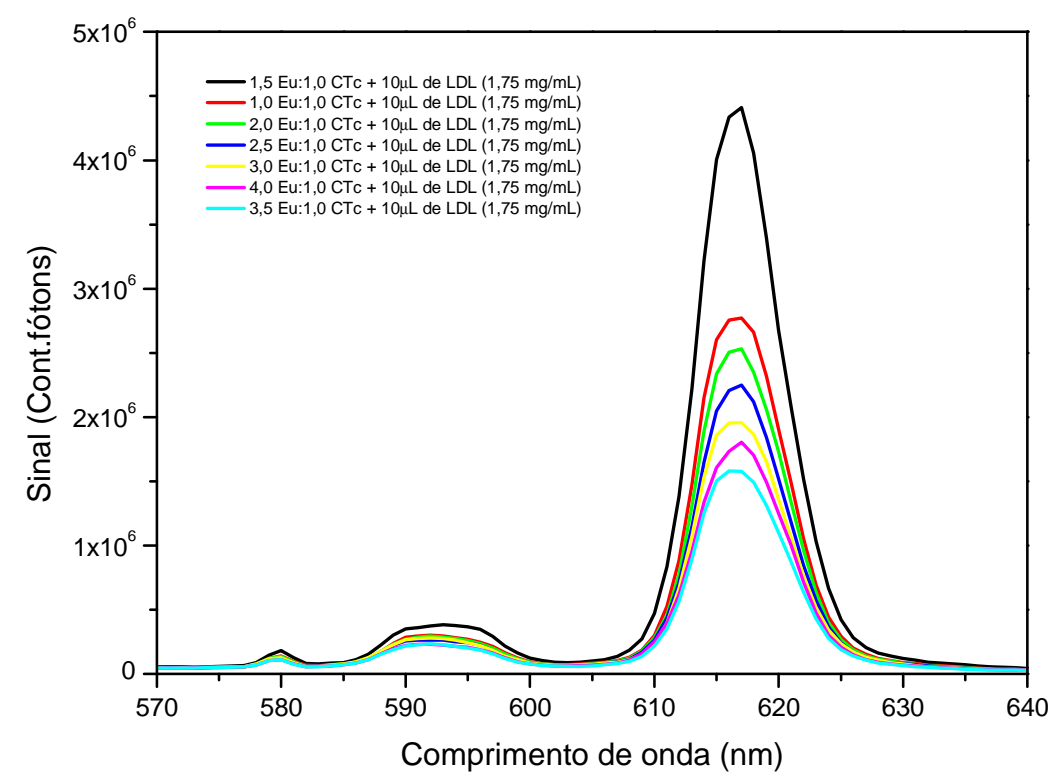

Figura 15: Espectro de emissão dos complexos de EuCTc

A Figura 16, mostra o espectro de absorção óptica do complexo EuMTc em diferentes razões molares de európio na presença de 3,6 mg/mL de LDL.

As bandas de absorção óptica dos complexos apresentaram pico de absorção óptica em torno de $390 \mathrm{~nm}$. O pico de absorção óptica do complexo EuMTc nas razões molares (1:1), (2:1) e (3:1) foram as que apresentaram maior densidade óptica, em torno de $3 \times 10^{-4}$.

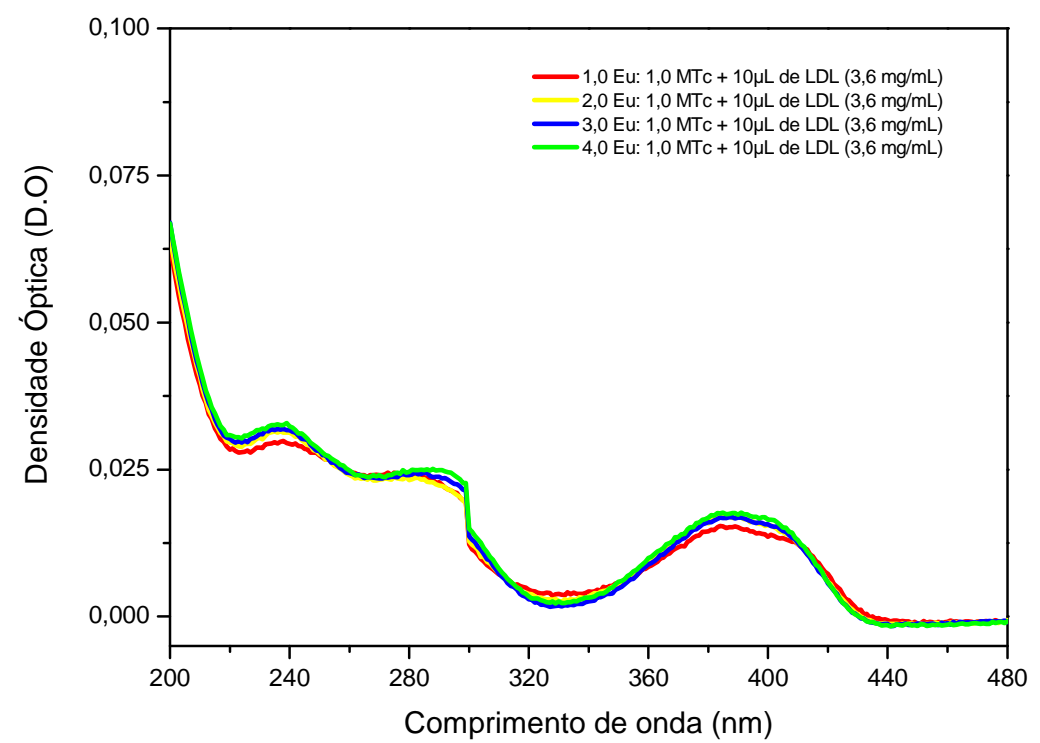

Figura 16: Espectro de absorção óptica do complexo EuMTc em diferentes razões molares de európio na presença de LDL. 
As medidas de emissão foram excitadas no comprimento de onda de 390nm. O complexo EuMTc na presença de LDL $(1,5 \mathrm{mg} / \mathrm{mL})$ apresentou maior intensidade de emissão na razão molar de $(1,5: 1)$ com pico de emissão em torno de $615 \mathrm{~nm}$ e intensidade de emissão em torno de 5,0 x 106 fótons de emissão,

Figura 17.

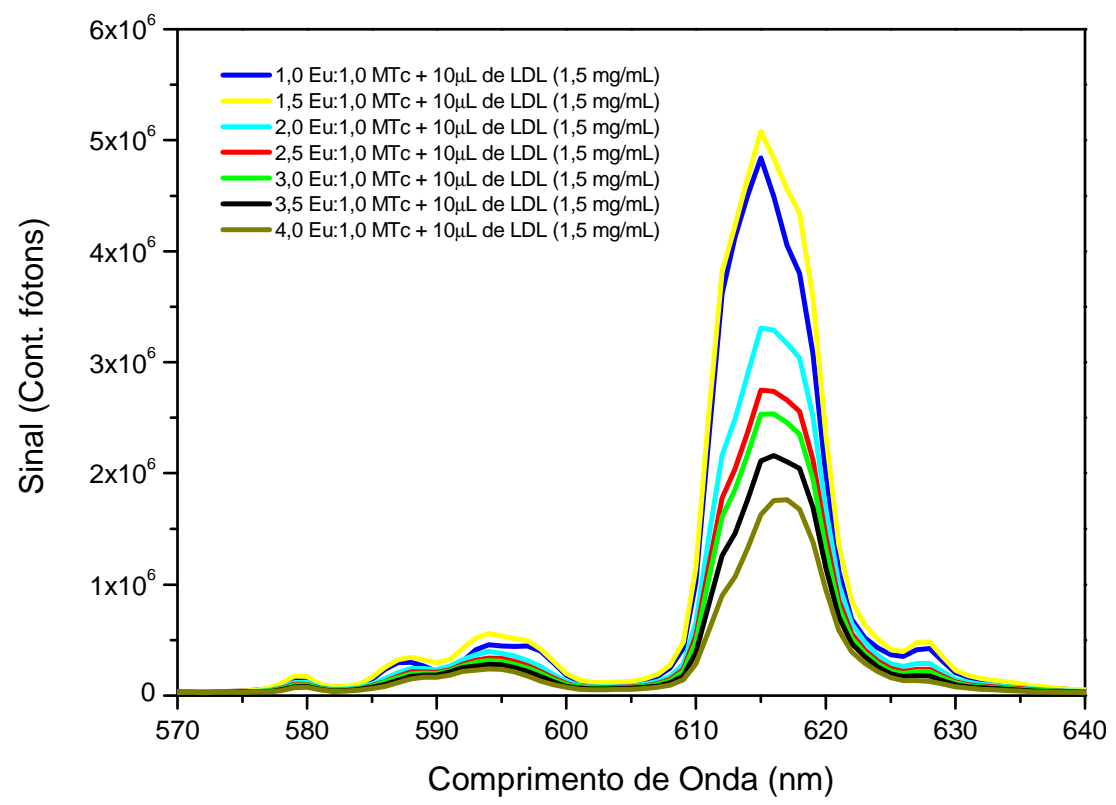

Figura 17: Espectro de emissão dos complexos de MTc

As medidas realizadas com os complexos EuTcs revelaram que não ocorreram deslocamentos nos comprimentos de onda dos espectros de absorção e de emissão na presença de LDL, o que evidencia a ausência de interação direta entre as Tcs e as moléculas de $\operatorname{LDL}^{48}$.

As melhores razões molares dos complexos EuTcs na presença de LDL foram: EuTc (3:1), EuOTc (1:1), EuCTc $(1,5: 1)$ e EuMTc $(1,5: 1)$.

5.2.2 Comparação dos complexos EuTcs na presença de diferentes concentrações de LDL

Após a escolha das melhores razões molares dos complexos EuTcs, prossegue-se o estudo com os complexos EuTcs em suas melhores razões molares na presença de diferentes concentrações de LDL. 
Realizou-se as medidas de emissão excitando as amostras nos comprimentos de onda relativo ao pico da banda de absorção óptica dos complexos de EuTcs na presença de LDL.

As amostras foram preparadas de maneira idêntica à etapa anterior, porém nessa etapa utilizamos diferentes concentrações de LDL, as amostras e as medidas foram realizadas em triplicata.

Os espectros de emissão das EuTcs com LDL estão apresentados na Figura 18, Figura 19, Figura 20 e Figura 21. As amostras foram excitadas nos comprimentos de ondas de 390nm para os complexos EuOTc e EuMTc e $400 \mathrm{~nm}$ para os complexos EuTc e EuCTc; todos na presença de diferentes concentrações de LDL.

A Figura 18 mostra o espectro de emissão do complexo EuOTc na presença de LDL nas concentrações (mg $/ \mathrm{mL}): 0 ; 0,20 ; 0,50 ; 1,00 ; 1,75 ; 2,00$ e 2,50 .

Verifica-se que o complexo EuOTc (1:1) na presença de LDL nas concentrações de 1,50;1,75;2,0 e 2,5 mg/mL apresentaram praticamente 0 mesmo aumento na intensidade de emissão, em torno de $20 \times 10^{6}$ fótons, o que revela uma saturação dos sítios de ligação do complexo EuOTc, isto é, os sitos já foram ocupados pelas moléculas de LDL e mesmo com o aumento da concentração de LDL não há mais sítios para as mesmas se ligarem.

A Figura 19 mostra o espectro de emissão do complexo EuMTc $(1,5: 1)$ na presença de LDL nas concentrações (mg/mL): 0;0,50;1,00;1,50;1,75;2,00 e 2,50. Pode-se observar que não houve aumento gradativo da emissão do complexo com o aumento da concentração de LDL. As concentrações mais baixas apresentaram praticamente a mesma intensidade de emissão comparada com as concentrações mais altas. As amostras apresentaram intensidades em torno de $5 \times 10^{6}$ fótons.

A Figura 20 e a Figura 21 mostram os espectros de emissão dos complexos EUCTc (1,5:1) e EuTc (3:1) na presença de LDL na concentrações $(\mathrm{mg} / \mathrm{mL}): 0 ; 0,20 ; 0,50 ; 1,00 ; 1,50 ; 1,75 ; 2,00 ; 2,50$ e 3,00. Nota-se um aumento gradativo na intensidade de emissão dos complexos com o aumento da concentração de LDL. Os complexos apresentaram maior intensidade de emissão 
na presença de LDL na concentração de $3,0 \mathrm{mg} / \mathrm{mL}$, com intensidade em torno de $13 \times 10^{6}$ fótons.

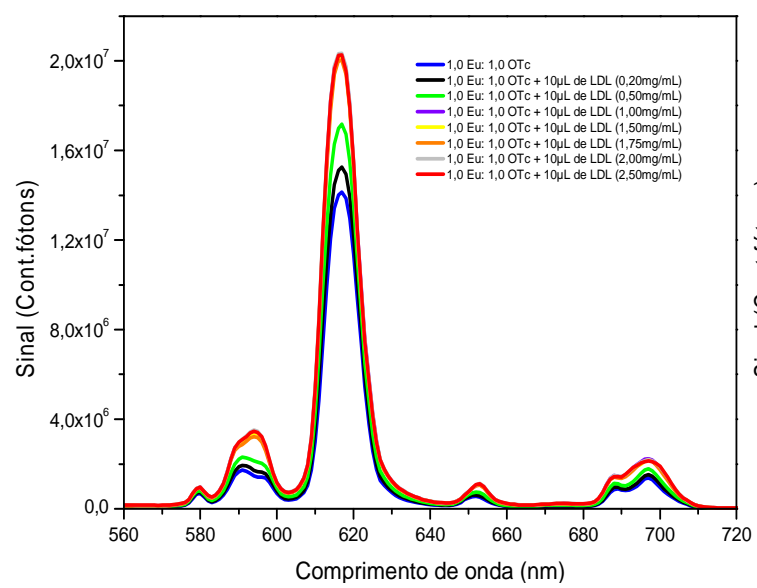

Figura 18: Espectro de emissão de EuOTc com LDL

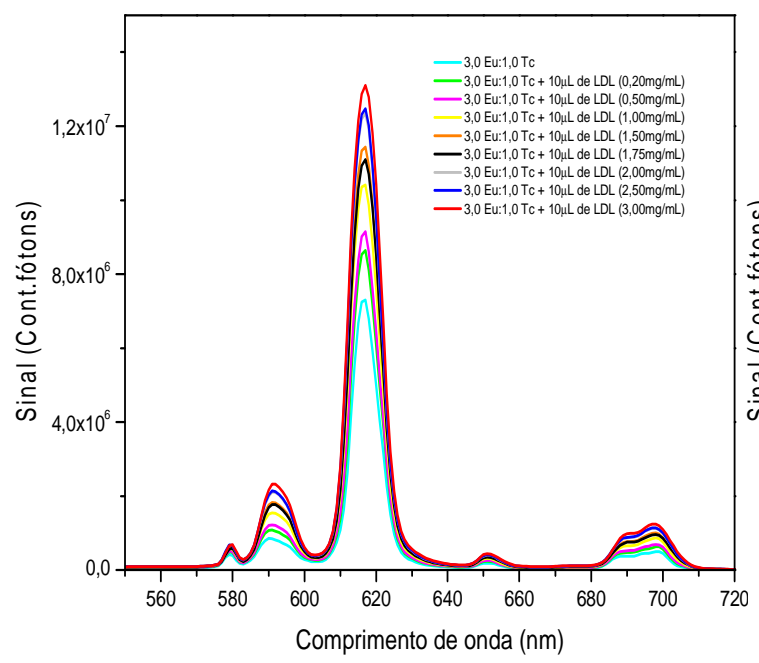

Figura 20: Espectro de emissão de EuCTc com LDL

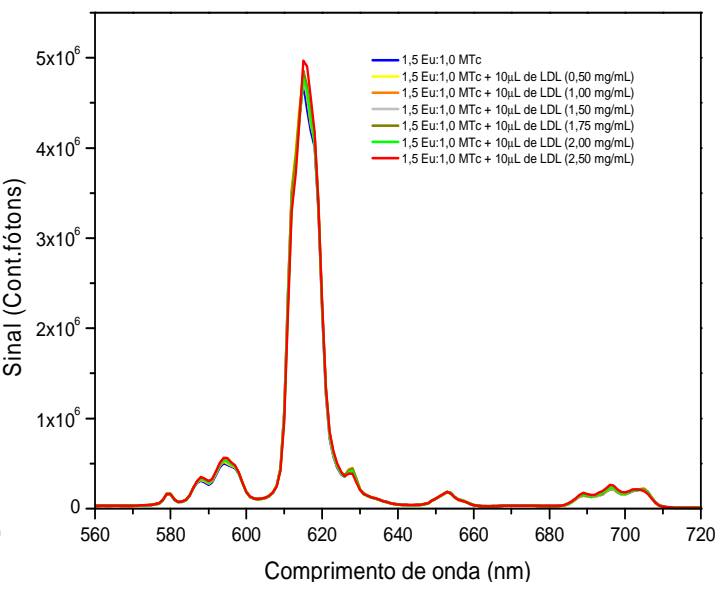

Figura 19: Espectro de emissão de EuMTc com LDL

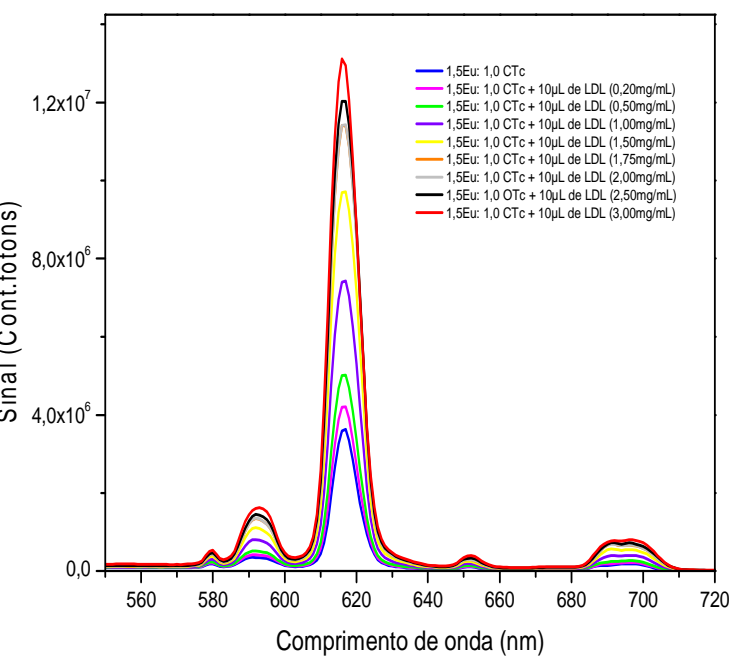

Figura 21: Espectro de emissão de EuTc com LDL

Para propor os possíveis sítios de complexação das Tcs com o íon európio na presença de LDL, foram necessários conhecer os possíveis sítios de ligação das tetraciclinas no pH de estudo,Figura 22.

De acordo com alguns estudos as tetraciclinas apresentam em geral 3 constantes de acidez (pKa) que variam em torno dos seguintes valores: pKa1= 3,30 , pKa2 $=7,29$ e pKa3 $=9,88$; há controvérsias quanto aos sítios de ligações das tetraciclinas no $\mathrm{pH}$ em torno de 7 . 
Hirschy e colaboradores observaram que em $\mathrm{pH} 7$ as tetraciclinas apresentaram ionização das hidroxilas presentes nos anéis $B C D^{3}$. Já Xia e colaboradores investigaram pela técnica fluorométrica, que em torno desse $\mathrm{pH}$ a hidroxila do $C$ (3) é ionizada, possibilitando a ligação com o íon európio ${ }^{49}$.

Sanli et al em estudo recente determinaram a protonação das Tcs pelas técnicas de potenciometria e cromatografia líquida e obtiveram o resultado que nessa faixa de $\mathrm{pH}$, a região ionizada nas tetraciclinas foi o sistema fenol dicetona compreendido entre $C(10)-C(12)$ dos anéis $B C D^{50}$.

De acordo com esses estudos e com os resultados que foram obtidos, foi proposto que as Tcs apresentem sítios de ligação semelhantes para o íon európio, isso porque todas apresentam uma estrutura química em comum, Figura 22. Porém existem regiões diferenciadas, caracterizadas pela presença de diferentes radicais localizados nas moléculas das tetraciclinas, o que possivelmente diferencia os sítios de ligações com o íon európio resultando em maior ou menor intensidade de emissão dos complexos formados.

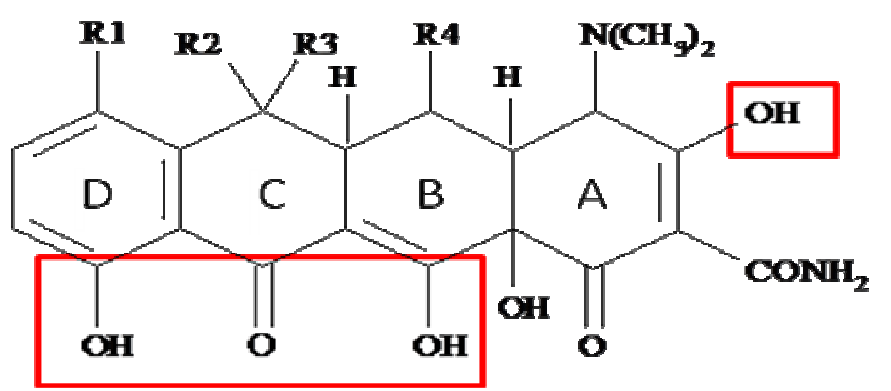

\begin{tabular}{llllll|} 
& $\boldsymbol{R}_{\mathbf{1}}$ & $\boldsymbol{R}_{\mathbf{2}}$ & $\boldsymbol{R}_{\mathbf{3}}$ & $\boldsymbol{R}_{\mathbf{4}}$ \\
\hline Tetraciclina & $\mathrm{H}$ & $\mathrm{CH}_{3}$ & $\mathrm{OH}$ & $\mathrm{H}$ \\
Clortetraciclina & $\mathrm{Cl}$ & $\mathrm{CH}_{3}$ & $\mathrm{OH}$ & $\mathrm{H}$ \\
Oxitetraciclina & $\mathrm{H}$ & $\mathrm{CH}_{3}$ & $\mathrm{OH}$ & $\mathrm{OH}$ \\
Metaciclina & $\mathrm{H}$ & $\mathrm{CH}_{2}$ & - & $\mathrm{OH}$ \\
\hline
\end{tabular}

Figura 22: Possíveis sítios em comum de ligações do íon európio com as Tcs

A menor intensidade de emissão do complexo EuMTc na presença de LDL pode ser explicada analisando a estrutura química da MTc. Na Figura 22 é possível observar que a MTc apresenta em sua estrutura química o radical $\mathrm{CH}_{2}$ 
localizado em R2, diferentemente das outras tetraciclinas que apresentam os radicais $\mathrm{CH}_{3}$ e OH em $\mathrm{R} 2$ e $\mathrm{R} 3$ respectivamente.

$\mathrm{O}$ radical $\mathrm{CH}_{2}$ favorece a hidrofobicidade na molécula de MTc devido a característica não-polar do radical, Figura 23. Dessa forma o íon európio é impedido de se ligar nesse sítio da molécula, diferente do que acontece com as outras Tcs.<smiles>C=C1c2c(O)ccc(O)c2C(=O)C2=C(O)C3(O)C(=O)C(C(N)=O)=C(O)C(N(C)C)C3(C3CCC3)C(c3ccco3)C12</smiles>

Figura 23: Molécula de MTc

Já o complexo EuOTc apresenta maior intensidade de emissão na presença de LDL. Provavelmente $0 \mathrm{pH}$ em torno de 7 provoca a ionização das hidroxilas presentes em R3 e R4 favorecendo a ligação do íon európio nesses sítios da molécula, Figura 24.<smiles>CN(C)C1C(O)=C(C(N)=O)C(=O)C2(O)C(O)=C3C(=O)c4c(O)cccc4C(C)(O)C3(C3CC3)C(O)C12</smiles>

Figura 24: Molécula de OTc

As moléculas de LDL apresentam um importante papel no aumento da intensidade de emissão dos complexos de Tcs. Visto que as medidas realizadas com os complexos EuTcs não apresentaram deslocamentos nos comprimentos de onda dos espectros de absorção e de emissão na presença de LDL, pode-se deduzir que há ausência de interação direta entre as moléculas de Tcs e as moléculas de LDL.

A formação dos complexos EuTcs não completam o número de coordenação do íon európio que geralmente é oito, portanto os complexos EuTcs 
apresentam cargas líquidas positivas relativa ao número de coordenação incompleto do íon európio ${ }^{47}$. Com isso, o íon európio interage com grupamentos que possam estar ionizados com cargas negativas como, por exemplo, hidroxilas e grupos fosfatos presentes na superfície da LDL dessa forma completando o número de coordenação do íon európio.

A molécula de LDL apresenta em sua superfície uma monocamada constituída por fosfolipídios, colesterol não esterificado e apoproteínas que são formadas por resíduos de aminoácidos ${ }^{51}$.

Os fosfolipídios são moléculas anfipáticas, isto é, apresentam uma região polar caracterizada pelo grupo fosfato e uma região apolar constituída por duas longas cadeias de hidrocarbonetos. As duas cadeias de hidrocarbonetos se estendem para $\mathrm{o}$ interior da particula e a parte polar se volta para o exterior onde se encontra a fase aquosa ${ }^{52}$.

O grupo fosfato localizado na região polar da particula de LDL quando em solução, apresenta-se com carga negativa; essa carga negativa pode interagir com o íon európio através da interação eletrostática ou ainda como um co-ligante completando o número de coordenação do íon európio ligado as Tcs.

O colesterol não - esterificado apresenta uma região polar caracterizada pela hidroxila que se localiza na região hidrofílica da monocamada da molécula de LDL, já o restante da molécula de colesterol caracteriza-se pelos quatro anéis fundidos localizados na região interna da monocamada ${ }^{52}$. A hidroxila possivelmente interage com o íon európio semelhante como ocorre com o grupo fosfato.

A formação do complexo ternário EuTcs-LDL favorece o aumento da fluorescência do íon európio diminuindo a perda de energia não radiativa para as moléculas de água ${ }^{53}$. 

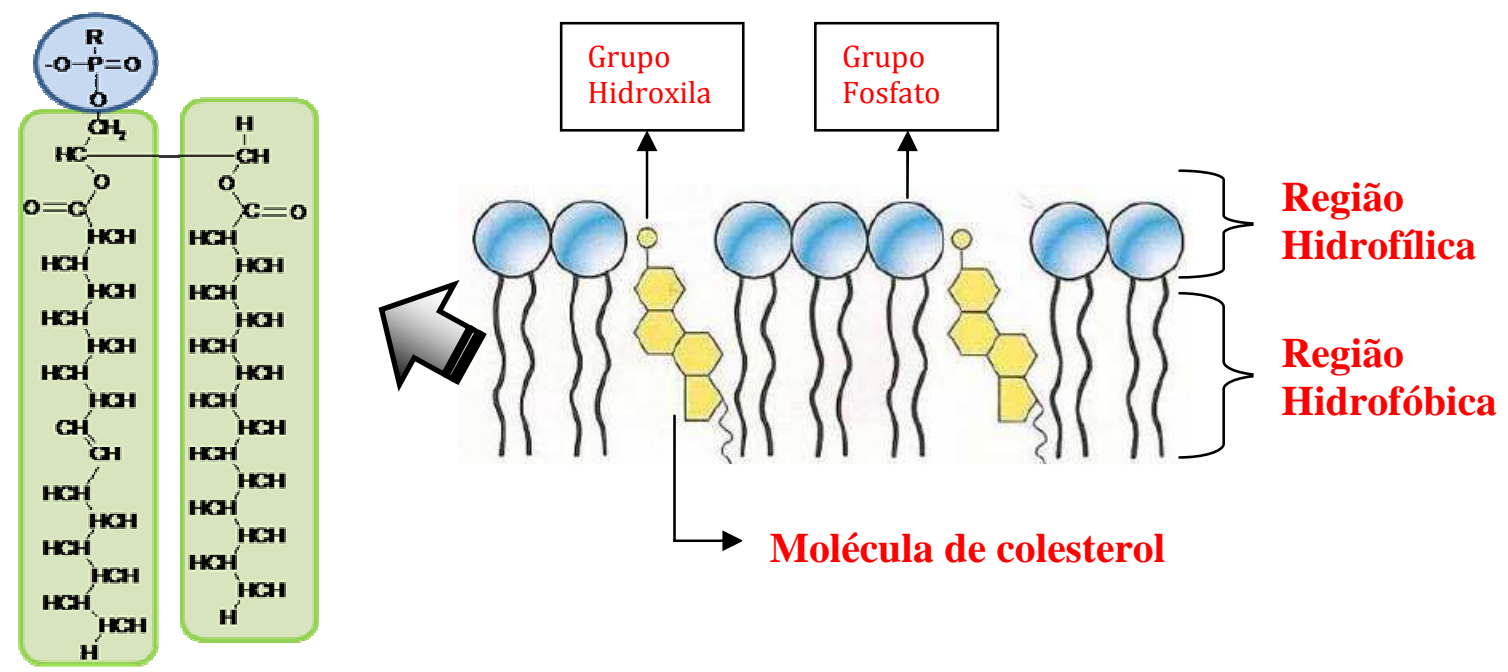

Fosfolipídio

Figura 25: Monocamada da particula de LDL ilustrando as regiões hidrofílica (região externa) e hidrofóbica (região interna) da molécula

\subsubsection{Curva de calibração dos complexos na presença de $L D L$}

A construção da curva de calibração é de fundamental importância para descrever a resposta de um detector sobre uma faixa de concentração de LDL. Dessa forma, uma curva de calibração permite a determinação da concentração de uma substância em uma amostra desconhecida ${ }^{54}$.

As concentrações de LDL e a resposta do instrumento para cada padrão podem ser ajustadas através da equação da reta, expressa como: $y=a+b x$, onde (y) é a resposta do instrumento de medida, (a) é uma constante que descreve o ruído de fundo e (b) representa o coeficiente angular. As concentrações desconhecidas de LDL é expressa por (x) que podem ser calculadas a partir desta equação.

O coeficiente de detecção, definido como a concentração mínima do analito, foi calculado pela fórmula: $L D=3 \sigma / \mathrm{m}$, onde $(\sigma)$ é a incerteza da medida do parâmetro b e $(\mathrm{m})$ é o coeficiente angular ${ }^{54}$.

A linearidade do método foi determinada pela análise de regressão linear com auxílio do software Origin $7.0^{\circledR}$.

Após a realização das medidas de emissão, as curvas de calibração foram construídas integrando a área do gráfico de emissão entre 560 a 720 nm, em seguida foi plotado um gráfico correlacionando a área do sinal de emissão 
(Contagem de fótons) em função da concentração de LDL. Para cada curva obtida estimou-se um erro de $5 \%$.

A Figura 26 mostra a curva de calibração do complexo EuOTc na presença de diferentes concentrações de LDL.

Os resultado foram descritos pela função linear $(y=a+b x)$ entre 0 a 1,0 $\mathrm{mg} / \mathrm{mL}$ de LDL, onde os valores de equação da reta com seus desvios padrão foram: $a=(2,18 \pm 0,02) \times 10^{8}$ e $b=(1,28 \pm 0,04) \times 10^{8} \mathrm{mg} / \mathrm{mL}$. O limite de detecção foi de $0,10 \mathrm{mg} / \mathrm{mL}$.

Verifica-se que o complexo EuOTc na presença de LDL nas concentrações de 1,$50 ; 1,75 ; 2,00$ e 2,50mg/mL apresentaram praticamente o mesmo aumento na intensidade de emissão, o que revela uma saturação no número de coordenação do íon európio, isto é, mesmo com o aumento da concentração de LDL não há mais sítios para as mesmas se ligarem.

De acordo com a Sociedade Brasileira de Cardiologia acima de $1,6 \mathrm{mg} / \mathrm{mL}$ o indivíduo apresenta um nível não desejável de $L D L$ no sangue e conseqüentemente maior risco de adquirir doenças cardiovasculares ${ }^{35}$. Portanto a saturação da emissão do complexo EuOTc a partir da concentração de 1,00 $\mathrm{mg} / \mathrm{mL}$ de LDL impossibilitaria a medição de LDL de indivíduos que apresentam níveis não desejáveis de $\mathrm{LDL}^{35}$.

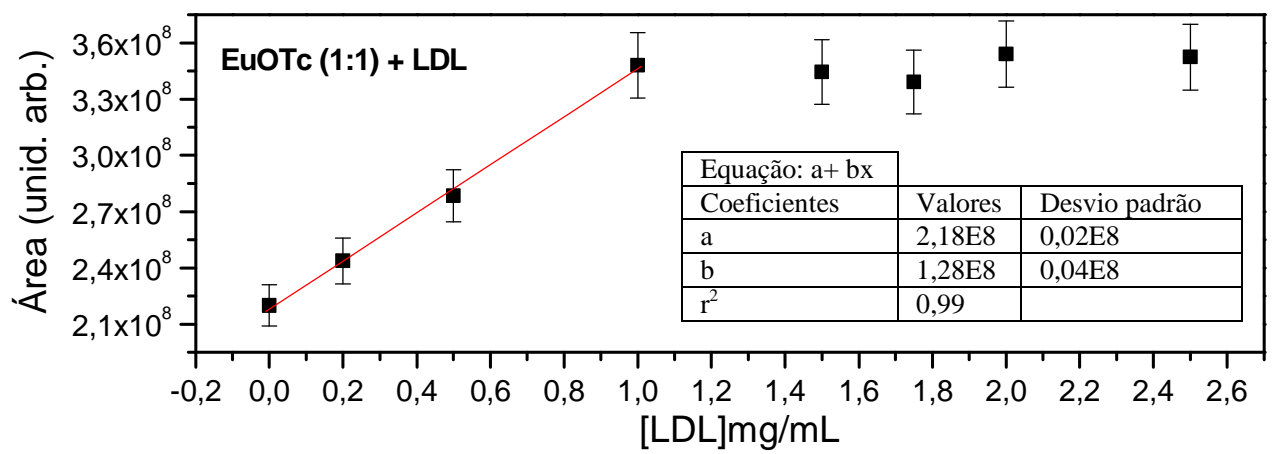

Figura 26: Curva de calibração do complexo EuOTc na presença de diferentes concentrações de LDL

A Figura 27, mostra a curva de calibração do complexo EuMTc na presença de diferentes concentrações de LDL. Analisando a curva de calibração é possível observar que aumentando a concentração de LDL não ocorre o aumento da intensidade de emissão, o que dificultaria a quantificação de LDL. 


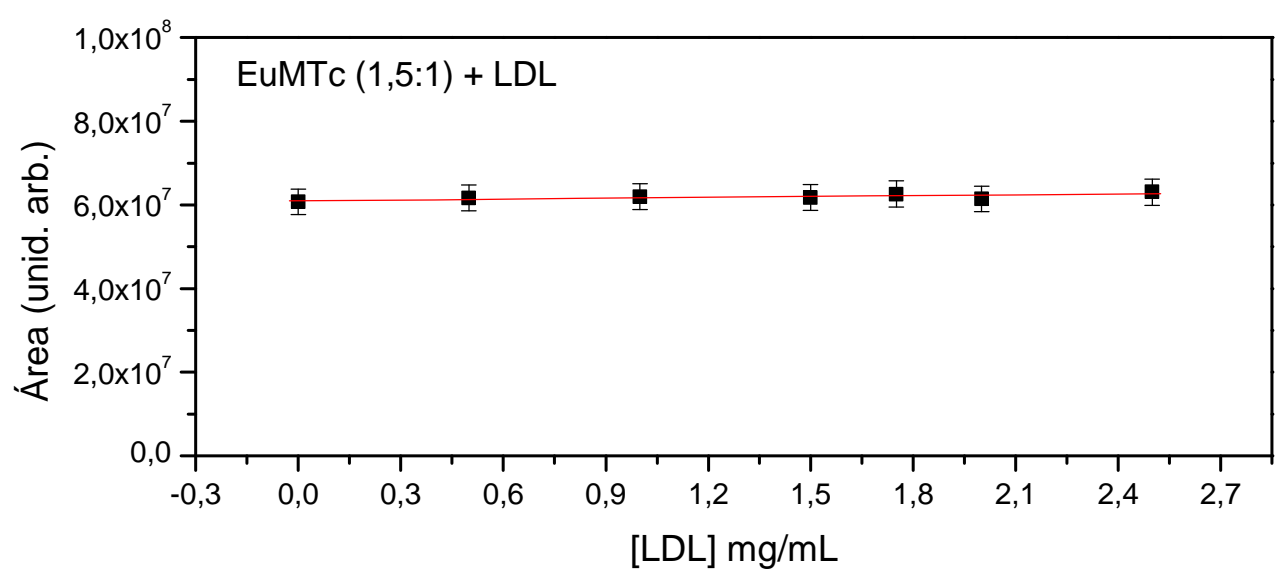

Figura 27: Curva de calibração do complexo EuMTc na presença de diferentes concentrações de LDL

A Figura 28 mostra a curva de calibração do complexo EuTc na presença de LDL. Os resultados plotados são descritos pela função linear entre 0 a 2,00 $\mathrm{mg} / \mathrm{mL}$ de $\mathrm{LDL}$, os valores de equação foram: $\mathrm{a}=(1,09 \pm 0,05) \times 10^{8}$ e $\mathrm{b}=(4,1 \pm$ $0,4) \times 10^{7} \mathrm{mg} / \mathrm{mL}$ e o limite de detecção foi de $0,29 \mathrm{mg} / \mathrm{mL}$.

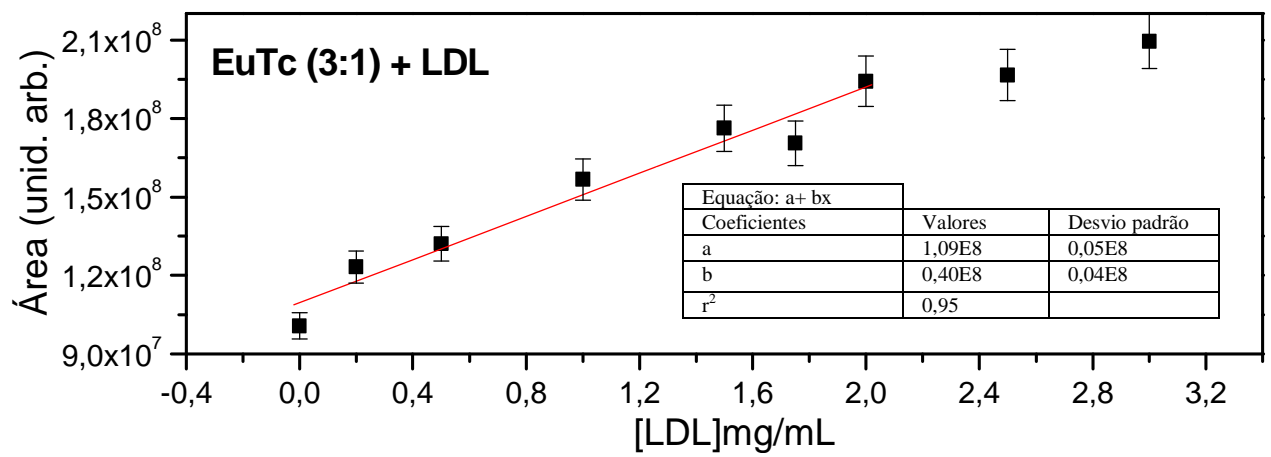

Figura 28: Curva de calibração do complexo EuTc na presença de diferentes concentrações de LDL

A Figura 29, mostra a curva de calibração do complexo EuCTc na presença de diferentes volumes de LDL. Os resultados plotados são descritos pela função linear entre 0 a 2,00 $\mathrm{mg} / \mathrm{mL}$ de $\mathrm{LDL}$, obtendo os seguinte parâmetros: $a=(4,7 \pm 0,4) \times 10^{7}$ e $b=(6,1 \pm 0,3) \times 10^{7}(\mathrm{mg} / \mathrm{mL})$. O limite de detecção é de 0,15 $\mathrm{mg} / \mathrm{mL}$. 


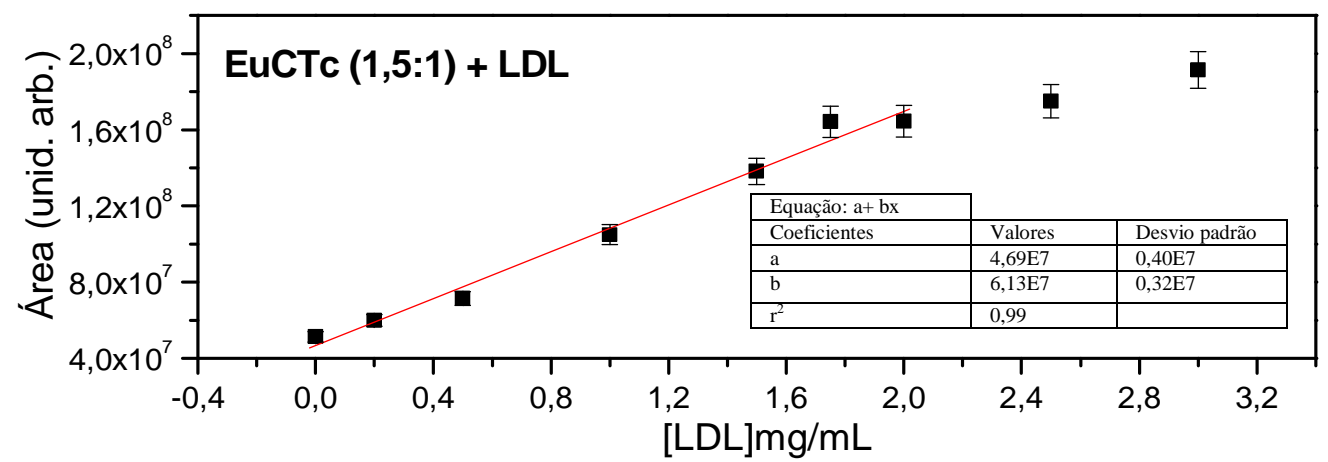

Figura 29: Curva de calibração do complexo EuCTc na presença de diferentes concentrações de LDL

Comparando as curvas de calibração dos complexos EuCTc e EuTc na presença de LDL é possível notar que o complexo EuCTc apresentou maior linearidade na curva de calibração e menor limite mínimo de detecção de LDL.

Os complexos EuMTc e EuOTc não apresentaram resultados adequado para quantificação de LDL; o complexo EuMTc não apresentou linearidade em sua curva de calibração com o aumento progressivo da concentração de LDL, o que dificultaria a quantificação da mesma. Já o complexo EuOTc na presença de LDL apresentou uma saturação em sua curva de calibração a partir da concentração de $1,00 \mathrm{mg} / \mathrm{mL}$ de LDL o que impediria quantificar concentrações acima desse nível.

Sendo assim prosseguimos o estudo com os complexos EuTc e EuCTc na presença de LDL por apresentar maior linearidade na presença de concentrações maiores de LDL.

5.2.4 Tempo de vida dos complexos EuTc e EuCTc na presença de $L D L$

A medida de tempo de vida, assim como as medidas de absorção óptica e de emissão é uma importante medida para a caracterização dos complexos.

O tempo de vida é o tempo que o sistema demora para retornar ao estado fundamental, isto é, o tempo de transição ${ }^{5} D_{0} \rightarrow{ }^{7} F_{2}$ do európio presente no complexo.

Geralmente sistemas complexos podem apresentar múltiplas espécies fluorescentes, e sendo assim, o perfil de decaimento da intensidade de 
fluorescência não pode ser ajustado por uma função exponencial simples. Dessa forma, foi ajustado por uma exponencial dupla:

$$
y=y_{0}+A_{1} e^{\left(-t / \tau_{1}\right)}+A_{2} e^{\left(-t / \tau_{2}\right)}
$$

onde o eixo y representa a intensidade do sinal (u.a) e o eixo $x$ representa 0 tempo $(\mu \mathrm{s}), \tau_{1}$ e $\tau_{2}$ são os tempos de decaimento e $A_{1}$ e $A_{2}$ são as amplitudes do $\operatorname{sinal}{ }^{55}$.

No caso de decaimento com múltiplas exponenciais, a média do tempo de vida $\left(\tau_{\mathrm{av}}\right)$, é proporcional a área total abaixo da curva de decaimento da fluorescência, definida por:

$$
\tau_{a v}=\frac{\sum_{i} A_{i} \tau_{i}^{2}}{\sum_{i} A_{i} \tau_{i}}
$$

Comparando o tempo de vida dos complexos EuTc e EuTc com LDL $(1,5 \mathrm{mg} / \mathrm{mL})$, Figura 30 e Figura 31 pode-se notar um expressivo aumento no tempo de decaimento na amostra que contêm LDL.

As médias do tempo de vida para as amostras são: $32,64 \mu$ s e $50,16 \mu$ s para EuTc e para a EuTc com LDL $(1,5 \mathrm{mg} / \mathrm{mL})$, respectivamente.

O aumento no tempo de vida também pode ser notado analisando a Figura 30 e a Figura 31, que demonstram um expressivo aumento no tempo de vida do complexo EuCTc na presença da lipoproteína. As médias do tempo de vida para as amostras são: $11,25 \mu$ s e $45,82 \mu$ s para EuCTc e para a EuCTc com LDL $(1,5 \mathrm{mg} / \mathrm{mL})$ respectivamente.

Para esse expressivo aumento no tempo de vida dos complexos na presença de LDL, sugerimos que as moléculas de água na solução contendo LDL são agrupadas em torno das hidroxilas e dos grupos fosfatos das partículas de LDL, isolando dessa forma o íon európio que se encontra ligado com as moléculas de tetraciclinas. Com menos moléculas na vizinhança do íon európio, a transferência de energia para as moléculas de água é minimizada, e a energia é 
então praticamente mantida para o íon európio, aumentando o tempo de vida e a intensidade da luminescência, resultando em um melhor rendimento quântico ${ }^{47}$.

Apesar do complexo EuCTc na presença de LDL apresentar menor tempo de vida comparado com o complexo EuTc na presença de LDL, essa diferença não é tão expressiva.

Analisando o grande aumento no tempo de vida do complexo EuCTc com LDL comparado com o complexo EuCTc, podemos notar o efetivo isolamento do íon európio, sendo a diferença no aumento do tempo de vida cerca de 4 vezes. Devido a este resultado, pode-se considerar que a medida temporal com a utilização do complexo EuCTc apresenta perspectivas promissoras na quantificação de LDL. É importante ressaltar que estudos de interferentes neste sistema são de fundamental importância para a aplicabilidade do complexo.

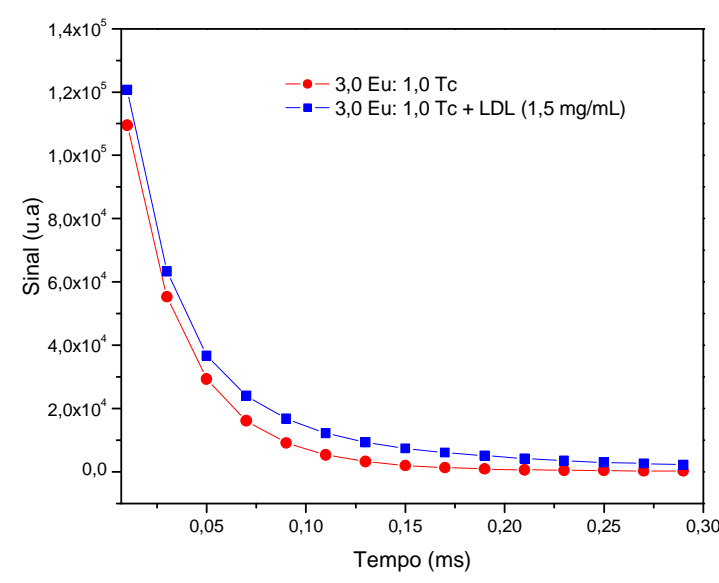

Figura 30: Tempo de vida do complexo EuTc com LDL

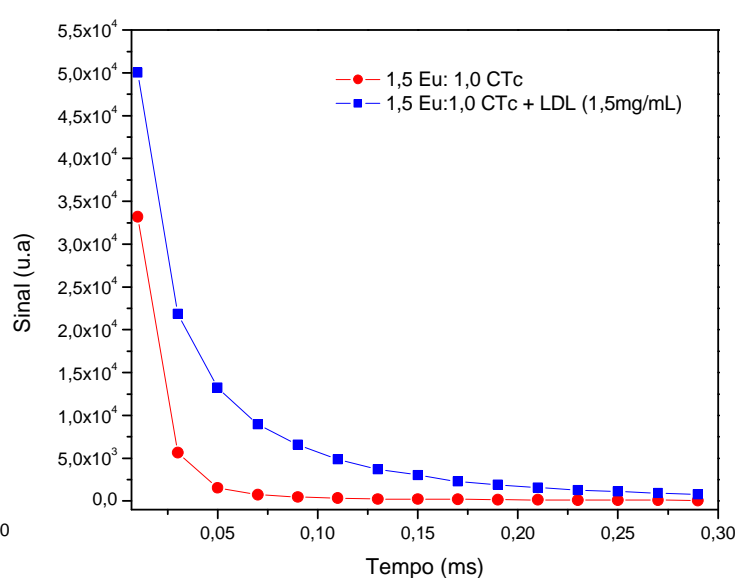

Figura 31: Tempo de vida do complexo EuCTc com LDL

Tabela 10: Parâmetro do ajuste das equações 1 e 2, para os dados experimentais da Figura0.

\begin{tabular}{|c|c|c|c|c|}
\hline Complexo & & netr & & $\tau_{a v}(\mu s)$ \\
\hline EuTc & $\begin{array}{lc}A_{1} & (7,0 \pm 0,4) \cdot 10^{4} \\
A_{2} & (8,6 \pm 0,5) \cdot 10^{4}\end{array}$ & $\begin{array}{l}\tau_{1} \\
\tau_{2}\end{array}$ & $\begin{array}{c}(2,00 \pm 0,06) \cdot 10^{-2} \\
(3,80 \pm 0,06) \cdot 10^{-2}\end{array}$ & 32,64 \\
\hline EuTc+LDL & $\begin{array}{ll}A_{1} & (4,5 \pm 0,3) \cdot 10^{4} \\
A_{2} & (1,27 \pm 0,02) \cdot 10^{4}\end{array}$ & & $\begin{array}{c}(7,39 \pm 0,32) \cdot 10^{-2} \\
(2,17 \pm 0,04) \cdot 10^{-2}\end{array}$ & 50,16 \\
\hline
\end{tabular}


Tabela 11: Parâmetro do ajuste das equações 1 e 2, para os dados experimentais da Figura1.

\begin{tabular}{cccccc}
\hline Complexo & \multicolumn{4}{c}{ Parâmetros } & $\tau_{\text {av }}(\boldsymbol{\mu s})$ \\
\hline & $\mathrm{A}_{1}$ & $(4,00 \pm 0,01) \cdot 10^{4}$ & $\tau_{1}$ & $(1,13 \pm 0,03) \cdot 10^{-2}$ & \\
EuCTc & $\mathrm{A}_{2}$ & $(4,00 \pm 0,01) \cdot 10^{4}$ & $\tau_{2}$ & $(1,13 \pm 0,03) \cdot 10^{-2}$ & $\mathbf{1 1 , 2 5}$ \\
& & & & & \\
EuCTc + LDL & $\mathrm{A}_{2}$ & $(2,5 \pm 0,1) \cdot 10^{4}$ & $\tau_{2}$ & $(6,2 \pm 0,2) \cdot 10^{-2}$ & $\mathbf{4 5 , 8 2}$ \\
& & & & & \\
\hline
\end{tabular}

5.2.5 Complexos EuTc+LDL e EuCTC+LDL na presença de possíveis interferentes inorgânicos.

Os complexos EuTc+LDL e EuCTc+LDL apresentaram os melhores resultados até essa etapa do estudo. Portanto esses complexos foram eleitos para a realização das medidas de emissão na presença de possíveis interferentes inorgânicos encontrados normalmente no plasma sanguíneo.

As amostras foram preparadas utilizando $500 \mu \mathrm{L}$ dos complexos de EuTc

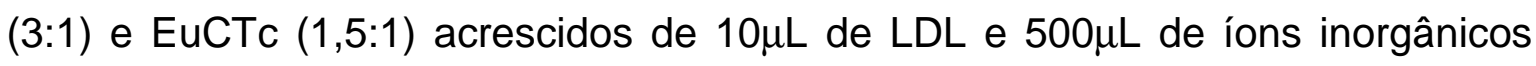
nas concentrações normalmente encontradas no plasma sanguíneo, Tabela 7. As amostras ficaram em repouso por 15 minutos antes de se realizar as medidas de emissão. As medidas de emissão foram realizadas excitando as amostras nos comprimentos de onda de 400nm.

O Gráfico 1 e o Gráfico 2 foram construídas com o objetivo de avaliar as possíveis interferências dos íons inorgânicos em relação a intensidade de emissão dos complexos EuTc+LDL e EuCTc+LDL.

As tetraciclinas formam complexos de coordenação estáveis com íons metálicos da primeira série de transição, entre eles estão os íons utilizados no estudo ${ }^{56}: \mathrm{Mg}^{2+}, \mathrm{Mn}^{2+}, \mathrm{Fe}^{2+}, \mathrm{Co}^{2+}, \mathrm{Ni}^{2+}, \mathrm{Cu}^{2+}, \mathrm{Ca}^{2+}$ e $\mathrm{Zn}^{2+}$.

Palm e colaboradores ${ }^{56}$ utilizaram a técnica de cristalografia para demonstrar que os cátions divalentes, citados acima, complexam com a tetraciclina no sistema dicetona compreendidos entre os carbonos (C11-C12) dos anéis BCD das tetraciclinas, semelhante ao que ocorre com o íon európio, a Figura 32 mostra o sítio de ligação dos cátions divalentes representados por $\mathrm{Me}^{2+}$. 


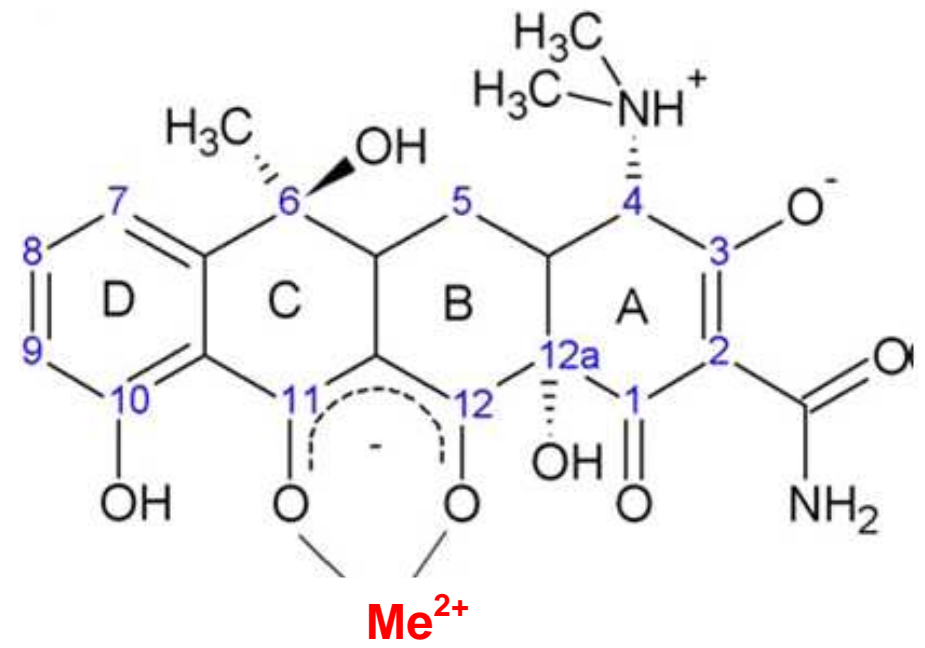

Figura 32: Sítio de ligação dos cátions divalentes

O estudo ainda constatou que apesar dos cátions divalentes se ligarem ao mesmo sítio a força de ligação varia de íon para íon, uma das explicações é a relação do tamanho do raio iônico com a força de ligação do íon com o sítio da tetraciclina, dessa forma quanto menor for o raio iônico mais forte é a ligação do íon ao sítio de ligação. $\mathrm{O}$ íon $\mathrm{Cu}^{2+}$ relatado no estudo de Palm foi o íon que apresentou maior força de ligação com a tetraciclina, já o íon $\mathrm{Ca}^{2+}$ apresentou uma baixa energia de ligação.

Os resultados obtidos neste trabalho, utilizando os complexos EuTcs+ LDL na presença de interferentes inorgânicos, mostraram que o íon $\mathrm{Cu}^{2+}$ foi o íon que mais interferiu na emissão dos complexos, o que pode ser explicado pela grande afinidade pelo sítio de ligação e pela competição com o íon európio pelo mesmo sítio, resultando em baixa emissão dos complexos EuTcs+LDL.

No complexo EuCTC+LDL o íon $\mathrm{Cu}^{2+}$ interferiu ainda mais na intensidade do complexo, provavelmente devido ao cloro, presente na molécula da clorotetraciclina, apresentar uma alta eletronegatividade, o que favorece a interação com o íon $\mathrm{Cu}^{2+}$.

No estudo realizado por Raya e colaboradores consideraram que os íons $\mathrm{Fe}^{3+}, \mathrm{Ni}^{2+}, \mathrm{Co}^{2+}$ podem interferir na intensidade de emissão dos complexos de EuTcs devido à sobreposição de seus espectros de absorção com algumas 
bandas de emissão do ín európio ${ }^{57}$. Pode-se observar as interferências na emissão do íon európio nos complexos de EuTcs+LDL observando o Gráfico 1 e o Gráfico 2.

Comparando de uma maneira geral os dois complexos na presença de íons inorgânicos é possível afirmar que o complexo EuTc+LDL foi o que sofreu menor interferência em sua intensidade de emissão, comparado com o complexo EuCTc+LDL na presença dos mesmos íons.

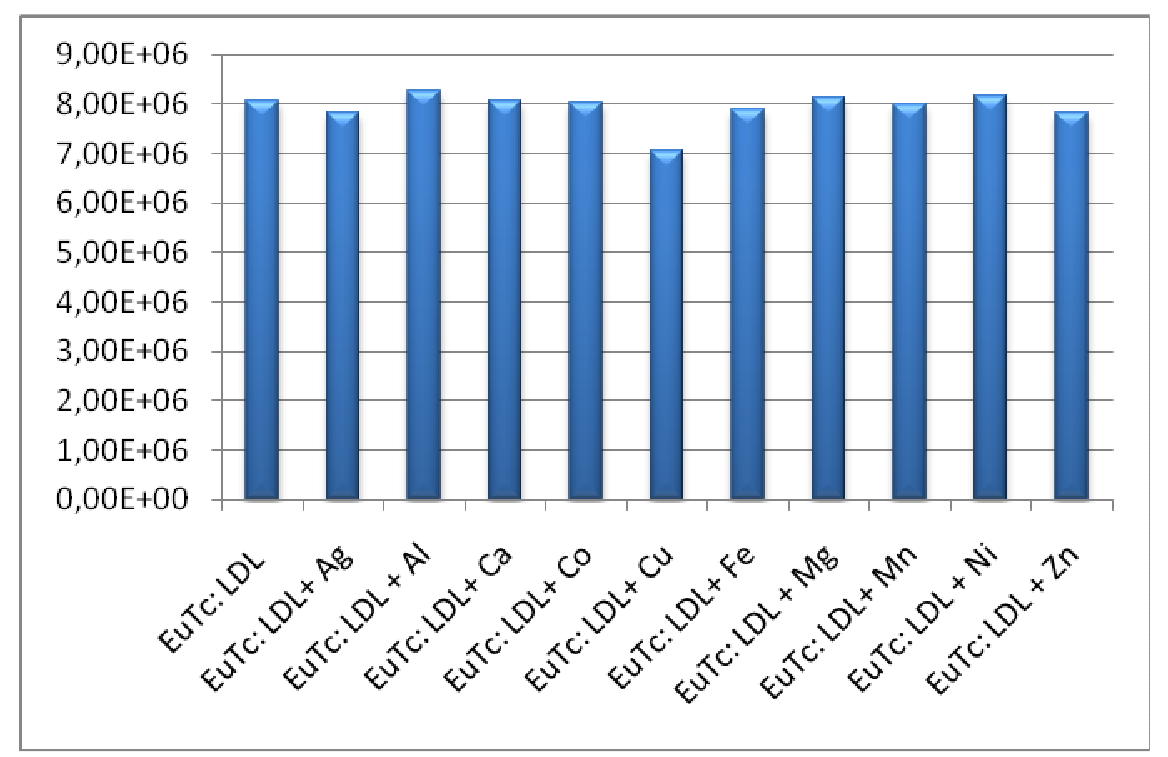

Gráfico 1: Complexo EuTc+LDL na presença de interferentes inorgânicos

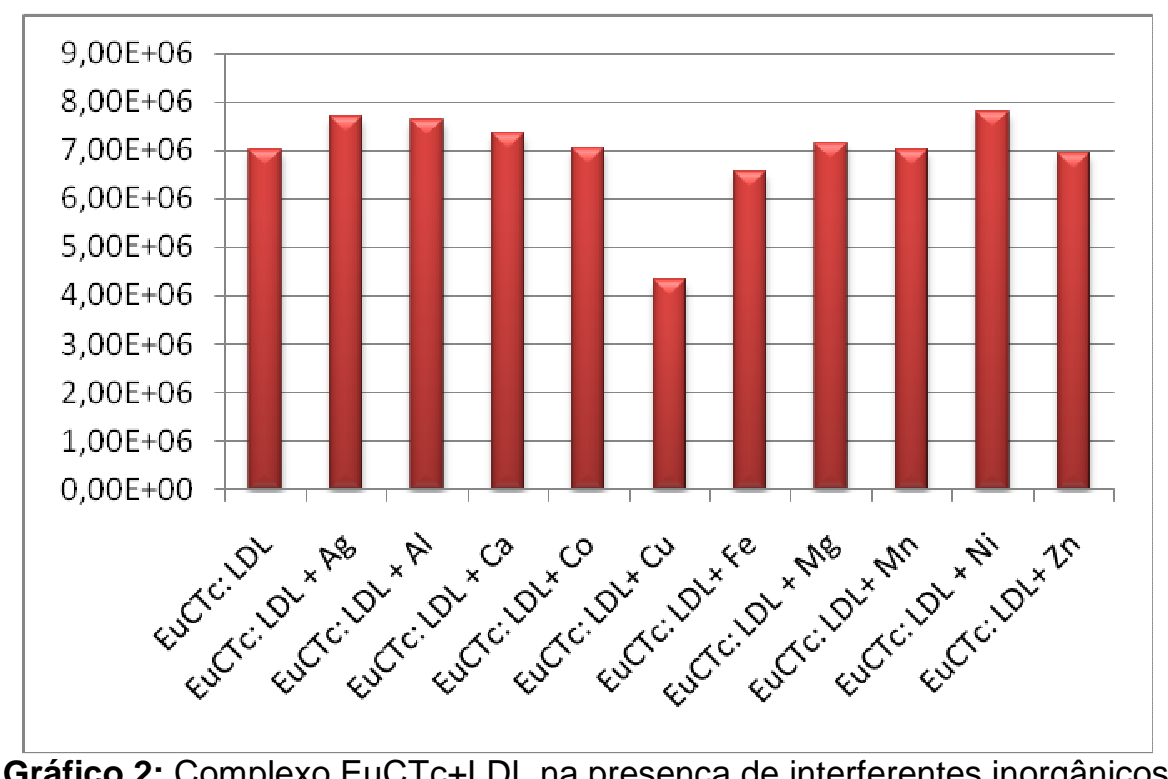

Gráfico 2: Complexo EuCTc+LDL na presença de interferentes inorgânicos 


\subsection{Medidas dos complexos EuTcs na presença de LDL oxidada}

5.3.1 Comparação das curvas de calibração dos complexos EuTcs na presença de diferentes concentrações de LDL oxidada.

Nessa etapa do estudo foram realizadas as medidas de emissão dos complexos de EuTcs na presença de LDL oxidada para observar seu comportamento em relação a intensidade de emissão dos complexos.

As medidas de emissão do complexo EuTc, EuCTc e EuOTc na presença de diferentes volumes de LDL oxidada foram realizadas em triplicata, excitando os complexos EuTc e EuCTc em $400 \mathrm{~nm}$ e EuOTc em $390 \mathrm{~nm}$. Para a construção da curva de calibração dos complexos EuTcs na presença de diferentes concentrações de LDL oxidada, foi realizada a integração das áreas das bandas dos espectros de fluorescência (obtidos em triplicata para cada concentração de LDL oxidada) calculada e plotada em função das concentrações de LDL oxidada. As concentrações de LDL oxidada $(\mathrm{mg} / \mathrm{mL})$ utilizadas nesse experimento são: 0 ; 0,$20 ; 0,50 ; 1,00 ; 1,50 ; 2,00 ; 2,50$ e 3,00 .

A partir das curvas de calibração apresentadas para todos os complexos estudados, a presença de LDL oxidada leva a um aumento na intensidade de emissão do európio no complexo. Os resultados foram descritos pela função linear $(y=a+b x)$ onde $x$ é a concentração de lipoproteína oxidada.

A curva de calibração do complexo EuOTc na presença de LDL oxidada foi construída com intervalo de linearidade entre ( 0 a $1,00 \mathrm{mg} / \mathrm{mL}$ ), os valores dos parâmetros obtidos foram: $a=(2,18 \pm 0,02) \times 10^{8}$ e $b=(1,35 \pm 0,03) \times 10^{8}$ $(\mathrm{mg} / \mathrm{mL}$ ) e o limite de detecção foi de $0,06 \mathrm{mg} / \mathrm{mL}$ (definido como 3 o/inclinação, onde $\sigma$ é a incerteza da medida do parâmetro b, Figura 33. A saturaçao da emissão do complexo EuOTc a partir da concentração de $1,00 \mathrm{mg} / \mathrm{mL}$ de LDL oxidada limita a utilização desse complexo. 


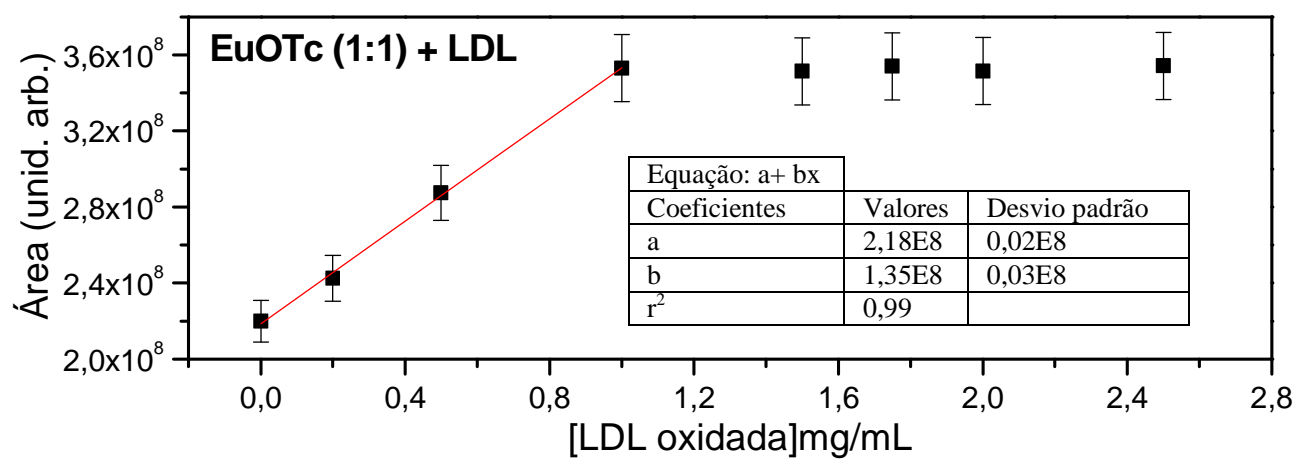

Figura 33: Curva de calibração do complexo EuOTc na presença de LDL oxidada

A curva de calibração do complexo EuCTc na presença de LDL oxidada foi construída com intervalo de linearidade entre (0 a $3,0 \mathrm{mg} / \mathrm{mL})$, Figura 34 . Os resultados dos parâmetros obtidos foram: $\mathrm{a}=(0,54 \pm 0,06) \times 10^{8}$ e $\mathrm{b}=(0,54 \pm$ $0,03) \times 10^{8}(\mathrm{mg} / \mathrm{mL})$ e o limite de detecção foi de $0,16 \mathrm{mg} / \mathrm{mL}$.

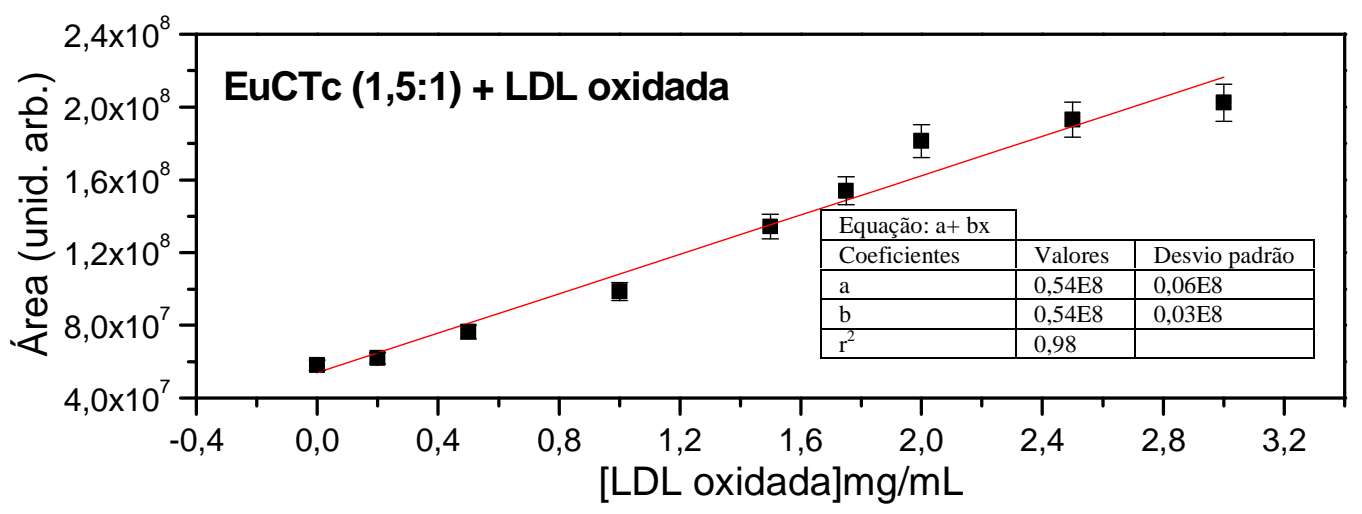

Figura 34: Curva de calibração do complexo EuCTc na presença de LDL oxidada

Já a curva de calibração do complexo EuTc na presença de LDL oxidada foi construída com intervalo de linearidade entre (0 a $3,00 \mathrm{mg} / \mathrm{mL})$, os resultados dos parâmetros obtidos foram: $a=(1,32 \pm 0,02) \times 10^{8}$ e $b=(0,33 \pm 0,01) \times$ $10^{8}(\mathrm{mg} / \mathrm{mL})$ e o limite de deteç̧ão foi de $0,09 \mathrm{mg} / \mathrm{mL}$, Figura 35 . 


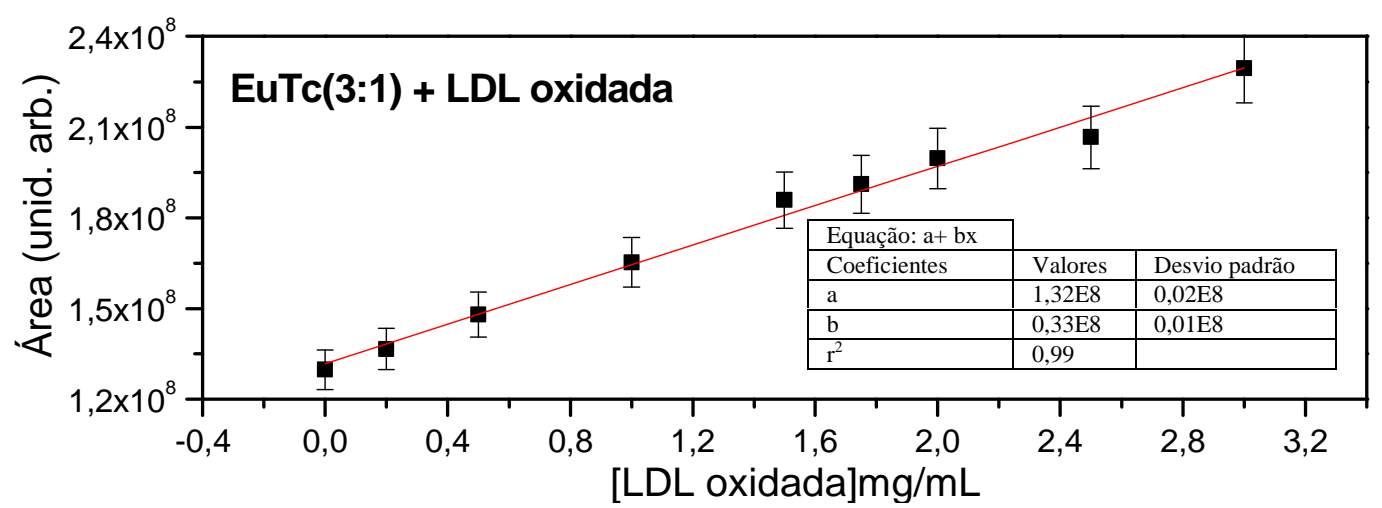

Figura 35: Curva de calibração do complexo EuTc na presença de LDL oxidada

Os complexos EuTc e EuCTc apresentaram maior range de detecção em comparação com o complexo EuOTc. Já comparando as curva de calibração dos complexos EuTc e EuCTc na presença de LDL oxidada é possível notar maior linearidade na curva de calibração do complexo EuTc e o limite de detecção desse complexo também é menor tornando-o mais adequado para a quantificação de LDL em concentrações menores.

5.3.2 Tempo de vida dos complexos EuTc e EuCTc na presença de LDL oxidada

Os complexos EuTc e EuCTc foram os que apresentaram melhores desempenho na presença de LDL oxidada. Portanto prosseguimos o estudo com as medidas de tempo de vida para esses complexos.

Analisando a Figura 36, Figura 37, Tabela 12 e Tabela 13, é possível notar um expressivo aumento no tempo de decaimento na amostra que contêm LDL oxidada. As médias do tempo de vida para as amostras são: $32,64 \mu \mathrm{s}$ e $47,97 \mu$ s para EuTc e EuTc com LDL oxidada $(1,5 \mathrm{mg} / \mathrm{mL})$ respectivamente. Já para as amostras EuCTc e EuCTc na presença de LDL oxidada $(1,5 \mathrm{mg} / \mathrm{mL})$ são: $11,25 \mu$ s e $50,08 \mu \mathrm{s}$.

Verifica-se desta forma que a presença da LDL oxidada leva a um aumento no tempo de vida da emissão do Európio. No entanto o complexo EuCTc na presença da LDL oxidada apresentou um aumento no tempo de vida maior que no complexo EuTc.

A concentração de LDL oxidada utilizada neste experimento é consideravelmente maior que a encontrada normalmente no plasma sanguíneo $(0,1 \mathrm{mg} / \mathrm{mL})^{58}$, desta forma em uma medida real seria muito difícil se quantificar 
LDL oxidada ou se distinguir a LDL oxidada da LDL nativa, pela medida de tempo de vida.

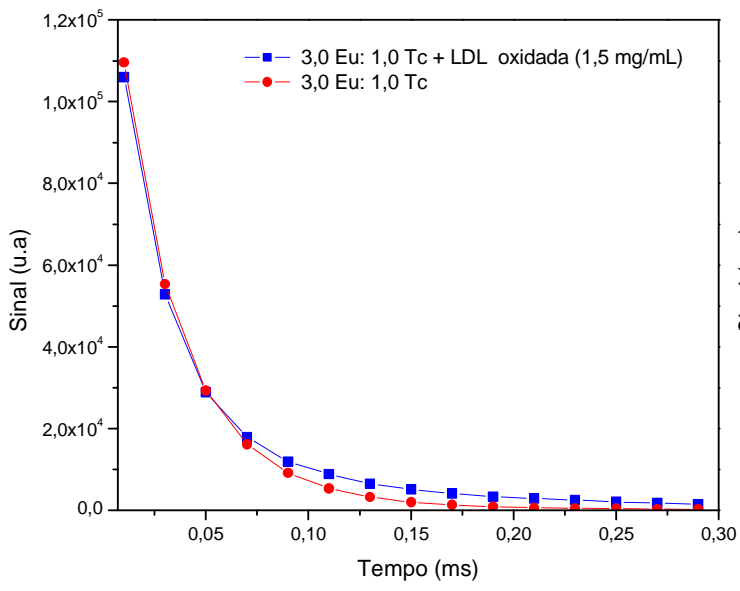

Figura 36: Tempo de vida medido do complexo EuTc com LDL oxidada

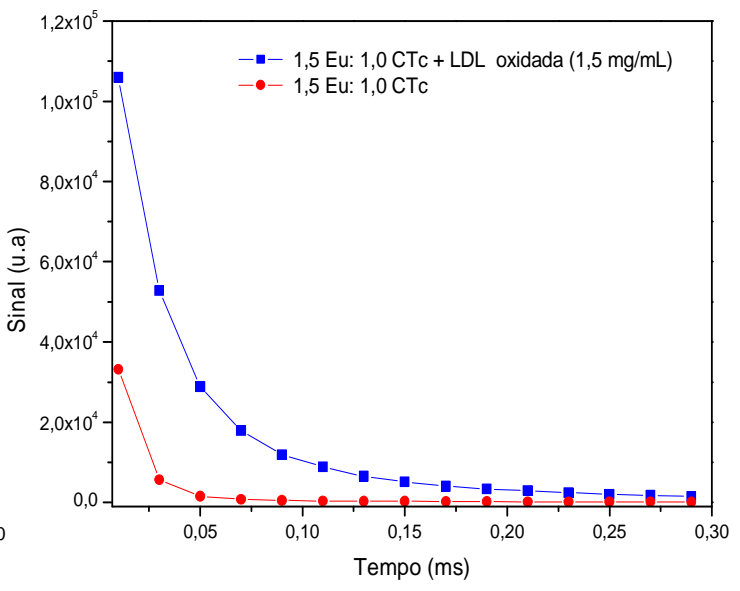

Figura 37: Tempo de vida medido do complexo EuCTc com LDL oxidada

Tabela 12: Parâmetro do ajuste das equações 1 e 2, para os dados experimentais da Figura 36.

\begin{tabular}{|c|c|c|c|c|}
\hline Complexo & & etr & & $\tau_{a v}(\mu s)$ \\
\hline EuTc & $\begin{array}{lc}A_{1} & (7,0 \pm 0,4) \cdot 10^{4} \\
A_{2} & (8,6 \pm 0,5) \cdot 10^{4}\end{array}$ & & $\begin{array}{c}(2,00 \pm 0,06) \cdot 10^{-2} \\
(3,80 \pm 0,06) \cdot 10^{-2}\end{array}$ & 32,64 \\
\hline $\begin{array}{c}\text { EuTc + } \\
\text { LDL oxidada }\end{array}$ & $\begin{array}{lc}A_{1} & (2,7 \pm 0,2) \cdot 10^{4} \\
A_{2} & (1,3 \pm 0,2) \cdot 10^{4}\end{array}$ & $\begin{array}{l}\tau_{1} \\
\tau_{2}\end{array}$ & $\begin{array}{c}(8,14 \pm 0,05) \cdot 10^{-2} \\
(2,25 \pm 0,04) \cdot 10^{-2}\end{array}$ & 47,97 \\
\hline
\end{tabular}

Tabela 13: Parâmetro do ajuste das equações 1 e 2, para os dados experimentais da Figura 37.

\begin{tabular}{|c|c|c|c|c|}
\hline Complexo & & letr & & $\tau_{a v}(\mu s)$ \\
\hline EuCTc & $\begin{array}{ll}A_{1} & (4,00 \pm 0,01) \cdot 10^{4} \\
A_{2} & (4,00 \pm 0,01) \cdot 10^{4}\end{array}$ & & $\begin{array}{l}(1,13 \pm 0,03) \cdot 10^{-2} \\
(1,13 \pm 0,03) \cdot 10^{-2}\end{array}$ & 11,25 \\
\hline $\begin{array}{c}\text { EuCTc + } \\
\text { LDL oxidada }\end{array}$ & $\begin{array}{ll}A_{1} & (9,3 \pm 0,1) \cdot 10^{4} \\
A_{2} & (4,4 \pm 0,2) \cdot 10^{4}\end{array}$ & & $\begin{array}{c}(1,43 \pm 0,05) \cdot 10^{-2} \\
(6,7 \pm 0,3) \cdot 10^{-2}\end{array}$ & 50,08 \\
\hline
\end{tabular}


5.3.3 Complexos EuCTC+LDL oxidada e EuTC+LDL oxidada na presença de possíveis interferentes inorgânicos.

As amostras dos complexos foram preparadas utilizando $500 \mu \mathrm{L}$ dos complexos acrescidos de $10 \mu \mathrm{L}$ de LDL oxidada e $500 \mu \mathrm{L}$ de íons inorgânicos nas concentrações normalmente encontradas no plasma sanguíneo,Tabela 6. As amostras ficaram em repouso por 15 minutos antes de realizar as medidas de emissão. As medidas de emissão foram realizadas excitando as amostras nos comprimentos de onda de $400 \mathrm{~nm}$.

O complexo EuTc na presença de LDL oxidada sofre menor interferência em sua intensidade de emissão na presença de íons inorgânicos.

Verificou-se também que todos os íons estudados com exceção do cobre levam a um aumento no sinal de emissão do európio no complexo EuCTc na presença de LDL oxidada. A explicação para isto pode ser a equação de Fenton (Equação 3) no sentido oposto, ou seja, a presença dos interferentes leva a produção de peróxido de hidrogênio que aumenta o sinal de emissão do európio.

$$
\mathrm{Cu}^{+2}+\mathrm{H}_{2} \mathrm{O}_{2} \leftrightarrows \mathrm{Cu}^{+3}+\mathrm{OH}+\cdot . \mathrm{OH}
$$

Esse processo ocorre com maior intensidade no complexo EuCTc devido a presença do cloro na molécula da clorotetraciclina, o cloro apresenta grande eletronegatividade favorecendo a interação com os cátions que por sua vez interage com a molécula de LDL oxidada favorecendo a peroxidação da LDL oxidada e dessa forma ocorrendo maior aumento na intensidade de emissão. 


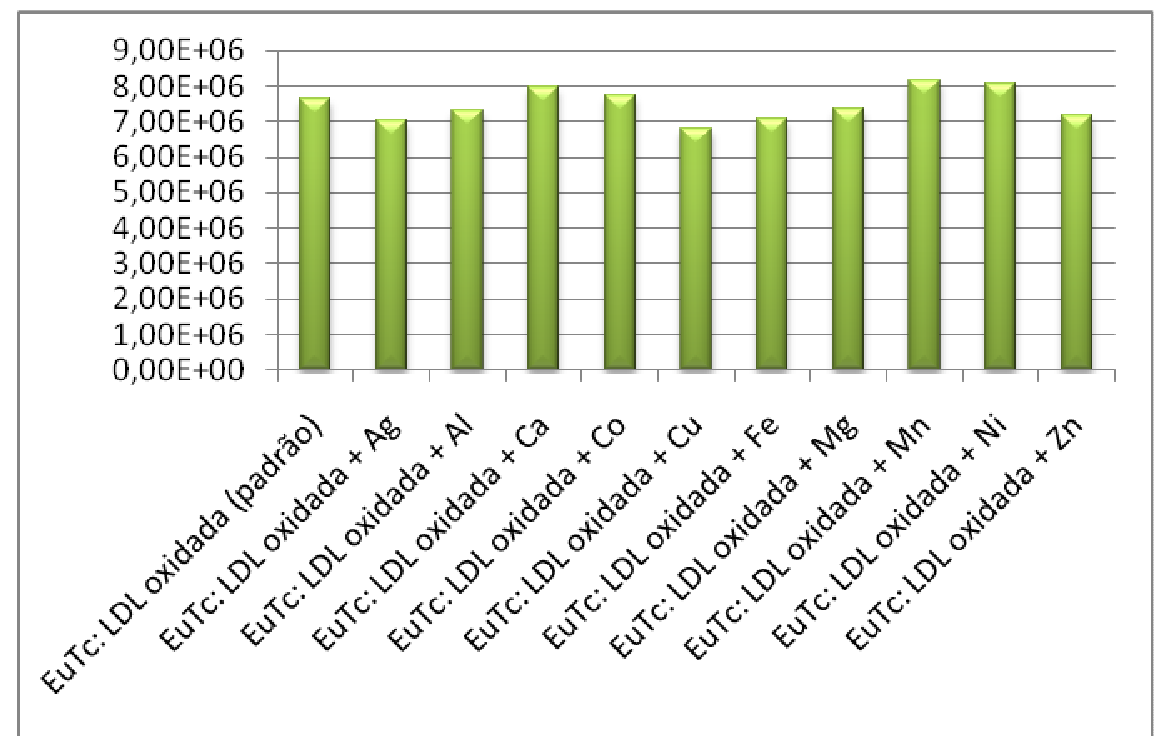

Gráfico 3: Complexo EuTc+LDL na presença de interferentes inorgânicos

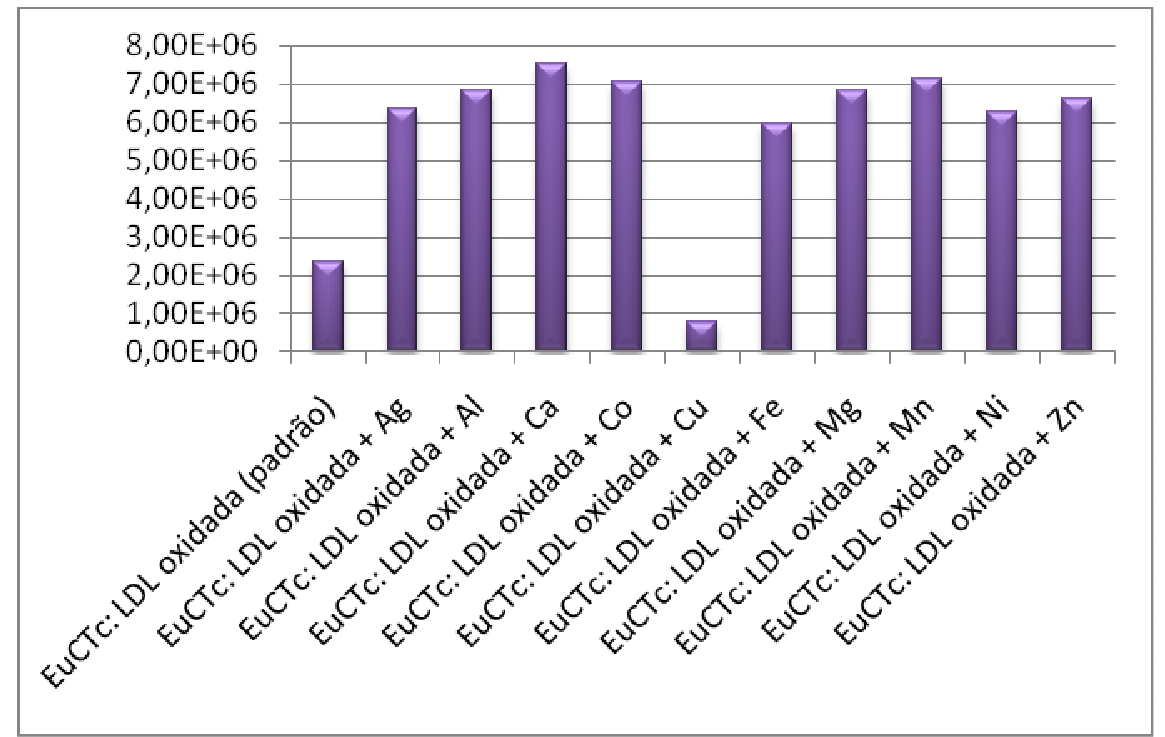

Gráfico 4: Complexo EuCTc+LDL na presença de interferentes inorgânicos 


\section{CONCLUSÕES}

Neste trabalho foram estudadas as propriedades ópticas dos complexos európio- tetraciclinas (EuTcs) na presença de LDL e LDL oxidada, com o objetivo de obter um biossensor com potenciais aplicações na quantificação de LDL e LDL oxidada.

Com os resultados das medidas de absorção óptica e de emissão foi possível identificar a formação dos complexos de EuTcs. Em comum, as Tcs apresentaram largas bandas de emissão, características de compostos orgânicos eletroluminescentes, porém quando as Tcs estam na presença do íon európio ocorre o deslocamento das bandas de emissão das Tcs para comprimentos de onda em torno do $615 \mathrm{~nm}$, demonstrando a efetiva transferência de energia intramolecular do ligante (Tcs), para o íon európio, o que revela a formação dos complexos de EuTcs. O forte pico de emissão ( 616 nm) decorre das transições ${ }^{5} \mathrm{D}_{0} \rightarrow{ }^{7} \mathrm{~F}_{2}$ do íon európio.

As medidas de absorção óptica e de emissão permitiram eleger as melhores razões molares do íon európio nos complexos EuTcs. As razões molares dos complexos EuTcs na presença de LDL foram: EuTc (3:1), EuOTc (1:1), EuCTc (1,5:1) e EuMTc (1,5:1).

Os resultados obtidos através das medidas de emissão também demonstraram que os complexos EuTc (3:1) e EuCTc (1,5:1) apresentaram aumento gradativo na intensidade de emissão de acordo com o aumento da concentração de LDL. O complexo EuOTc (1:1) na presença de LDL nas concentrações de 1,$50 ; 1,75 ; 2,0$ e $2,5 \mathrm{mg} / \mathrm{mL}$ apresentaram praticamente 0 mesmo aumento na intensidade de emissão, em torno de $20 \times 10^{6}$ fótons, o que revela uma saturação dos sítios de ligação do complexo EuOTc que possivelmente foram ocupados pelas moléculas de LDL, e mesmo com o aumento da concentração de LDL não há mais sítios para as mesmas se ligarem. Já para o complexo EuMTc $(1,5: 1)$ na presença de LDL nas concentrações $(\mathrm{mg} / \mathrm{mL}): 0 ; 0,50 ; 1,00 ; 1,50 ; 1,75 ; 2,00$ e 2,50 , observou-se que não houve aumento gradativo da emissão do complexo com o aumento da concentração de LDL.

De acordo com estes resultados, foi proposto que as Tcs apresentam sítios de ligação semelhantes para o íon európio, isso porque todas possuem uma 
estrutura química em comum, porém existem regiões diferenciadas, caracterizadas pela presença de diferentes radicais localizados nas moléculas das tetraciclinas, o que possivelmente diferencia os sítios de ligação do íon európio resultando em maior ou menor intensidade de emissão dos complexos. Já as moléculas de LDL apresentaram um importante papel no aumento da intensidade de emissão dos complexos EuTcs. Visto que as medidas realizadas com os complexos EuTcs não apresentaram deslocamentos nos comprimentos de onda dos espectros de absorção e de emissão na presença de LDL, pode-se concluir que há ausência de interação direta entre as moléculas de Tcs e as moléculas de LDL. A formação dos complexos EuTcs não completam o número de coordenação do íon európio que geralmente são oito, portanto os complexos EuTcs apresentam cargas positivas relativa ao número de coordenação incompleto do íon európio. Com isso, o íon európio interage com grupamentos que estão ionizados com cargas negativas como, por exemplo, hidroxilas e grupos fosfatos presentes na superfície da LDL dessa forma completando o número de coordenação do íon európio.

Através das curvas de calibração foi possível descrever a resposta dos complexos de EuTcs sobre uma faixa de concentração de LDL. Os complexos EuTc e EuCTc na presença de LDL foram os que apresentaram maior linearidade na curva de calibração e desta forma, esses dois complexos foram escolhidos para a continuidade do estudo. Os complexos EuTc e EuCTc apresentaram faixa de linearidade de 0 a $2,00 \mathrm{mg} / \mathrm{mL}$ e limites de detecção de $0,29 \mathrm{mg} / \mathrm{mL}$ e 0,15 $\mathrm{mg} / \mathrm{mL}$ respectivamente.

Os resultados das medidas de tempo de vida e emissão na presença de possíveis interferentes inorgânicos encontrados no plasma sanguíneo, demonstraram que o complexo EuTc na presença de LDL apresentou maior aumento no tempo de vida comparado com o complexo EuCTc também na presença de LDL, e as medidas realizadas na presença de íons inorgânicos demonstraram que o complexo que sofre menor interferência dos íons inorgânicos em relação à intensidade de emissão também foi o complexo EuTc. O íon $\mathrm{Cu}^{+2}$ foi o íon que mais interferiu na intensidade de emissão dos complexos, sendo que no complexo EuCTc ele interferiu ainda mais, possivelmente devido a 
eletronegatividade do elemento cloro presente na molécula de CTc que acaba atraindo o íon $\mathrm{Cu}^{+2}$ presente na solução.

Foram realizadas medidas de emissão dos complexos na presença de diferentes concentrações de LDL oxidada, e de acordo com as curvas de calibrações os complexos que apresentaram maior range de detecção foram EuTc e EuCTc, ambos com faixa de linearidade de 0 a $3,00 \mathrm{mg} / \mathrm{mL}$. Porém comparando as curva de calibração destes dois complexos foi possível notar que o valor do limite de detecção do complexo EuTc foi de $0,09 \mathrm{mg} / \mathrm{mL}$ já o EuCTc foi de $0,16 \mathrm{mg} / \mathrm{mL}$, tornando-o mais adequado para a quantificação de LDL.

As medidas de tempo de vida mostram que o complexo EuCTc na presença de LDL oxidada apresenta maior tempo de vida quando comparado com o complexo EuTc na presença de LDL. Já o estudo das medidas de emissão na presença de íons inorgânicos demonstraram que o complexo que sofreu menor interferência em sua intensidade de emissão foi o complexo EuTc.

Sendo assim, o complexo que apresentou melhores resultados tanto na presença de LDL e de LDL oxidada foi o complexo EuTc. Este complexo apresenta potenciais características para ser um biossensor utilizado em quantificação de LDL e LDL oxidada in vitro. 


\section{PRODUÇÕES BIBLIOGRÁFICAS}

Artigos completos publicados em periódicos

Teixeira, Luciane dos Santos ; Grasso, Andréa Nastri ; Monteiro, Andrea Moreira ; Neto, A.M. Figueiredo ; Vieira Jr., Nilson Dias ; Gidlund, Magnus ; Courrol, Lilia Coronato . Enhancement on the Europium emission band of Europium chlortetracycline complex in the presence of LDL. Analytical Biochemistry (Print) נcr, v. 400, p. 19-24, 2010.

GRASSO, A. N. ; Teixeira LS ; VIEIRA JUNIOR, Nilson Dias ; COURROL, L. C. Optical Properties of Metacycline, Oxytetracycline and Chlortetracycline Europium Complexes in the presence of Hydrogen Peroxide. Journal of Fluorescence scR, v. 19, p. 715-721, 2009.

Trabalhos completos publicados em anais de congressos

GRASSO, A. N. ; Teixeira LS ; VIEIRA JUNIOR, Nilson Dias ; COURROL, L. C. .Comparison of optical properties of europium-oxytetracycline and europiumtetracycline complexes in the presence of peroxides. In: XXXII Encontro Nacional de F sica da Mat eria Condensada / ID: 261-1, 2009, Aguas de Lindoia. Anais da óptica, 2009.

Teixeira LS ; GRASSO, A. N. ; A. M. Monteiro ; FIGUEIREDO NETO, A. M. ; GIDLUND, M. ; VIEIRA JUNIOR, Nilson Dias ; COURROL, L. C. Comparison of the emission efficiencies of EUTC and EUOTc complexes in the presence of LDL. In: XXXII Encontro Nacional de Física da Matéria Condensada / ID: 261-1, 2009, Aguas de Lindoia. Anais da óptica, 2009.

Resumos publicados em anais de congressos

GRASSO, A. N. ; Teixeira LS ; VIEIRA JUNIOR, Nilson Dias ; COURROL, L. C. . Optical Properties of Metacycline, Oxytetracycline and Chlortetracycline Eu Complexes in the presence of Hydrogen Peroxide and Urea Hydrogen Peroxide. In: 
The 15th International Conference on Luminescence and Optical Spectroscopy of Condensed Matter (ICL/08), 2008, Lyon. Procedia, 2008. 


\section{REFERÊNCIAS BIBLIOGRÁFICAS}

\section{CONSENSO BRASILEIRO SOBRE DISLIPIDEMIAS DETECÇÃO, AVALIAÇÃO E TRATAMENTO.}

Disponível em: < http://publicacoes.cardiol.br/abc/1996/6702/67020009.pdf> Acesso em 16 fev. 2009.

2. MARTINS, M. Biossensores de Colesterol Baseados no Sistema Poli(Álcool inílico) / Ftalocianina. Dissertação apresentada a Faculdade de Engenharia da Universidade Federal de Itajubá.p.56-72, 2006.

3. HIRSCHY, L. M. et al. Characteristics of the binding of Europium(III) to Tetracycline. Analytica Chimica Acta, v. 166, p. 207-219, 1984.

4. Silva, F. R.O.; SAMAD, R. E.; GOMES, L.; COURROL, L. C. Enhancement of Europium Emission Band of Europium Tetracycline Complex in the Presence of Cholesterol. Journal of Fluorescence, v. 18, n. 1, p. 169-174, 2008.

5. MITSCHER, L. A. The Chemistry of the Tetracycline Antibiotics, New York: Marcel Dekker, 1978.

6. CHOPRA, I.; ROBERTS, M. Tetracycline Antibiotics: Mode of Action, Applications, Molecular Biology, and Epidemiology of Bacterial Resistence, Microbio. And Mol. Bio. Rev., v. 65, n. 2, p. 232-260, 2001.

7. RODRIGUES, M, GONZÁLES, G., PENIÉ, B., et al. Tetraciclinas. Acta Medica; v. 8, p. 75-9, 1998.

8. DALE, M., RANGE, H. P., RITTER, J. M. Farmacologia. 4 ed. Elsevier: São Paulo, 2003 p.584.

9. COUTO, C., CONCEIÇÃO, M., MONTENEGRO, B., REIS, S. Complexação da tetraciclina, da oxitetraciclina e da clortetraciclina com o catião cobre (II). Estudo potenciométrico, Química Nova; v. 23, p. 457-459, 2000. 
10. HIRSCHY, M., DOSE, E., WINEFORDNER, J., Lanthanide-sensitized luminescence for the detection of tetracyclines. Anal. Chim. Acta, v. 147, p. 311-316, 1983.

11. PALM, G. et. al. Specific binding of divalent metal ions to etracycline and to the Tet repressor/tetracycline complex. J Biol Inorg Chem. v. 13, p. 1097-1100, 2008.

12. Sá, G. F. et al. Spectroscopic properties and design of highly luminescent lanthanide coordination complexes. Coord. Chem.Rev., v. 196, p. 165-195, 2000.

13. MENDES, M,V. Desenvolvimento e caracterização fototérmica de novos materiais vítreos dopados com íons emissores terra-raras. Dissertação apresentada ao Instituto de Física da Universidade de Uberlândia, p. 22, 2009.

14. GUIANINI, W. Produção e caracterização de dispositivos orgânicos eletroluminescentes (oleds) baseados em complexos (beta)-dicetonatos de terras-raras. Dissertação apresentado ao Instituto de Física da Pontífica Universidade Católica do Rio de Janeiro- PUC-RIO. p. 75-90, 2007.

15. SANTOS, T.S. Emissão de luz em matrizes policristalinas de H3BO3. Dissertação apresentada ao Instituto de Física da Universidade Federal de Sergipe. p. 23, 2008.

16. MONTEIRO, J. E. Estudo das propriedades spectroscópicas de matrizes de urânio dopadas com európio. Dissertação apresentada ao Instituto de Pesquisas Energéticas e Nucleares, p. 36-43. 2007.

17. MARTINS, T., ISOLANI, P. Terras raras: aplicações industriais e biológicas. Quim. Nova, v. 28, p.111-117, 2005.

18. MAAS, H.; CURRAO, A.; FERRI, G. C. Encapsulated lanthanide as Luminescent Materials. Angew. Chem. Int. En., v. 41, n. 14, p. 2495-2497, 2002.

19. TURRO, C., FU, P., BRADLEY, P. Lanthanide íons as luminescent probes of proteins and nucleic acid. Departamento de Química. Universidade do Estado de Ohio. USA, 1998. 
20. QUIRINO, W.G. Produção e caracterização de dispositivos orgânicos eletroluminescentes (OLEDS) baseados em complexos (Beta)-Dicetonatos de terrasraras. Dissertação apresentada a Pontifícia Universidade Católica do Rio de Janeiro (PUCRIO). 2007.

21. WOLFBEIS, O., DURKOP, A., MU, M., LIN, Z. Europium ion-based luminescent sensing probe for hydrogen peroxide. Angew. Chem. Int. v. 41, p. 4495-4498, 2002.

22. WU, M.,LIN, Z., SCHAFERLING, M., DURKOP, O., WOLFBEIS, O. Fluorescence imaging of the activity of glucose oxidase using a hydrogen peroxide sensitive europium probe, Anal Biochem., v.1, p. 6673, 2005.

23. ZHU X. J.; WANG X. L.; JIANG C. Q. Spectrofluorimetric determination of heparin using a tetracycline-europium probe. Analytical Biochemistry, v. 341, n. 2, p. 299-307, 2005

24. COURROL, L., BELlini, M., TARELO, L., SILVA, F., MANSANO, R., VIEIRA, N., SHOR, N., Urea hydrogen peroxide determination in whole blood using europium tetracycline probe. Anal Biochem. v.355, p. 140-144, 2006.

25. ARNAUD, N.; GEORGES, J. Comprehensive study of the luminescent properties and lifetimes of $\mathrm{Eu}^{3+}$ and $\mathrm{Tb}^{3+}$ chelated with various ligands in aqueous solutions: influence of the synergic agent, the surfactant and the energy level of the ligand triplet. Spectrochimica Acta, Part A: Molecular and Biomolecular Spectroscopy, v. 59A, p. 1829-1840, 2003.

26. YATSIMIRSKII, K., DAVIDENKO, K., Coordination Chemistry Reviews, Absorption spectra and structure of lanthanide coordination compounds in Solution, v. 27, p. 223-73, 1979. 
27. PEIXOTO,P.H.; COURROL, L.C.; TATUME, S.H. Aumento da banda de emissão da sonda Európio-Tetraciclina sob ação do colesterol. Boletim Técnico da Fatec, 20, pp. 29-31, 2006.

28. COURROL, L. C.; MONTEIRO, A. M.; Silva, F. R.O.; GOMES, L.; VIEIRA JR, N. D.; GIDLUND, M. A. ; FIGUEIREDO NETO, A. M. Novel Fluorescent Probe for Low Density Lipoprotein. Optics Express, v. 15, p. 7066-7074, 2007.

29. GENNES, J.L., CARVALHO, M. O colesterol e a aterosclerose. São Paulo: Editorial Presença, p.111, v.5.

30. GAW,A.,SHEPHERD, J. Lipids and atherosclerosis annual. New York: Editora Martin Dunitz,P.250.

31. SILVA, A.M. Métodos para avaliação do grau de oxidação lipídica e da capacidade antioxidante. Quím. Nova. V.22. 1999

32. LEHNINGE, A. Principles of Biochemistry,. Editora: W.H. Freeman. p. 1119.

33. Manuais de Cardiologia. Disponível em:

<http://www.manuaisdecardiologia.med.br/Dislipidemia/Lipid1_Page538.htm>Acesso em: 09 jan. 2010.

34. SILVA, A.N. Quatificação de Lipoproteínas por Espectroscopia de Ressonância Magnética Nuclear (RMN). Dissertação apresentada ao Instituto de Física da Universidade de São Paulo. p .37-46, 2008.

35. Ministério da Saude. Disponível em:

<http://portal.saude.gov.br/portal/arquivos/pdf/coletiva_saude_061008.pdf> Acesso em: 09 abril. 2010.

36. ARAUJO, D. Efeitos pleiotrópicos com reduções equivalentes do LDL-colesterol: estudo comparativo entre sinvastatina e associação sinvastatina/ezetimiba. Dissertação apresentada a Faculdade de Medicina daUniversidade de São Paulo. p.65-79, 2007. 
37. ABDALLA, D. ET. AL. LDL: da Síndrome Metabólica à revisão Instabilização da Placa Aterosclerótica Disciplina de Endocrinologia (AFAS). Universidade Federal de São Paulo - UNIFESP/EPM, p. 167, 2006.

38. DUARTE, M. MORESCO, R., FABRO, A. Assays for measurement of oxidized low density lipoprotein and its application as a marker of cardiovascular risk. RBAC, v. 40,p. 101-106, 2008.

39. PIVAL, J., FERNANDES, T. Comparação analítica de valores de LDL-colesterol utilizando a dosagem direta e o cálculo pela fórmula de Friedewald. RBAC, V. 40, p. 279-283, 2008.

40. SEILER, G.. Handbook on metals in clinical and analytical chemistry, 2006.

41. GITELMAN, J.. Aluminum and Health: a critical review. Nova York: Marcel Dekker, 1989.

42. ANDRIOLO, A. Guia de medicina ambulatorial e hospitalar da UNIFESP. São Paulo: Manole, p.256, 2006.

43. MANUAL MERCK. Exames Laboratoriais e de Diagnóstico Comuns.

44. PERRELli, G.; PIOLATTO, G.. Tentative reference values for gold, silver and platinum: literature data analysis. The Science Of The Total Environment, Amsterdam, n. , p.93-96, 1992.

45. MAAS, H.; CURRAO, A.; FERRI, G. C. Encapsulated lanthanide as Luminescent Materials. Angew. Chem. Int. En., v. 41, p. 2495-2497, 2002.

46. SCHRENKHAMMER, P. et al. Time-Resolved Fluorescence-Based Assay for the Determination of Alkaline Phosphatase Activity and Application to the Screening of Its Inhibitors. J Biomol Scree, v. 13, p.9-16,2008.

47. PENG, Q. et. al . Fluorimetric study of the interaction between nicotinamide adenine dinucleotide phosphate and tetracycline-europium complex and its application. Analytica Chimica Acta, v. 549, p. 26-31, 2005. 
48. LIU, X., ZONG, Y., XIANG, Y. Time-resolved fluorescence studies of the interaction of the Eu3+ complexes of tetracycline analogues with DNA. Analytica Chimica Acta, v. 345, p. 213-217, 1997.

49. Xia et al. Study on the interaction between protein and Eu(III)-chlorotetracycline complex and the determination of protein using the fluorimetric method Luminescence v.19, p. 352-357, 2004.

50. SALI, et. al. Determination of Protonation Constants of Some Tetracycline Antibiotics by Potentiometry and LC Methods in Water and Acetonitrile-Water Binary Mixtures. J. Braz. Chem. Soc., v.. 20, p. 939-946, 2009.

51. ABDALLA, L., CAVALCANTI, K., SENA, M., Biomarcadores de peroxidação lipídica na aterosclerose. Rev. Nutr., v. 21, p.10-16, 2008.

52. LEHninger, A., COX, M., NELSON, D., Princípios de Bioquímica. Sarvier, v. 4, pg 53-60, 1995.

53. TURRO, C. PATTY, K., BRADLEY, M. Lanthanide Ions as Luminescent Probes of Proteins and Nucleic Acids. Met Ions Biol Syst. v. 40, p. 323-340, 2003.

54. SILVIA, F.R.O. DESENVOLVIMENTO DE UM BIOSSENSOR DE PERÓXIDO DE HIDROGÊNIO DE BAIXO CUSTO BASEADO NA EMISSÃO DO EURÓPIO III. Dissertação apresentada à Escola Politécnica da Universidade de São Paulo, p. 72, 2008 .

55. SILVA, F.; COURROL, L.; GOMES, L.; MANSANO, R.; VIEIRA J., NILSON, D. STUDY OF MATERIALS FOR HYDROGEN PEROXIDE AND UREA HYDROGEN PEROXIDE BIOSSENSORS. In: SBPMat, 2006, Florianópolis. Anais do Congresso SBPMat, p. 126, 2006. 
57. RAYA, C. Fluorescence Quenching of the Europium Tetracycline Hydrogen Peroxide Complex by Copper (II) and Other Metal Ions. Appl Spectrosc. v. 59, 1209$1216,2005$.

58. ITABE, H. Sensitive detection of oxidatively modified low density lipoprotein using a monoclonal antibody. Journal of Lipid Research, v. 37, p. 45-53, 1996. 